\title{
HIGHER EDUCATION STUDENT SERVICES: A QUALITATIVE STUDY OF TWO MID-SIZE UNIVERSITIES' DIRECT EXCHANGE PROGRAMS
}

\author{
A Dissertation Proposal \\ presented to \\ the Faculty of the Graduate School \\ at the University of Missouri \\ In Partial Fulfillment \\ of the Requirements for the Degree \\ Doctor of Education \\ by \\ TAYLOR N. KINDE \\ Dr. Sandy Hutchinson, Dissertation Supervisor \\ MAY 2020
}


(C) Copyright by Taylor N. Kinde, 2020 All Rights Reserved 
The undersigned, appointed by the dean of the Graduate School, have examined the Dissertation entitled

HIGHER EDUCATION STUDENT SERVICES: A QUALITATIVE STUDY OF TWO MID-SIZE UNIVERSITIES' DIRECT EXCHANGE PROGRAMS

presented by Taylor N. Kinde, a candidate for the degree of Doctor of Education in Educational Leadership and Policy Analysis, and hereby certify that, in their opinion, it is worthy of acceptance.

Dr. Sandy Hutchinson

Dr. Shellie Hewitt

Dr. Barbara N. Martin

Dr. Doug Thomas 


\section{DEDICATION}

Since I was a young girl, my grandma, Marilynn Taylor Gee, was the kind of woman I aspired to be. She was a woman of God: kind, giving, and intelligent. She was a nurturing woman who would offer guidance to anyone who required or requested it. My

daughter and I were both named after her, so her legacy will live on. I would like to dedicate this body of work to my grandma, whom I miss every day. I know she would be so proud of me. 


\section{ACKNOWLEDGEMENTS}

This dissertation is a result of my own experience in and passion for international education. First, I want to thank my husband, Derik Kinde, who provided me with love and wisdom, and my daughter, Cora Lynn Kinde, who was my biggest motivator and always brought a smile to my face. Thank you, too, to my parents, Gary and Patti Gee, for their love, prayers, and caring gifts, and to my older sisters, Jasmyn Walker and Haleigh Slater, for always being there for me. Finally, thank you to my friends, who always bring me happiness and comfort, and to my in-laws, who always care for and support our family in any journey.

I would also like to acknowledge my dissertation advisor, Dr. Sandy Hutchinson. She provided endless guidance, advice, and fostering and was always there to support me in every way. From the moment I met Dr. Hutchinson, I knew she was special, and I feel blessed every day that our paths crossed and I was able to experience this journey with her. I will always cherish her friendship and her leadership.

I wish to thank Shelly Sadler, who was instrumental in the process of completing this dissertation. I would also like to express my gratitude to my committee members, Dr. Shellie Hewitt, Dr. Barbara N. Martin, and Dr. Doug Thomas, who provided support, advice, and feedback on my dissertation.

Thank you to all of the individuals who participated in this study. I sincerely appreciate the hospitality extended to me during my research at Örebro University. A heartfelt thank you to Ulrika Kvist, the International Student Services Coordinator at Örebro University. It is because of people like Ulrika, with her knowledge of 
international education, her heart, and her willingness to learn about other cultures, that international education is so special to me.

Finally, thank you to my alma mater, University of Central Missouri, for supporting my academic pursuits and always encouraging me, both professionally and personally. I will always be proud to call myself a Jenny! 


\section{TABLE OF CONTENTS}

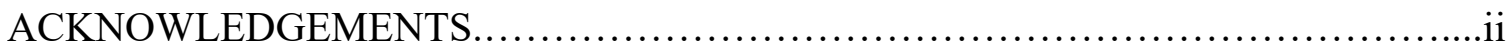

ABSTRACT ..................................................................

1. INTRODUCTION TO DISSERTATION-IN-PRACTICE $\ldots \ldots \ldots \ldots \ldots \ldots \ldots \ldots \ldots . . .1$

Introduction.............................................................

Statement of Problem....................................................4

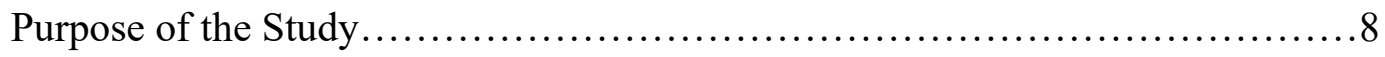

Research Questions................................................9

Conceptual/Theoretical Framework.....................................9

Schlossberg's Transition Theory................................11

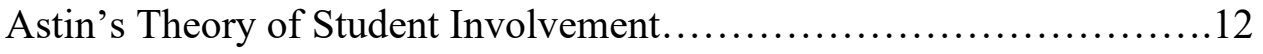

Design of the Study................................................. 12

Setting ........................................................ 12

Participants................................................. 13

Data Collection Tools............................................15

Data Analysis................................................. 16

Qualitative Research Design....................................17

IRB Approval................................................ 19

Limitations and Design Controls..................................20

Limitations...................................................20

Design Controls..................................................20

Definition of Key Terms............................................21

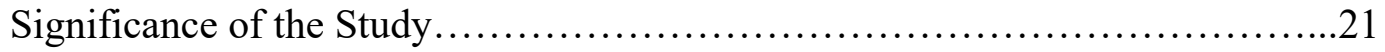




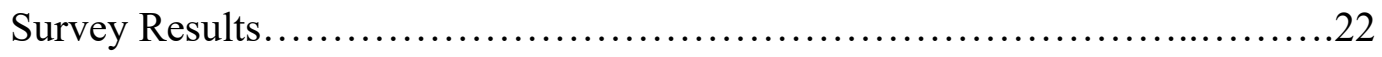

Observation Results...........................................................23

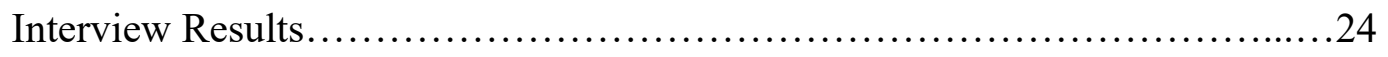

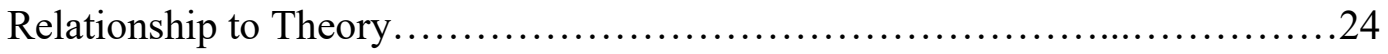

Answers to Research Questions...........................................25

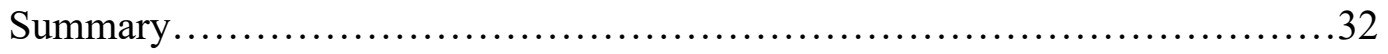

2. PRACTITIONER SETTING FOR THE STUDY ...................................34

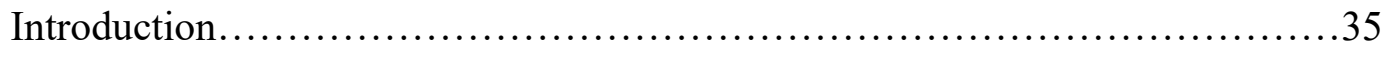

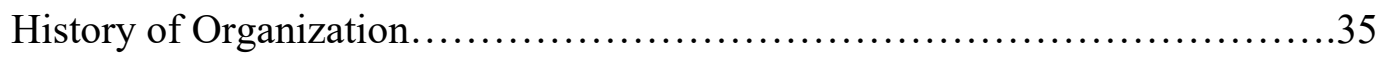

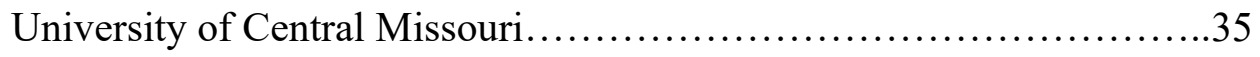

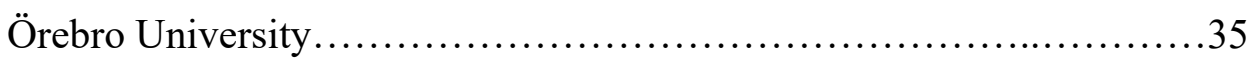

Direct Exchange between UCM and Örebro University...................36

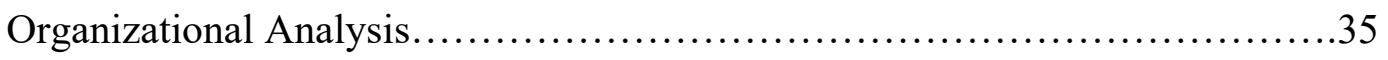

Leadership Analysis...................................................... 37

Implications for Research in the Practitioner Setting....................38

Implications within the History of the Organization......................39

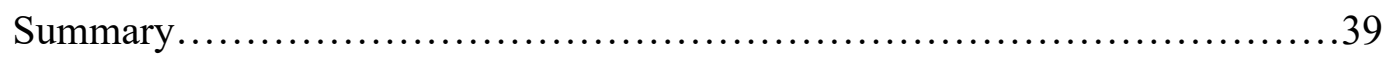

3. SCHOLARLY REVIEW FOR THE STUDY ...................................41

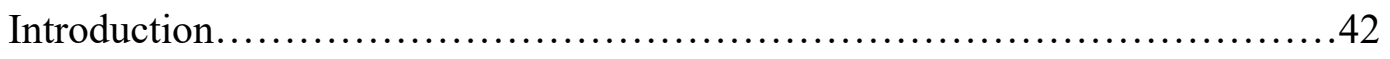

Conceptual Frameworks..................................................45

Schlossberg's Transition Theory......................................46

Astin's Theory of Student Involvement...............................48

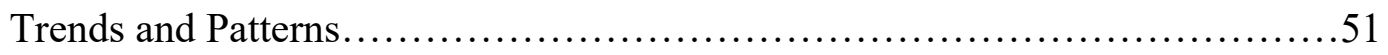


The International and American Experience.......................54

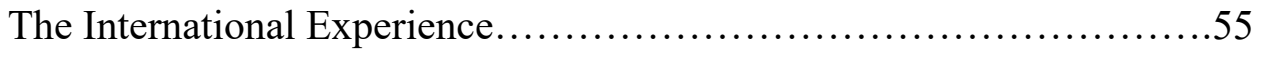

Summary.......................................................56

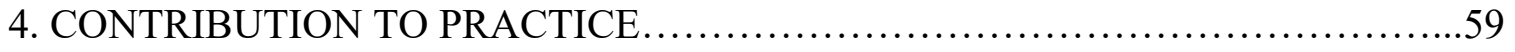

Dissemination of Practitioner Contribution...............................6 60

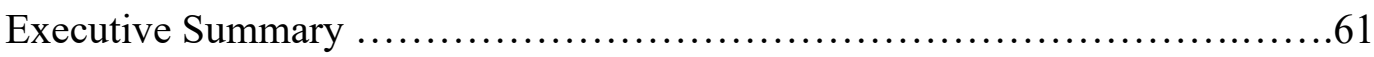

Presentation for University Leadership ...............................71

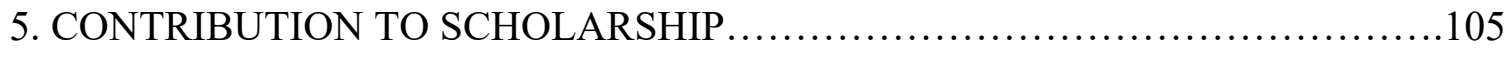

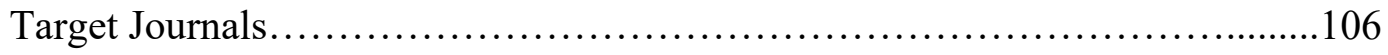

Journal Article.................................................... 107

Abstract........................................................ 108

Research Questions...........................................110

Conceptual/Theoretical Framework..............................110

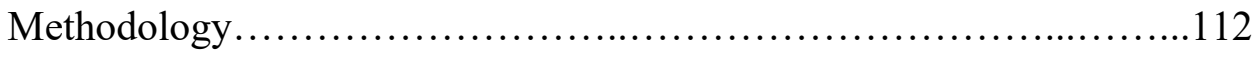

Participants................................................112

Data Collection.............................................112

Qualitative Data Analysis.....................................113

Qualitative Findings........................................114

Recommendations and Future Research..........................122

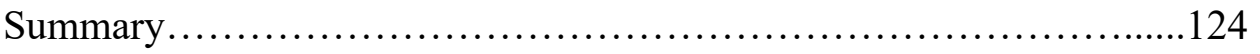

References............................................... 125

6. SCHOLARLY PRACTITIONER REFLECTION ............................. 127

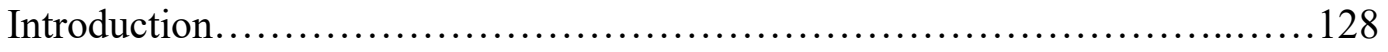


Dissertation Contributions to Personal Growth and Excellence in Education

Leadership.

The Dissertation Experience and its Effect on Personal Scholarly

Advancement.....

130

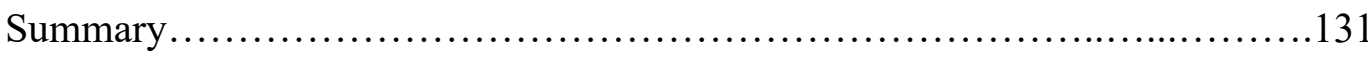

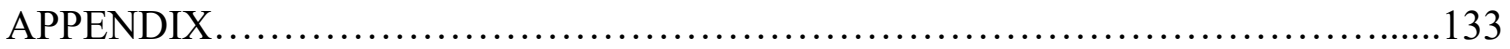

A. INTERVIEW QUESTIONS FOR STUDENTS ......................... 134

B. INTERVIEW QUESTIONS FOR STUDENT SERVICES STAFF........135

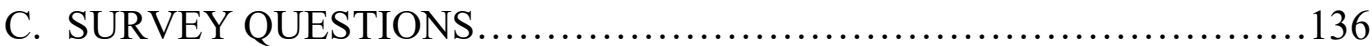

D. INDIVIDUAL INTERVIEW CONSENT FORM ....................... 140

E. EMAIL TO STUDY ABROAD PARTICIPANTS AT THE UNIVERSITY

OF CENTRAL MISSOURI ........................................... 142

F. EXCHANGE STUDENTS ELECTRONIC GOOGLE SURVEY CONSENT

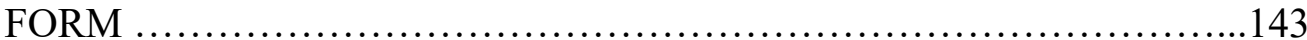

G. THEMES ....................................................... 144

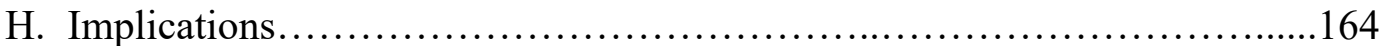

REFERENCES....................................................... 166

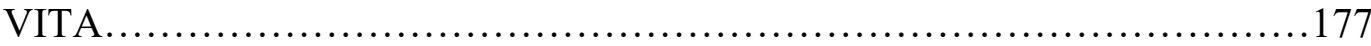




\begin{abstract}
This qualitative study was designed to explore the experiences of students and student services staff involved in the direct exchange program between University of Central Missouri (UCM) and Örebro University. The researcher explored the impact of student services staff assistance on students participating in this direct exchange.

The conceptual framework of this research study included Schlossberg's Transition Theory (1984), which was selected as it explains what happens for students who are experiencing a significant transition. It directs them to the help they need when studying abroad in a new culture. Another theory that was utilized was Astin's Theory of Student Involvement (1985), which reveals how students who get involved in their study abroad experience through co-curricular activities have a better overall experience.

Participants of this student included students who participated in this direct exchange as well as student services staff who work very closely with the exchange students. Data collection for this qualitative student included individual interviews, observations, and an online survey. For accuracy and credibility, the researcher did "member checking” as defined by Creswell, meaning the researcher shared the information revealed by the data analysis process with the participants to ensure the information was accurate (Creswell, 2014; Merriam \& Tisdell, 2016; Seidman, 2013).

Overall analysis of the data disclosed many themes, such as volunteer opportunities, comfort, relationships, multiple challenges, independence, personal and professional development, study differences (orientation, support, etc.), and reaching out. All of the findings provide real information describing the richness of the direct exchange established between UCM and Örebro University.
\end{abstract}


SECTION ONE:

INTRODUCTION TO THE DISSERTATION-IN-PRACTICE 


\section{Introduction}

Student services leaders are a key component of colleges and universities worldwide. Student services are connected to the core of learning for all students and, combined with academic services, provide a full educational experience for those students. Sweden has a unique teaching model, which is based on the motto of "freedom with responsibility" (Sweden Sverige, 2019). This means that students experience less classroom lecture time and pursue much of their studies individually or in groups, which pushes them to think independently.

Swedish higher education, currently ranked \#8 in the world, is free and accessible to all students (U.S. News \& World Report, 2019, Additional ranking section). Tuition is free in Sweden for all individuals who are a part of the European Union (Ekström et al., 2011). When college is free and accessible, students are provided a pathway to opportunity and success (Ekström, Liu, \& Beljulji, 2011). In the United States, many students cannot afford to go to college. As specified by the U.S. Department of Education, college in the United States is more expensive than ever, but it is also more imperative than ever (U.S. Department of Education, 2019). Therefore, one very important distinction in higher education in these two countries is accessibility; it is accessible in Sweden while it is less so in the United States.

Administrators, professors, and student services staff want students to be involved, and they want students to be successful. To make this possible, Swedes create an inclusive and unique environment at their institutions in terms of student services (Deen, 2007). Among other things, student services at Swedish institutions include academic advising, counseling, and student involvement (Zhelanov, 2019). Swedish student services also include career services, disability services, a student health center, 
information technology services and support, faculty coordinators, and study abroad advisors (Deen, 2007). The main goal of student services staff in Sweden is to help guide student development in higher education. A great deal of adaptation is needed from faculty and student services staff to help international students be successful (Bista, 2015).

Arthur (2003) discussed the needs of international students living in cross cultures as well as the demands placed on them. The author stated that international students face significant difficulties when compared to domestic students and suggested that counseling services are vital to an international student's success. As such, student affairs professionals need training and experience in counseling to best serve these students (Arthur, 2003). Kronholz (2015) researched the significance of counseling international students in the ever-changing, globalized world of academia and suggested using theory and intervention when working with these students. Even though it has been determined international students struggle and need help integrating into the new culture, and counselors are often aware of these struggles, difficulties exist in knowing how to intervene appropriately (Arthur, 2003; Goldon, 2010; Kronholz, 2015).

The present study looked at a study abroad direct exchange agreement between two mid-size universities. A direct exchange is an agreement between two institutions that is a "student swap" for either a semester or a year. In this study, the direct exchange is between the University of Central Missouri (UCM), which is located in Warrensburg, Missouri, and Örebro University, located in Örebro, Sweden. The direct exchange happens when UCM sends students to Örebro University and Örebro University sends students to UCM. When studying at Örebro University, UCM students pay UCM rates 
for tuition, fees, and housing. Similarly, Örebro students pay Örebro rates when studying at UCM. This study focused specifically on the student services experiences of students studying at each of the partner institutions.

\section{Statement of Problem}

Over the past two decades, the number of students studying abroad has more than doubled (Institute for International Education, 2019). Based on a review of the literature, one identified problem is there is little to no research on whether or not student services in Sweden impacts international students who study there. There is literature on studying abroad in general; however, there is very little about studying in the country of Sweden in particular.

Many colleges and universities hope to increase student participation in study abroad, and UCM is no exception (Redding, 2019). The available data show many students are interested in studying abroad, but the number of students who actually follow through and complete a study abroad experience is not as high as colleges and universities would like.

Consistent with the data is evidence that the direct exchange between UCM and Örebro University is experiencing a decrease in student involvement. While the international leadership at Örebro University has remained the same, UCM has seen its leadership change numerous times. New staff in new roles has resulted in barriers that must be broken down, a process that is continuous. As Bolman and Deal (2013) stated, "Troubles arise and performance suffers from deficits, remedies through problems solving and restructuring” (p. 45). 
After conducting research on this decrease, it appeared the reason behind the decline in the direct exchange between UCM and Örebro University was a purposeful decision made by UCM leadership. The research showed that many students at UCM were participating in the faculty-led programs more than they were participating in the direct exchange programs.

Since 2016, enrollment has slowly declined. Students at UCM have not traveled abroad as much as they have previously, which resulted in an imbalance in the one-forone exchange. This led to the budget at UCM also being out of balance, so university leadership decided that this deficit needed to be addressed. The solution was to offer only a true one-for-one exchange, whereas prior agreements with institutions were that UCM would accept three or more students at the university. However, since UCM was not sending as many students as they were accepting, the pass-through budget was negatively impacted.

In 2016, the study abroad office and the Graduate School and International Student Services at UCM were tasked with rewriting the agreements with the participating institutions. Significant changes included that UCM was only going to accept one student from each institution, UCM would decrease the number of partnerships they had, and UCM would no longer give full scholarships to the students coming in. Tuition would still be waived, but participating students would need to pay any other fees that had before been covered by the agreements. If an institution wanted to send more than one student to UCM, which is called exchange beyond match, UCM would welcome them; however, the sending institution would have to pay both tuition and fees for these additional students. 
Also, the contracts with each participating institution were all different, and the leadership at UCM wanted them to be consistent. Consequently, direct exchange is now a one-for-one agreement.

To facilitate the growth of the direct exchange programs, the Graduate School and International Student Services offices at UCM are helping the study abroad office promote the exchange (S. Hewitt, personal communication, October 2019). Much of this assistance has to do with the structure within the University's international office. In 2016, the international office went through significant restructuring, and some other offices on campus held that studying abroad was no longer part of an undergraduate study opportunity.

New federal legislation was designed to increase the participation of US students in study abroad programs. On April 11, 2019, the Paul Simon Study Abroad Act was passed. This legislation is important to the increase of study abroad participants as it emphasizes the value of international skills necessary for understanding the global nature of the society in which we live.

Evans, Forney, Guido, Patton, and Renn (2010) described the student development that occurs when studying abroad and the value it has on students' collegiate experience. Within higher education, studying abroad is valued as a way of adding cultural learning and global perspective to a student's worldview. College students often find themselves exploring who they are and figuring out who they want to be, thus discovering their identity (Evans et al., 2010).

When thinking about the education abroad context for students, it can be much more complicated. Identity can vary from culture to culture, so studying abroad allows 
for a deeper examination of self-identity (Evans et al., 2010). No matter what the students' identities were before they studied abroad, returning to their home country will impact their identities, leading to possible change (Evans et al., 2010; Kim, 2012).

Likewise, Chickering and Reisser (1993) maintained identity is a part of college exploration and includes learning how to manage emotions and develop integrity. In essence, students who study abroad are trying to create their purpose (Bennet, 2010; Braskamp, Braskamp, Merill, \& Engberg, 2010).

Furthermore, Paige, Harvey, and McCleary (2012) stated while colleges and universities worldwide are trying to increase their study abroad enrollment, there is limited research focused on the significance of an increase in international study in Sweden specifically. Students do not understand the benefits of international study, particularly in Sweden. The perception is that it is very expensive to live in Sweden when, in reality, the county has a great deal to offer those who go there. Specifically, the Swedish higher education system has much to offer those students who choose to study there. In addition, Rosvall and Nilsson (2016) highlighted one unique aspect of education in Sweden: those students are specifically required to take courses in social and physical well-being. This unique characteristic of Swedish higher education illustrates the emphasis placed on students taking care of themselves

To help students take care of themselves, Sweden offers student services that are very different from student services in the US. Those differences begin with the Swedish approach to student success, which is based on an understanding of the importance of individual study and increased freedom. While there is evidence of the impact student services staff has on American university students, there is limited research on what 
makes Swedish student services unique and impactful. Little is known about how Swedish student services professionals help their students be successful. The information that does exist indicated the retention and graduation rates of Swedish institutions is $77 \%$, which may be due, in part, to the effectiveness of their student services (OECD, 2018).

\section{Purpose of the Study}

The purpose of this study was to gain a rich understanding of the student services offered at two direct exchange universities, one in Sweden and the other in the United States, and the impact those services have on exchange students' collegiate success. The data collected provided information on the impact of student services on students who study abroad, particularly in Sweden and the United States, ultimately allowing for the creation of a student services program that provides an enriching international experience for exchange students.

The study was based on a qualitative research approach. Interviews were conducted with 10 students from Örebro University who had studied at UCM and 10 UCM students who had studied at Örebro University. In addition, student services personnel from both universities were interviewed. Observations were conducted by the researcher at an academic advising appointment as well as a student programming event. Students who are returnees of the direct exchange program completed the surveys. It was from this perspective that this study approached the two overarching questions: "How does student success relate to study abroad advisement?" and "How can student services support international students studying in a new culture?" 


\section{Research Questions}

The following research questions guided this study.

1. How would Swedish students define their study abroad experience regarding student services?

2. How would American students define their study abroad experience regarding student services?

3. How do exchange students perceive cultural learning?

4. What are the greatest challenges facing student affairs professionals regarding international education?

5. How do student affairs personnel prepare students for the psychosocial aspects of the study abroad experience?

\section{Conceptual/Theoretical Framework}

The number of international students studying in the United States, according to 2018 Open Doors Report on International Educational Exchange, is now 1,094,792, representing approximately $5.5 \%$ of all US universities' students (2019, May 1). There are also many international students at Swedish institutions. Enrollment of international students at Swedish institutions has increased because of the many Asian students who are choosing to study there (Viggo, 2018). According to the Pie News, News and Business Analysis for Professionals in International Education, the number of international students in Sweden during the 2016-17 academic term was 35,900 (Viggo, 2018).

The increase in international student enrollment at Swedish institutions has had student services teams, administrators, and faculty thinking of the best way to serve these 
students. International students, regardless of their background, experience different barriers from what non-international students experience. Barriers can include, but are not limited to, language, smooth assimilation into a new culture, lack of involvement on campus, and lack of social and academic support from the institution they are attending (Braskamp, Braskmap, Merill \& Engberg, 2013).

Gill (2018) identified the different barriers that international students may encounter. Identifying these barriers allowed interested parties at universities to assist those students in overcoming them (Brock, 2010). For that to happen, it is essential that students be provided with the necessary direction (Gill, 2018).

For this study, the Student Developmental Theory of Schlossberg's Transition Theory (1984) was utilized. Schlossberg developed this theory as a way to explain and understand adult development. The four S's, Situation, Self, Support, and Strategies, outline the challenges these international students face when studying abroad. Schlossberg's Transition Theory helps one understand the four S's that influence a student's transition into a new culture. Student developmental theories as such are helpful to guide student affairs practitioners. A main goal of Schlossberg's Transition Theory (1984) was to facilitate an understanding of adults in transition and to assist them in connecting to individuals who can help them adjust to their situation.

Astin's Theory of Student Involvement (1993) was also explored as a way to understand the importance of student involvement, both academic and social, when studying abroad. Astin's Theory of Student Involvement is a simple approach to the learning that occurs and, in this study in particular, to learning that occurred while studying abroad. This learning happened through social, academic, and cultural lessons. 
Student services teams provide different areas of student involvement. This involvement includes, but is not limited to, student programming, student organizations, advisory boards, and cultural immersion trips. When a student is involved, they become more aware of their new culture and truly immerse themselves in their new environment, which leads to their success (Astin, 1993).

\section{Schlossberg's Transition Theory}

When investigating the experiences of students who study abroad, transition tends to be at the forefront of those experiences. All students experience transitions in their collegiate experience, and this is especially true when studying abroad. Schlossberg et al. (1995) emphasized two areas that affect students' transitions: a) demographic characteristics and b) psychological resources.

Schlossberg's Transition Theory (1993), known as the "4S model" (Situation, Self, Support, and Strategies), is a helpful framework for student services staff to use when working with students who are adjusting to a new culture. The guidance that Schlossberg's Transition Theory provides to the student affairs staff will help them support students through this significant change in their lives. The foundation of this theory, as outlined below, explains the different transitions students will experience.

The guidance that students need as they study abroad can come from members of the university's student services team (Andrade, 2006). It can also come from the communities themselves, including the community of Warrensburg and the community of Örebro. Finally, guidance and support can come from family and friends. By learning the needs of these study abroad students, advisors can implement Schlossberg's 
Transition Theory (1993) and understand the best way to provide the assistance students need as they transition into these new environments.

\section{Astin's Theory of Student Involvement}

Another viewpoint was the importance of student involvement during the study

abroad experience. It is vital that students who are studying abroad during their collegiate experience become involved socially as well as academically. The goal of student services teams and faculty is for their students to be equally successful both inside and outside of the classroom (Astin, 1993). According to Astin (1993), students who are most successful are involved within their academics as well as extracurricular activities.

\section{Design of the Study}

\section{Setting}

The setting of this study was two public universities of similar size, University of Central Missouri (UCM) in Warrensburg, Missouri, and Örebro University in Örebro, Sweden. These two institutions have a direct exchange program.

UCM is a public, state-funded university located in Warrensburg, Missouri, United States. UCM was founded in 1871 and has total enrollment of 11,487 (University of Central Missouri [UCM], 2018). The number of international students is 799 undergraduate and graduate students from 55 different countries (UCM, 2018). UCM also has 25 international direct exchange agreements with universities worldwide (UCM, 2018).

Örebro University is a public state university located in Örebro, Sweden. The university was founded in 1977 as a college and became a university in 1999 (Facts, 2019). Örebro University offers various programs of study as well as professional 
schools of medicine and law. They have a total student enrollment of over 15,000, with 172 international students currently enrolled in both undergraduate and graduate direct exchange programs (Facts, 2019).

\section{Participants}

Twenty former exchange students were selected and interviewed. Ten were students from UCM who had studied at Örebro, while 10 were Örebro students who had studied at UCM. In addition, the International Student Services Coordinator from Örebro and the Study Abroad Coordinator from UCM were interviewed. Finally, the Study Advisor from Örebro and the Coordinator of Exchange and Sponsored Programs from UCM were interviewed.

The interviews, which occurred on-site at UCM and Örebro University, featured a semi-structured interview protocol that focused on certain research questions (Appendix A) and allowed the former exchange students being interviewed to explain their study abroad experiences and the effect student services had on them. The interviews of the Coordinator of Exchange and Sponsored Programs, Study Abroad Coordinator, Study Advisor, and International Student Services Coordinator also utilized a semi-structured interview protocol. Each of these questions (Appendix B) focused on a specific component of the research questions and allowed these individuals to discuss perceptions of their contributions to students' study abroad experiences.

Merriam and Tisdell (2016) determined that interview questions based on the research questions are the best way to naturally elicit responses from the interviewees. The interviews were semi-structured, as suggested by Merriam and Tisdell (2016), meaning the questions were phrased with the intent of exploration, leading to a more 
natural conversation. All questions asked were open-ended to make the participants feel they could answer more candidly (Creswell, 2014).

Fink (2017) suggested piloting a survey before it went out through email as that offers a way to ensure the survey provided the researcher with the information needed. Because it was important to protect data, an online consent form was sent to the participants before the survey went out through email. Fink (2017) stated that some individuals are hesitant to complete online surveys as they are concerned about their privacy.

The researcher selected the former exchange students and the student services staff, which constituted a form of purposeful sampling (Merriam \& Tisdell, 2016), as participants to represent the international direct exchange program between UCM and Örebro University (Creswell, 2014) and to gain information that could assist with answering the research questions. The International Student Services Coordinator at Örebro University was selected as she is the main point of contact for student services at that institution. She connects with the students both before they study abroad and when they return. Should a concern arise, she is also there to assist the Swedish students who are studying at UCM as well as those UCM students who are studying at Örebro University.

A survey (Appendix C) was also sent out by the International Student Services Coordinator of Örebro University, and the Study Abroad Coordinator of UCM did the same. The surveys were sent out through email to returnees of the direct exchange program. Twenty total surveys were sent out, and nineteen were completed and returned. 
The Study Abroad Coordinator at UCM was also selected as he is one of the points of contact for international student support for direct exchange students going abroad. The in-depth knowledge these two coordinators have of direct exchange programs provided insight into the international education that is occurring at both direct exchange institutions. The Study Advisor of Örebro University and Coordinator of Exchange and Sponsored Programs of UCM were selected as they also help with the academic component of the direct exchange.

All interviews were audio recorded. Prior to beginning, each participant was required to sign verbally an informed consent form (Appendix D) that had been approved by the University of Missouri Columbia Institutional Review Board. The interviews were scheduled via email (Appendix E). Before conducting the interviews, the researcher determined which individuals had language barriers and offered to provide a translator, if needed. Every individual spoke English well, so this resource was not needed for this study.

Lastly, two different types of observations occurred. First, there was an observation of an academic advising appointment, and, secondly, a student programming event was observed.

\section{Data Collection Tools}

Creswell (2014) noted there are steps that must be taken in the data collection process. These steps include setting the restrictions for the study, gathering information through interviews, observations, etc., and establishing the rules for recording.

According to Datnow and Park (2014), "information is data with meaning" (p.

12). Descriptive data were collected by the International Student Services Coordinator at 
Örebro University from UCM students who studied at Örebro University. Data were also collected by the Study Abroad Coordinator at UCM from Örebro University students who studied at UCM. The data collected came from surveys that were distributed by the International Student Services Coordinator of Örebro University and the Study Abroad Coordinator of UCM to the former exchange students who participated in the direct exchange. Rich data also came from interviews that were conducted with students and student services staff.

Creswell outlined many advantages of observations, another method of data collection. One advantage is that unusual aspects can be perceived when these observations occur (Creswell, 2014). While observing, the researcher took field notes on the activities occurring at the research sites, which included UCM and Örebro University (Creswell, 2014).

\section{Data Analysis}

The first step in data analysis was to organize the data. To facilitate the organization required for this step, the researcher transcribed the interviews and prepared typed notes. Furthermore, writing notes following each interview in the course of this project meant reflecting on each interview, identifying emerging themes, and developing early ideas about where the research was heading (Merriam \& Tisdell, 2016; Seidman, 2013) (Appendix F).

The second step was coding the data, which is clearly defined as assigning a place that fits a variety of data so the data can be easily retrieved (Merriam \& Tisdell, 2016; Seidman, 2013). The coding was done by the researcher, who categorized the data into sections that had common themes as they corresponded to the research questions 
identified above (Creswell, 2014). Creswell suggested that a researcher should take notice of the different codes, especially those that may be surprising or unique to the study (Creswell, 2014). This coding process established the description of the setting, which included the people and locations of UCM and Örebro University.

To complete the coding, the researcher reviewed the transcriptions line by line, found the themes that were consistent through the interviews, and assigned codes (Creswell, 2014). This was done by "hand coding," as defined by Creswell. This, of course, was very time-consuming; however, this hand coding allowed the researcher to work in-depth with the data. When the coding was completed, the researcher wrote an individual summary of reflection for each interview completed. The interview transcripts were then read again for accuracy as the researcher wanted to ensure that she was reflecting fairly on what the participants had stated.

As recommended by professionals, the researcher started the data analysis very quickly after the data were collected in Örebro and UCM (Creswell, 2016; Merriam \& Tisdell, 2016; Seidman, 2013).

\section{Qualitative Research Design}

The researcher traveled to Sweden to collect data by conducting interviews and observations on the site of Örebro University. Nineteen of those surveys were returned. Lastly, the researcher conducted ten interviews at UCM with students who had participated in the direct exchange as well as two interviews with student services staff who support international students.

The interviews were semi-structured and consisted of open-ended questions intended to produce the views and perceptions of the interviewees (Creswell, 2014). 
Interviews lasted 30-60 minutes. The interviews were audio recorded, and each participant's interview was transcribed into written text. Notes, comments, and perceptions of each individual being interviewed were written by the researcher during the interview as well as after it was completed. The goal of this individualistic note approach was to ensure the researcher distinguished between each student's personality and perception of their study abroad experience and student services received as well as the student services team members' perceptions of their contributions to students.

The researcher also conducted two types of observations. The first observations occurred at student advising appointments at both UCM and Örebro University. A student advising appointment is when an academic advisor meets with a student to help guide them through the enrollment process and determine the courses they need to enroll in to complete their studies. The advising observations lasted one hour.

The second set of observations occurred at student programming events at both UCM and Örebro University. A student programming event is a social event for students to help with their assimilation into a new culture. The student programming observations lasted two hours.

Finally, the International Student Services Coordinator at Örebro University conducted surveys through Google Forms by collecting data on the UCM students who studied there. Likewise, the Study Abroad Coordinator at UCM collected data by way of surveys, also through Google Forms, from the Swedish students who had studied at UCM. Descriptive statistics helped recognize the sample data and identify any interesting patterns by calculating average responses for the Likert scale data and examining characteristics of those who participated in this study. 
These surveys assisted the researcher in understanding the values, feelings, and behavior on the issue of studying abroad (Fink, 2017). Fink (2017) suggested that the researcher conduct reliable surveys so that the information obtained would be consistent. The surveys were made available online, which made them accessible to all interviewees, both those who are local and those who are abroad. As Fink (2017) suggested, questions on the survey varied, depending on the amount of time and reflection the interviewees would require before answering. Some questions required little to no thought, while others required more. The researcher always respected confidentiality as a top priority, something that was also suggested by Fink (2017).

\section{IRB Approval}

Because the interviews included research on human subjects, an application was submitted to the Institutional Review Boards at the University of Central Missouri and the University of Missouri for approval of this research. This application recognized the participants' rights during data collection (Creswell, 2014). The interviews would not cause any danger to participants, and the researcher guaranteed that participants could decline to continue at any time during this study. Participants' names were kept confidential. The risks involved were minimal and were no more than the risks of everyday life. 


\section{Limitations and Design Controls}

\section{Limitations}

The study was limited in that it focused exclusively on UCM and Örebro University. Many universities offer student services of varying degrees of quality; however, this study focused only on the two universities identified above.

Another limitation was the connection between the researcher of this study and the two universities involved. The researcher is an employee of UCM and was a participant in the direct exchange between UCM and Örebro University. The researcher was mindful of the potential for bias within this study and the results outlined therein. However, the researcher took all steps necessary to ensure this bias did not present itself in the finished work.

\section{Design Controls}

One design control of the study was purposeful sampling. This was necessary because the participants must be either students who took part in the direct exchange or staff who worked closely with the students in the exchange. Another design control was the semi-structured interview questions, which allowed the interviewees to share their opinions without taking on the researcher's viewpoints (Merriam \& Tisdell, 2016). To achieve the goal of the study, certain information was required, and the interview questions were written in such a way to elicit that information from the respondents. Finally, member checking was also a form of control, as it helped the researcher convey accurate information gathered from the participants (Creswell, 2014). Using interviews, surveys, and observations, the researcher was able to triangulate the data (Merriam \& Bierema, 2014). 


\section{Definition of Key Terms}

Defining key terms helped provide an understanding of the research and its key components. The following terms guided this inquiry:

Cultural learning: When students study abroad, they need to understand their new culture. As such, they are constantly learning about that new culture in order to assimilate smoothly.

Direct exchange: A direct exchange is an agreement between two institutions. This exchange happens when the partners send students to each other's institutions. In this case, UCM is sending students to Örebro University, and Örebro University is sending students to UCM. This direct exchange is, essentially, a "student swap" for either a semester or a year. Students participating in the exchange pay the same tuition, fees, and housing that they would pay at their home institutions.

Student services: These are services provided to assist students with their growth and development and their ability to navigate the bureaucracy of higher education. This would include areas such as academic advising, counseling, and student involvement.

\section{Significance of the Study}

This study provided an understanding, from the students' perspective, of the positive impacts a student services team can have on students when studying abroad, whether at UCM or at Örebro University. As the literature described, students who study abroad grow in ways they never could have imagined or anticipated (IES Abroad, 2019). Not only do they have the benefit of a broadened educational experience, but students who study abroad also report a changed worldview. 
IES Abroad (2019) stated that many students continue their education after studying abroad and noted benefits of their study abroad experiences ranging from personal growth, professional growth, and an improved sense of self after returning to their home country, and elaborated on the personal growth of students who study abroad. For instance, living in an unfamiliar culture with people who are different pushes students out of their comfort zone, resulting in personal growth (IES Abroad, 2019)

This study makes an invaluable contribution to the literature on international education and study abroad involvement because it relies on the authentic experiences of students with study abroad experiences. When universities have relationships with other universities, known as "direct exchanges," a positive relationship develops over the years to help students be successful. Passionate student services teams in both the United States and Sweden will ensure a student knows they are valued, which will, hopefully, result in an overall positive experience. Partial results of this study, including answers to the research questions, will be presented.

\section{Survey Results}

The surveys that were sent to 20 students, 19 of which were completed and returned, were beneficial to this study as they provided answers to questions that had not previously been asked in interviews. The survey results also provided answers to questions of where students came from before studying at Örebro University or UCM. They also provided information on the year of their study. Lastly, the surveys included many questions that were open-ended, both of which encouraged students to answer more freely. 
The results of the survey indicated that $48 \%$ of students grew up in the United States, $35 \%$ of students grew up in Sweden, and the remaining $17 \%$ grew up elsewhere around the world. The answers to the question of gender revealed that $35 \%$ of the students were male and $65 \%$ were female. This gender gap, with more females than males studying abroad, is consistent with the gender gap that exists in college students, in general. Another survey question asked about the students' academic year and revealed that $20 \%$ were sophomores and $80 \%$ were juniors.

Additional survey results included responses about what students enjoyed most about studying in Sweden or the US. Students stated they enjoyed meeting new friends, trying new foods, and exploring new cities. Over half of the students indicated that what they found to be the most impactful was that, over time, they began to feel like they were a local. They were neither living the American nor Swedish life, which was the goal of the experience, and they felt they could fully experience the way of life in their host country.

\section{Observation Results}

Observations were conducted at programming events and meetings between student services staff who support international students and the students themselves. It was evident that many students felt nervous when they first came into the advisor's office to visit with them. It took some time for students to become comfortable in their environment, but after their meeting began, students became more at ease. It also appeared that both the advisors and the students were prepared for the meeting. The students came with questions, and the advisors always had answers. 


\section{Interview Results}

Below is a table of the individuals interviewed. For confidentiality purposes, the participants are identified by a pseudonym.

\begin{tabular}{|c|c|c|}
\hline Pseudonym & Institution & Participant Type \\
\hline Andrea & Örebro University & Student Services Staff \\
\hline Becky & Örebro University & Student Services Staff \\
\hline Michelle & UCM & Student Services Staff \\
\hline Nick & UCM & Student Services Staff \\
\hline Jessica & Örebro University & Student \\
\hline Erin & Örebro University & Student \\
\hline Mallorie & Örebro University & Student \\
\hline Sarah & Örebro University & Student \\
\hline John & Örebro University & Student \\
\hline Caleb & Örebro University & Student \\
\hline Ashley & Örebro University & Student \\
\hline Rebecca & Örebro University & Student \\
\hline Beth & Örebro University & Student \\
\hline Jacqui & Örebro University & Student \\
\hline Dana & UCM & Student \\
\hline Lacey & UCM & Student \\
\hline Brittney & UCM & Student \\
\hline Jade & UCM & Student \\
\hline Amanda & UCM & Student \\
\hline Hannah & UCM & Student \\
\hline Blake & UCM & Student \\
\hline Shannon & UCM & Student \\
\hline Veronica & UCM & Student \\
\hline David & UCM & Student \\
\hline
\end{tabular}

\section{Relationship to Theory}

Schlossberg's Transition Theory (1984) of the 4 S's (Situation, Self, Support, and Strategies) as well as Astin's Theory of Student Involvement (1993), both of which focus 
on how students change in relation to being involved, were utilized in this study. These theories are closely intertwined, making them very relatable to a student's experience abroad. In addition, they both emphasize the significance of student services staff and their impact on study abroad students.

Both of these theories apply to what students said about their experiences in the direct exchange as well as the comments of student services staff. Many students stated they experienced the 4 S's while studying in Sweden or the United States. They noted the "situation" they were in, which was studying in a new culture, themselves as the "self", the "support" that came from their friends, family, and student services staff, and the "strategies" they developed that allowed them to be successful.

Astin's Theory of Student Involvement (1993) also was reflected in many of the interviews, both of the students and the student services staff. Students stated they felt more connected to their host university when they became involved in a student organization or group. Student services staff encourage exchange students to become involved during their stay in a new country, and they have found that the more the students get involved, the better their experience is. Michelle confirmed this when she stated,

Students from Sweden sometimes stick together and want to only do things together. It is a comfort thing, however; I encourage them to go join a student organization that is about music. Even if they aren't interested in music, they could be after joining. 


\section{Answers to Research Questions}

Research Question 1: “How would Swedish students define their study abroad experience regarding student services?"

Student perception. The experience of Swedish students at UCM appeared to be positive at the beginning of their time at UCM, but they believed that support was lacking throughout the entire semester, citing a lack of programming or things to do regarding programming. Students believe that if they had an issue, they could reach out to the student services staff; however, the staff did not do a well-being check on them. Sarah stated, "It would have been thoughtful to just receive a simple email stating, 'How is your stay going? Anything I can help you with while you are here? Anything you need or have questions about?” Another student, Jessica, stated, “A quick one sentence email asking how I am doing and there anything I need direction with would have helped.” John added, "I am not the type to email or stop by someone's office when I am struggling or have a question, so if they would have had some sort of communication that goes out to students with the subject, any questions, that would have helped me."

In addition to Jessica's response, Erin stated, "I wish there was some sort of more routine check-in with the exchange students. There were moments when I had questions but was simply too shy to ask." Likewise, Beth stated,

An automatic email that goes out to students as a well-being check would be helpful. Then you can either act and respond, or you keep to yourself, but having that option would be nice, nice knowing there is someone to help if you need it. Student services staff perception: Student services staff believe they gave the students the necessary support when they arrived but understood they could do better at 
pushing students to be involved and to ask for help when they needed it. The student services staff in Sweden believed they were always available to the students, both before their arrival and throughout their entire stay there. Students also confirmed this perception. The student services staff in the U.S. also believed they were always open to meet with students when needed.

Becky from Örebro University stated, "When students have questions, I hope they know they can email me and ask for help. I am always here to help and give direction."

Andrea from Örebro University stated, "I often think that students are not comfortable with reaching out when they need help. They may be embarrassed or feel they can just ask a friend.”

Research Question 2: “How would American students define their study abroad experience regarding student services?"

This question corresponds to the two conceptual frameworks, Schlossberg's Transition Theory (1984) and Astin's Theory of Involvement (1993). Analysis of this study's results revealed that study abroad participants experienced the 4 S's (Situation, Self, Support, and Strategies), of Schlossberg's Transition Theory (1984) during their study abroad experience and that they were more successful in their study abroad experience emotionally and socially if they become involved.

Student perception: American students at Örebro University felt they had support throughout their entire stay, beginning with the month-long orientation and extending to their interaction with the international office throughout their stay.

Jacqui's reflection on her study abroad experience included all of the 4S's of Schlossberg's Transition Theory (1984). She noted that even though she anticipated 
transition, it was transition nonetheless, and moving in, moving through, and moving out were all parts of the transition process. This confirms the notion that adults are in constant transition, especially when studying abroad, and that the reactions of adults to certain transitions depend on the type of transition, their perceptions of the transition, and the setting and the effect it is having on their lives.

Student services staff perception: Student services staff in Sweden felt they were supportive before the students arrived and remained supportive throughout their study there, and the comments of the American students studying in Sweden confirmed this. It was found through analyses of the data that student services staff can help provide goal setting, interventions, and relationship building, all to help guide students through the 4 S's. It was also found that student services staff can help students by listening and responding to their needs by advocating, providing specialized services, and counseling. Research Question 3: "How do exchange students perceive cultural learning?"

Cultural learning occurs in the classroom, in grocery stores, and anywhere a student is interacting with someone from another country. What one student would identify as a cultural learning experience may be different from what another student would identify.

Student perception: Cultural learning is the constant state of learning that occurs globally as well as in the classroom and occurs when an individual is studying in a new country. During that study, one is exposed to a new language and a new atmosphere, which results in cultural learning about their host country.

One student, Mallorie, mentioned, 
When I studied abroad in the US, I felt cultural learning occurring when I would attend programming events that UCM put on. A lot of these had other exchange students present as well as US students. One event I remember in particular was the culture food show. I was able to taste food from all around the world.

Student Services staff perception: Cultural learning occurs when students interact and gain new information and then share that information with their peers. Research Question 4: "What are the greatest challenges facing student affairs professionals regarding international education?"

One student services staff member, Michelle, stated,

“Cultural learning occurs when students are exploring a new city, grocery store, or even in their new classroom. When they are pushed out of their comfort zone, they are learning about new cultures."

The job of student services staff, especially international student services staff, changes daily. There are new immigration laws and regulations to be monitored, and these changes affect the student services staff as well as the students. The challenge for some is staying current on these immigration regulations, but it is vital that student services staff receive the training necessary to stay up to date with these regulations.

Student perception: The main challenge perceived by students was the support they received from the advisors. Students often felt they needed help, but that help was not always provided to them. The students did not know how to ask for support when they needed it, and they often felt they were being an inconvenience to the advisors when they did ask for assistance.

One student, Mallorie, stated, 
The most frustrating thing that occurred for me when abroad was, I needed guidance and help but often it seemed the advisor wanted to do everything through email, and I really wanted to meet them in person. With the language difference, I think an in-person meeting would have been more effective than through email communication.

Student services staff perception: Student services staff noted that the main challenge facing international education right now is the constant change in policies, especially in immigration rules and regulations. In addition, they believed the type of student they are helping is changing, including the overall demographic of the students who study abroad but specifically the needs, wants, and desires of those students. Another challenge for student services staff is the ability to stay up-to-date with changes in the types of students who study abroad and the needs of students currently participating in the direct exchange.

A student services staff member, Nick, explained that, In the US, we have the challenge of immigration and visa regulations always changing. This is hard for us to communicate to our students going on exchange. The visa application takes a lot of time and diligence. Sometimes, they think they can get it done very quickly, when in reality accuracy is the key. We do not want their visa to not get approved. I could have a student going abroad this summer, but then this fall, something could change for the visa application process, so it is important I always stay current with the changing regulations and rules affecting our students. 
Research Question 5: "How do student affairs personnel prepare students for the psychosocial aspects of the study abroad experience?"

It is the goal of student services staff to prepare students before going abroad for the feelings of loneliness and any other psychosocial aspects they may encounter. Both universities do this through orientation before the students depart for their study abroad experience.

Student perception: It was found that all students who study abroad experience a sense of homesickness and isolation. For some students, it happened more than once throughout their study while, for others, it was a one-day experience as they worked through it with support from friends and families. Many students said friends who had studied abroad told them about experiencing the hardships of missing family, significant others, and friends at home. To counteract those hardships, they reminded themselves that the study abroad experience is temporary and that they must enjoy it fully or they would regret being invested in their sad feelings and wasting their precious time away. Rebecca's comment supported this notion. She said, "When you study abroad, you are most likely doing it alone. You leave your home country and go experience a new one." She went on to say, "I know it is so exciting to do something new, but I also experienced that feeling of culture shock and I needed the support of student services staff to support me through."

Similarly, Hannah stated, "I think that when you study abroad you experience so many emotions. Thankfully, the orientation before I left informed me of this and how to seek the support when I needed it." 
Student services staff perception: It is evident that when students study abroad, they will experience loneliness and stress. These emotions arise at different times during the study abroad experience. It is important that student services staff are aware of these feelings and experiences so they can prepare students ahead of time for whatever culture shock they might experience during their time abroad.

All student services staff hold an orientation for students before they go abroad, but it was found that staff needed to be more inclusive and obvious about these types of experiences. Often, students are excited about going abroad because it is an exhilarating time, but it is also a time of reality. They may experience feelings of isolation, which is to be expected, and it is the role of student services staff to prepare students for those feelings.

Andrea, a student services staff, opened up about the importance of what she covers at orientation.

All students are excited when they come to orientation and cannot wait for their experience in another country. However, there is the importance of speaking honestly to them, taking care to point out the different types of emotions they might experience and ways to understand those emotions. I want students to be successful during their time abroad, so I work very diligently to bring attention to the psychosocial aspects that affect students.

In addition, Michelle, another student services staff, stressed the importance of preparing students for the psychosocial aspects of studying abroad. She said, "The emotions I see most frequently in students are stress, loneliness, and social integration. 
Through orientation, I address the importance of being aware of the different emotions that can occur during the study abroad experience."

\section{Summary}

The purpose of this study was to examine the student services of higher education at Örebro University and University of Central Missouri to understand what makes each unique. Higher education is becoming the norm in the 21 st century, and providing access to college and study abroad is vital because it leads to a well-rounded student.

According to the National Association of Foreign Student Advisors (2008), there will continue to be growth in the number of students choosing to study abroad. While this is an excellent opportunity for those students, they should be aware of the difficulties associated with transitioning into a new culture. With the assistance of student services teams, international students can find ways to successfully assimilate into the new culture, resulting in enriched educational experiences that last well into their adult lives.

According to the Study Abroad Coordinator at UCM (M. Chiesi, personal communication, May 2019), statistics show that from 1987 to 2019, UCM sent 78 students to Örebro University, demonstrating the strong relationship these two institutions have enjoyed with each other over the years. With the knowledge that international enrollment and study abroad is increasing, the researcher hoped to ensure that all students who participate have a meaningful and successful experience. 


\section{SECTION TWO:}

PRACTITIONER SETTING FOR THE STUDY 


\section{Introduction}

Leadership can be complex, but it is necessary for making a difference (Northouse, 2016). The goal of a leader should be to leave a place better than they found it. In international education, anyone who is a leader is also a learner. As a leader, one should want to make a difference in international education, which means they must also be a change agent (Merriam \& Bierema, 2014). International education is an everchanging field, and successful programs for students must have leaders who understand that change may need to be implemented.

\section{History of Organization}

\section{University of Central Missouri}

The University of Central Missouri (UCM) was founded in 1871 as Normal No. 2. It later became known as Warrensburg Teachers College and, throughout the years, has had numerous name changes (University of Central Missouri, 2019). The institution became Central Missouri State Teachers College in 1919, Central Missouri State College in 1945, and Central Missouri State University in 1972. Finally, in 2006, it became the University of Central Missouri (University of Central Missouri, 2019) and remains that today. UCM is an accredited four-year public university offering more than 150 academic programs at the undergraduate and graduate levels (UCM, 2018).

\section{Örebro University}

Örebro University was established in Örebro, Sweden, during the 1960s when Uppsala University began offering courses. In 1999, the institution was awarded the status of university by the Government of Sweden, making it the 12th university in the country (Örebro University, 2018, Örebro University in figures section, para. 1). 


\section{Direct exchange between UCM and Örebro University}

The direct exchange between UCM and Örebro University began in 1992 as a result of work done by Terry Rodeburg, Director of International Programs at UCM at that time (T. Rodeburg, personal communication, September, 2019). The agreement was made by two individuals, Rodeburg (representing Central Missouri State University at that time) and Anna Hatziantoniou (Örebro University).

\section{Organizational Analysis}

Organizations are interesting structures that are always developing (Manning, 2013). In general, the organization of a university begins with the president and a chancellor, who report to a higher authority. For instance, the president at UCM reports to the Board of Governors and Örebro University leadership reports to the Government of Sweden. Under the leadership at both institutions are provosts, deans, department chairs, and directors.

The organizational framework of UCM is the hierarchy design, which provides an understanding of the organization's structure (Bolman \& Deal, 2013). Within the context of this study, the Director of Academic Outreach at UCM oversees all aspects of the study abroad students' experiences going to Örebro University, while the Graduate and International Student Services office assists the incoming international students from Örebro University. This is in contrast to Örebro University, where different situations are handled by different members of leadership.

Like UCM, Örebro University also has an organizational framework. There is a university board, which is the university's highest decision-making body. This board includes the president, vice-chancellor, and student representatives. Within that 
framework, the international student services staff report to the vice-chancellor. In addition, there are staff representatives from across campus who have the right to attend board meetings and share thoughts, if they wish.

Within each institution is a strategic plan, including goals and benchmarks for knowing if those goals have been met. The leadership at both UCM and Örebro University are responsible for influencing others and facilitating the actions necessary for reaching the goals set within the strategic plans (Northouse, 2016).

One of the goals established by those strategic plans that leaders at both institutions are working to achieve is to internationalize their campuses. According to the structural frame, it is necessary to identify the tasks required to reach a goal and then delegate the responsibilities associated with those tasks. It is through this identification and delegation that an organization can reach its goals. Each individual area of the university, for example, international education, works to ensure their area is effective (Bolman \& Deal, 2013).

Örebro University, specifically, has made great strides in internationalizing its campus. They have exchange agreements with almost 150 universities globally, evidence of the increase in the interest in studying abroad. In the last academic year, 184 students from around the world took advantage of the opportunity to study at Örebro University. In the year 2020, it is expected that more than 230 students will engage in a study abroad experience there.

When looking at two different universities, one in the Midwest United States and the other in Sweden, it is possible to identify differences in how they operate. Some of those differences include, but are not limited to, funding, goals, and missions. Northouse 
(2016) stated that being a leader means influencing others to reach a common goal, so regardless of what the university structure may be and the resulting differences in how they operate, a leader is the one working to ensure common goals are met.

Heifetz and Laurie (2011) outlined guiding adaptive work, which is the primary responsibility of each office's director. They noted the necessity of leaders "getting on the balcony" (p. 38), which means noticing the adaptive challenges that are occurring, giving back to the organization, and shielding any members under their leadership. Heifetz and Laurie (2011) also stated, "Leadership has to take place every day. It cannot be the responsibility of the few, a rare event, or a once-in-a-lifetime opportunity" (p. 78). For the direct exchange agreement to increase its numbers at UCM and Örebro University, the support and leadership from those within the student services at both institutions are a necessity.

\section{Leadership Analysis}

As Merriam and Bierma (2014) stated about learners, each individual holds important opinions on certain topics and has unique viewpoints on a situation. This is the case within international education. Needs vary from student to student, and it is important to understand that although international students come from different backgrounds, we must always value the issues of ethics and diversity.

Those issues of ethics and diversity are perhaps more important now than they ever have been, and leaders must assume the responsibility for ensuring both are valued. This begins by ensuring everyone acts ethically, appreciates the value of diversity, and understands the evolving and ever-present issues related to the realities of an ethical, diverse environment. According to Taylor and Cranton (2012), "Perhaps we need to 
reframe our intention: may we live simply not run from the fire" (p. 547). It is important, therefore, that we encourage others to embrace both ethics and diversity when working in international education (Cohn \& Mullenix, 2007).

The Coordinator of Exchange and Sponsored Programs at UCM is housed in the Graduate and International Student Services office. This individual helps exchange students with their visas, student involvement, and integration into the UCM campus culture. The Study Abroad Coordinator at UCM is housed in the Center for Global Education. Both of these individuals play a vital role for the exchange students from Örebro University.

As for Örebro University, the international support staff is housed within the International Office located in Långhuset, which also houses the Student Center. There are four international coordinators, each helping students from specific countries as well as Swedish students going abroad. There is also an international student assistant, who helps with orientation, programming events, and social and practical support for the international students. Lastly, there is an international operational coordinator, a newly created position that is part of the university's efforts to strengthen its resources for internationalization. This person's responsibilities include overall responsibility for the international office and serving as the main point of contact for researchers, teachers, and staff who have questions about international opportunities.

\section{Implications for Research in the Practitioner Setting}

For international educators to increase the number of students studying abroad in this direct exchange, they must feel empowered. This empowerment begins by having their social, personal, and academic needs met. Educators who feel empowered are likely 
to be more effective (Bolman \& Deal, 2013). The descriptive statistics provided by the Center for Global Education at UCM show that the number of students studying abroad through the direct exchange has decreased from when the exchange began in 1992. This researcher hoped to shed light on this decrease while also identifying measures necessary to reverse this trend.

\section{Implications within the History of the Organization}

There have been many changes within the international education leadership at UCM. In 1992, when the direct exchange was created, the director of the international office implemented and grew the international center immensely. Since that time, there have been different leaders and different strategic plans. Ultimately, international education has declined at UCM with fewer students from UCM studying abroad. This is in contrast to Örebro University, which has continued under much of the same leadership and common goals, resulting in an increased enrollment of study abroad participants.

\section{Summary}

There have been changes within leadership and staff at UCM while those have remained relatively constant at Örebro University. The organizational structure at both UCM and Örebro University are included in the overall study abroad initiatives at the respective universities. While it is clear that those in leadership positions have a direct impact on the success of the study abroad programs themselves, it is equally clear that there are many people who share in the responsibility of ensuring the success of the students who participate in those study abroad programs. 
SECTION THREE:

SCHOLARLY REVIEW FOR THE STUDY 


\section{Introduction}

Zhou and Cole (2017) indicated that in 2012 approximately 4.5 million students pursued higher education outside of their home country. This is double the number of students who took advantage of the same kind of higher education opportunity in 2000 (Zhuo \& Cole, 2017), with the United States responsible for the vast majority of those international student enrollments. For this literature review, the researcher investigated student services in a higher educational setting for two direct exchange universities, University of Central Missouri (UCM) in Warrensburg, Missouri, and Örebro University in Örebro, Sweden. The researcher also examined the importance of student services staff and how they impact the experiences of international students at both UCM and Örebro University.

Whether in the United States or Sweden, student services are important to both the academic and personal success of students. Jones and Abes (2013) provided direction to student services professionals as they connected the work of higher education to the development of all students. This handbook serves as a tool for personnel as they assist students in having successful study abroad experiences. Agosti, Andersson, Bringsén, and Janlöv (2019) also want students to be successful, and that can occur through the worklife balance they recommend for all students.

One question asked by many is why students choose to study abroad. Lesjak et al. (2015) identified the main reasons as personal and professional growth. According to Van Hoof and Verbeetem (2005), the number one reason North American students choose to study abroad is for personal development. In addition, Zhelanov (2019) stated that students choose to study in Sweden more for personal growth than academic growth. 
Presumably, this is because of the independent approach to instruction and the freedom to study whatever they wish, which is unique and remarkable to Sweden. Finally, McMilan and Opem (2019) and Terzuolo (2018) noted that intercultural competence, the ability to communicate effectively with members of another culture, is an expected outcome and another important reason students choose to study abroad.

Anderson and Lawton (2015) discussed the nature and location of study abroad program choice as it is related to a student's development. The authors explained that students have a motive when choosing what country they wish to go to, whether that be for career aspirations or cultural learning. Additional motives could be the availability of academic programs and involvement in certain events (Altbach \& Knight, 2007; Anderson et al., 2015; Golden, 2010; Svensson \& Wihlborg, 2010).

Understanding what students hope to gain through their study abroad experience would help with accommodating those needs as a way to increase interest in studying in Sweden. Those accommodations could include, but are not limited to, program modifications and outcomes. Therefore, Anderson and Lawton (2015) encouraged students to be aware of their motives when choosing a study abroad location.

Civinini (2019) surveyed 1,900 students interested in studying abroad and revealed that the main motivations of students choosing where to study were related to career choices that would lead to improved employment opportunities. The survey also identified motives such as cultural experience and interest in a particular university (Civinini, 2019). Results of the survey indicated that most students aspired to study in Canada, followed by the US, UK, and Australia. Many researchers would say students seek English-speaking countries so they will not experience the difficulties associated 
with a foreign language in addition to the numerous other difficulties they will face (Deardorff, 2008).

Regardless of the study abroad location, prospective students say they want the university's website to be updated so they know what to expect regarding their international experience. This includes providing information such as academic offerings and student involvement opportunities (Civinini, 2019). Civinini (2019) asserted that universities need to brand their institution in a way that highlights their unique features if they hope for students to choose them as a study abroad location. Bracht et al. (2006) found that competencies acquired as part of a student's study abroad experience are important to prospective employers. Dwyer (2004) also supported the influence that studying abroad can have on students' career goals.

In the Zhelanov (2019) study, students were asked why they chose to study in Sweden in particular. The reasons given were varied and included being interested in a certain subject, creating a better life for themselves and changing their life course, giving them something to do, making a difference for others, and simply trying it out. In addition, studying abroad in Sweden is desirable because of "ansvarsfrihet," which is "freedom with responsibility" and allows students to study more freely and independently (Zhelanov, 2019).

As of 2019, the number of students studying abroad has more than doubled since 2000 (Institute for International Education, 2019). Even though enrollment had increased, however, research by Karmelita (2018) indicated that completion rates have not increased quite as rapidly. That is not necessarily the case for Sweden, though. The research that 
does exist on Swedish institutions, limited though it may be, shows they have a graduation rate of 77\% (OECD, 2018), an indication of effective student services.

While it is acknowledged that student services are important for college students, there is limited research on why they are important, particularly in Sweden. In fact, there is much less information on students in Sweden than on students in the United States. With the growing number of students choosing to study abroad, Aveni (2019) stressed the importance of having quality student services staff, and that begins by hiring individuals who have experience working with international students and who know how to help them be successful. In addition, Karmelita (2018) found that adult learners who study abroad will experience a variety of barriers, so it is also important to hire individuals capable of working with a wide variety of students and their varying needs.

This was the perspective from which the two overarching questions in this study were addressed: "How does student success relate to study abroad advisement?" and "How can student services support international students studying in a new culture?"

\section{Conceptual Frameworks}

Theory is a way for student services staff to "describe, explain, predict, influence outcomes, assess practice, and generate new knowledge and research" (Jones \& Abes, 2013, p. 151). Therefore, in this section, the two theoretical frameworks on which this study was based were explored. First, Schlossberg's Transition Theory (1984) of the 4 S's, Situation, Self, Support, and Strategies, will be presented. Next, Astin's Theory of Student Involvement (1993), which focuses on how students change in relation to being involved, is presented. These theories are closely intertwined, often making it difficult to 
distinguish one from the other, but they both emphasize the significance of student services staff and their impact on study abroad students.

\section{Schlossberg's Transition Theory}

Schlossberg's Transition Theory (1984) is used by many student services staff to understand the transitions that college students experience. This theory is very relevant to international students, in particular, who must also assimilate into a new culture (Ehrenberg, 2012). The primary goal of student services staff is to assist students with their transition into college (Bista, 2015).

A qualitative study conducted in Helsinki, Finland, revealed that the college experience itself is a transition for students. When that also includes a study abroad experience, the transition is that much more complex. In addition to other researchers, Coertjens, Brahm, Trautwein, and Lindblom-Ylänne (2017) discussed the importance of understanding students" enculturation into college and noted, "Transition is regarded as a phase, rather than a single event" (p. 359). For students who study abroad, that transition is comprised of a variety of phases, including the honeymoon phase, frustration, adjustment, and acceptance.

Kim’s (2012) ethnographic study supported Schlossberg's Transition Theory as he noted that studying abroad could be a time of transition for students. Living away from home and learning a new culture different from your own both require reflection.

Schlossberg's Transition Theory (1984) acknowledges the need to facilitate this transition for international students and offers suggestions for how to deal with it smoothly. When using this theory effectively, one can distinguish factors that are related to the transition of study abroad students and that are likely to influence their full international experience. 
Furthermore, extant literature (Adewale et al., 2018; Stribling, 2018) explained that when international students experience a new culture that is away from what they know, including home, friends, family, and surroundings, they could experience issues such as depression or anxiety. That is when the authors recommended student services staff step in and, using Schlossberg's Transition Theory (1984), help students through those issues. Both authors identified the benefits that international students provide to college campuses, and they emphasized the importance of using the framework of Schlossberg's Transition Theory (1984) to understand the transition these students experience and the support they need from international student services staff.

This view was further supported in an article by Thundborg and Bron (2019), which was based on narratives of two students in Sweden who used Schlossberg's Transition Theory (1984) to understand their transition before, during, and after their higher education experiences. The students in Thundborg and Bron's study explained that student services staff played an important role in helping them adjust smoothly through the various transitions because students like themselves often lack social and cultural feeling and need that extra support (Thundborg \& Bron, 2019).

One aspect of the transition students experience is transformation, which is evident in many areas of a student's life, including their study abroad experiences (Head \& Alford, 2013; Northouse, 2016). Specifically, transformation occurs as study abroad students create long-term goals for those experiences.

Karmelita's (2018) phenomenological study on the experiences of five adult learners enrolled in a transition program at the university they were attending utilized Schlossberg's Transition Theory (1984) by applying the 4 S's to the transitions those 
students were experiencing. The findings illustrated that these students had a reliable support system because of the relationships they formed with other students in the transition program. The perceptions of those five adult learners supported this finding with comments such as "The good part about talking to the student services staff is that I feel as though I don't have to protect anything" and "I may want to give up but my support system will not let that happen" (Karmelita, 2018, p.24).

It is the consensus of many researchers that adult learners pursue a college education for a variety of reasons and face a variety of struggles. In fact, Karmelita (2018) saw the need to explore the struggles adult learners face in college, and Schlossberg's Transition Theory was applied in an attempt to fully understand those struggles. Karmelita also saw the need to assess adult learners who were experiencing transition, and study abroad was an ideal situation for that assessment.

As further noted by Karmelita (2018), Schlossberg's Transition Theory states that transition occurs over a period of time, and the combination of the 4 S's affects the way students handle changes as they are occurring. In addition, Nilsson (2015) stated that transitioning from one's home country into a new country could be shocking. Schlossberg's Transition Theory, therefore, contributes to an understanding of that transition.

\section{Astin's Theory of Student Involvement}

The second theory, Astin's Theory of Student Involvement, is relevant to the current study of international students because of its emphasis on the importance of student involvement, both academic and social, when studying abroad. Research documents the significant personal and professional benefits to students who are involved 
during their study abroad experiences (Astin, 1999; Elkins et al., 2011). Kjellberg and French (2011) also agreed with the importance of involvement during the study abroad experience and encouraged students to take part in social and cultural immersion activities on campus.

According to Astin (1999) and Elkins et al. (2011), the time students spend outside of the classroom is as important to their learning as the time they spend inside the classroom. As is commonly acknowledged, Astin's (1999) theory has been applied for many years and is especially noteworthy for his assertion that "students learn by being involved" (p. 133). Ultimately, the more students become involved in their collegiate experience, the more in-depth their learning and personal growth will be (Astin, 1999).

Like Astin (1999), Zhuo and Cole (2017) also discussed the importance of involvement, both academic and social. For instance, academic involvement can lead to student satisfaction, but it can also be challenging for some international students because of the language barriers (Zhuo \& Cole, 2017). Similarly, social involvement can be challenging for international students, but it is vital to their growth (Brock, 2010).

A common theme within the current literature is that international students have concerns about loneliness and social isolation because of cultural and language barriers as well as limited communication with family and friends at home (Zhuo \& Cole, 2017). Astin (1999) asserted that involvement helps a person both academically and personally, which should alleviate any discomfort the person may feel. In a study by Zhuo and Cole (2017), they noted that this involvement can be a result of interacting with faculty and student services staff, studying with peers, and even attending social events with friends of the host institution or other international students (Zhuo \& Cole, 2017). 
One way of breaking down these barriers is through social media. Sawyer and Chen (2012) discussed how international students use social media to help with their cultural integration. The authors found that social media creates an environment for international students to connect with individuals in their new country as well as their home country, which gives them a sense of belonging (Sawyer \& Chen, 2012). Likewise, Murray (2011) stated that the use of social media allows students to integrate into a new culture and helps them stay intertwined. Lastly, international students use social media to create identities (Junco, 2014).

Fass-Holmes and Vaughn $(2014,2015)$ argued that international students are struggling academically now more than ever. They need the support of student services staff to guide them through and assist them with this important part of their study abroad experience. While it is true that students are in the host country to learn about another culture, their academic experiences will be important when they return to their home countries. Many international students earn credits when studying abroad, so their grades do matter. Student services staff should be encouraged to provide services that focus on and support the academic needs of students. One concept suggested by many researchers for those working with international students who have academic needs is to adopt the "Neighborhood Student Success Collaborative Model”, which includes academic proficiency, invitational navigation, and social-emotional engagement (Royal, Noto, High McCord, \& Pitcher, 2015).

Örebro University works closely with Erasmus Student Network (ESN), which is a non-profit organization supporting international students. This organization plans activities for students to help with their involvement such as outdoor activities, 
excursions, and other activities that extend beyond the classroom. This is one significant way of helping international students integrate into their new culture (U. Kvist, personal communication, November 2019).

Finally, Gillie and Chen (2019) stated that through the lens of Astin's Theory of Student Involvement, student services play an important part in facilitating the academic success of international students. Research suggested that most students have the greatest difficulty transitioning into their new culture during the first 6 months of their stay in the new country, which would negatively impact their ability to be academically successful (Gillie \& Chen, 2019); therefore, it is important that international students are not simply admitted and then not assisted throughout their stay (Gillie \& Chen, 2019). Rather, these students need guidance transitioning smoothly, both academically and socially (Gillie \& Chen, 2019), and student services staff, administrators, and faculty need to provide that guidance.

\section{Trends and Patterns}

According to Sweden-An Overview (2018), studies thus far have shown that more students from the EU than from the US choose to study in Sweden. Everything is much more expensive in Sweden, making cost of living one reason many students from the US choose not to study there. Despite that high cost of living, however, Sweden-An Overview (2018) noted that Sweden is a beautiful country that is safe for all who live and visit there.

According to the Open Doors Report on International Education Exchange (2018), in 2015-2016, the number of international students studying in the US increased 
by 7\%. More recently, from March 2018 to March 2019, the number of international students studying in the US decreased by $2.7 \%$ (Redden, 2019).

In contrast, according to University World News (2019), the number of international students attending universities in Sweden has increased by $20 \%$ since March 2016. According to Milinchuk (2017) and Kalpazidou Schmidt (2017), Sweden has had a long history of higher education, primarily because there are numerous authorities who work together to create quality higher education for Swedish as well as international students.

As the number of international students increases, the importance of understanding their needs increases as well. Nilsson (2015) conducted a qualitative study that explored student transition and the experiences they have while studying abroad and that contributed to the understanding of life satisfaction among international students studying in Sweden and the US. To conduct this qualitative study, students at Umeå University in Sweden completed a survey before and after their study abroad experience. It was determined by Nilsson (2015) that students had lower levels of somatic symptoms and psychosocial health issues after studying abroad compared to levels before studying abroad, which is evidence of the profound impact student services staff can have on these international students.

In another study, this one by Gillie and Chen (2019), it appeared that the US welcomes international students, but the authors also noted there are challenges to being an international student. The purpose of their study was to discover what challenges international students may face in a new culture, which could include, among other 
things, language differences, homesickness, academic style changes, and navigation of a new environment (Gillie \& Chen, 2019).

Carr, Koyama, and Thiagarajan (2003) suggested group counseling as a way to help international students. A group dynamic was suggested as they felt it gives the students a way of feeling connected to their cultural identity (Smith \& Khawaja, 2011). Also suggested was to have an international student advisor in the counseling session to help ease the anxiety of learning about different cultures, immigration, and cultural sensitivity (Smith \& Khawaja, 2011). Similar to other studies, Kronholz (2015) suggested bringing another staff member into the counseling sessions to develop the support system. It is vital that student services staff recognize the need for international student support. Students study abroad to learn, grow, and thrive, but they also need the support of student services staff. Another author, Olivas (2006), stated that counseling services must adjust their sessions for international students. How counselors would handle domestic student sessions is different from international student sessions. Incorporating frameworks and theories into practice will help student services staff support all of these students.

Gillie and Chen (2019) also suggested that even though there is a large number of international students, it seems that many student services personnel still do not understand this student population or how to serve them. It is critical, however, that student services personnel and administrators alike acquire that understanding because "Colleges and universities spend a considerable amount of money and energy to provide student services and support, with the goal of increasing students' social and academic integration" (Sidelinger, Frisby, \& Heisler, 2016, p. 168). This is evidence of the 
important role that student services play for all students, but especially for international students.

Altschwager, Dolan, and Conduit (2018), along with many other researchers of international education, recommended orientation for all new international students as a way to welcome them into their new culture and reduce or eliminate the challenges of being an international student. Altschwager et al. (2018) made clear that these orientations are significant, and participating in them is a way for student services staff, administrators, and faculty to assist students in a variety of ways, such as advisement and mentorship (Altschwager et al., 2018; Schmidt, 2017). Altschwager et al. (2018) elaborated on the importance of orientations because of the intellectual and sensory experiences gained.

\section{The International and American Experience}

Institutions of higher education, both international and American, acknowledge the importance of student involvement. In their article, Zhuo and Cole (2017) identified similarities between international and American students, one of which was the involvement of students during their study abroad experience. They noted that involvement could be influenced by a student's background, meaning that what a student was passionate about in their home country will likely be something they will get involved with during their study abroad experience. In addition, Juno (2014) discussed how many universities worldwide are using social media to create workshops and student engagement events to help with the international students' involvement during their study abroad experience. 
In addition, both populations of students, international and American, are influenced by the amount of interaction they have with faculty and the nature of that interaction. The more involved students are with their mentors, the more likely they are to get involved in activities and organizations recommended by those mentors. Student services staff, then, can engage students and encourage them to seek out new opportunities for involvement (U. Kvist, personal communication, November 2019),

\section{The International Experience}

When it comes to higher education, every country is unique in the experiences they provide to students and the US and Sweden are no exception. Although they offer different experiences, however, the common desire in both countries is for students to be successful. What that success looks like, and what contributes to it, is one of the distinguishing features of higher education in Sweden (Braskamp, et al., 2013).

One characteristic of higher education in Sweden is who pays for that education. In Sweden, tuition is free, as the money to pay for both undergraduate and graduate education comes from the government (Andersson, et al., 2017). Without the burden of college expenses, students are able to focus on the educational experience itself, which contributes to the likelihood of their success. Zhelanov (2019) explained that in Sweden education is a way of improving people's lives and well-being.

Their commitment to higher education is another unique characteristic of Sweden. Evidence of this commitment is the development and implementation of three different systems for ensuring their higher education is of superior quality (Schmidt 2017). Sweden's financial commitment is the focus of the study by Andersson, Antelius, Mansson, and Sund (2014), which made clear that the amount of money the Swedish 
government spends on higher education is significant (Andersson et al., 2017). Despite that spending, however, Sweden is facing budget cuts, but they avoid making cuts to student services staff because that is one of the main contributors to student success (Andersson et al., 2017).

In a quantitative study by Zhelanov (2019), the author analyzed the Bologna reform in Sweden, yet another characteristic of higher education in that country. Swedes believe they are in a state of "lagom," meaning they are in a continuous state of learning their entire life (Zhelanov, 2019). Therefore, Sweden wants to be a part of the "Bologna process," which, essentially, is the desire to promote continuous learning with the ultimate goal of completing a degree and finding satisfying employment. It is under the guidance and direction of student services staff that students will be able to accomplish both of those goals (Zhelanov, 2019).

The final and most compelling characteristic of higher education in Sweden is their approach to teaching and learning. The Swedish method is based on independent study and affords students the opportunity to explore for themselves. Deen (2007) noted that all students enjoy a teaching and learning model where they are challenged by faculty and student services staff to think freely and independently. Not only are students encouraged to think freely, they also have freedom in what they choose to study. Students in Sweden do not need a major to graduate, meaning they can study a broad range of nonprogram courses and successfully earn a general qualification degree.

\section{Summary}

There is clearly a history of and a passion for study abroad involvement at both universities involved in the direct exchange. Although both institutions value the study 
abroad experience, it is clear that both must advocate for study abroad involvement. Doing so means, in part, ensuring students understand the support they will receive from student services staff who are working to bring them comfort in an uncertain time.

Studying abroad is a personal choice and will result in changes to the individual as a person and as a student. Because of this change in students, student services in higher education must also change to meet their needs. While studying abroad is exciting for the student, it is the responsibility of student services personnel and faculty to deliver a meaningful educational experience while also creating an environment that will lead to the student's success (Zhou \& Cole, 2017).

Örebro University in Sweden and UCM in the United States are unique, and the direct exchange relationship between the two universities is well respected by students, staff, and faculty at both institutions. The goal of this research was to explore the relationship between these two direct exchange universities and the impact student services at each university has on the students who choose to study abroad there, ultimately leading to a student services program that will provide an enriching international experience for study abroad students.

The overall perspective on this topic was that higher education is constantly changing, and faculty and staff must be willing to adapt in the services they provide and the ways they provide them. The goal of everyone in higher education should be the success of students, and that means being willing to do whatever it takes to ensure that success. Previous literature provides valuable information on the nature of post-study abroad experiences. 
Researchers have found that building relationships between international students and faculty, student services staff, and friends will help the students' development and reduce their stress levels. These support structures provide international students a feeling of worth and help facilitate overall integration into a new culture (Arthur, 2003;

Kronholz, 2015; Olivas, 2006). 


\section{SECTION FOUR:}

CONTRIBUTION TO PRACTICE 


\section{Dissemination of Practitioner Contribution}

A PowerPoint presentation and executive summary were created for the International Education Leadership teams at both universities. The presentation will be made in person at University of Central Missouri and through Zoom to personnel at Örebro University. The PowerPoint will cover the design and purpose of this specific study, and the executive summary will serve as a resource for the individuals attending the presentations. The goal of this presentation to the International Education Leadership teams is to enrich experiences of exchange students, ultimately increasing the number of students participating in the studying abroad direct exchange between UCM and Örebro University. 


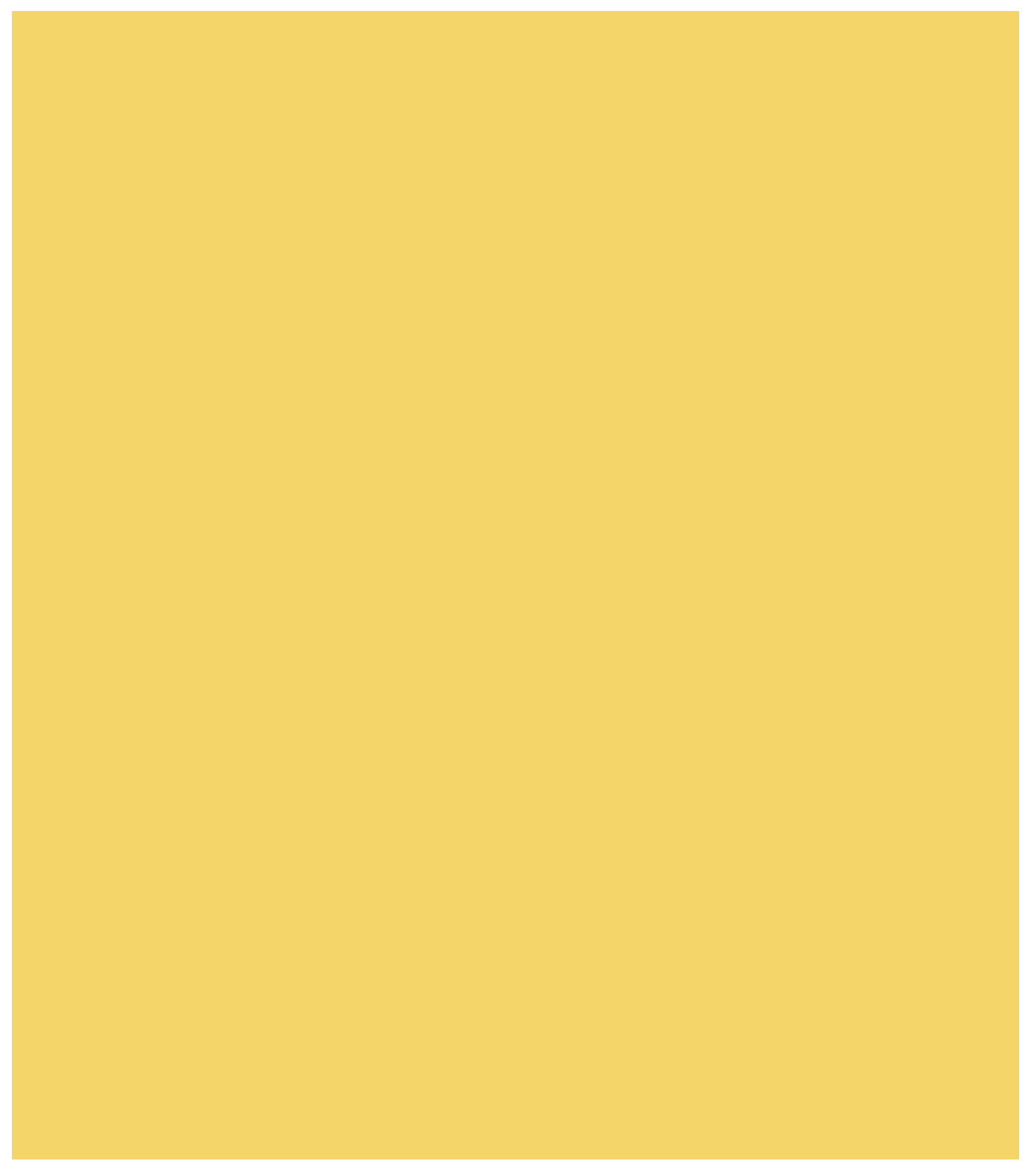

Executive Summary 


\section{University of Missouri}

Taylor N. Kinde

Higher Education Student Services: A Qualitative Study of Two Mid-Size Universities' Direct Exchange Programs

\section{Statement of the Problem}

As of 2019, the number of students studying abroad has more than doubled since 2000 (Institute for International Education, 2019). Even though enrollment had increased, however, research by Karmelita (2018) indicated that completion rates have not increased quite as rapidly. That is not necessarily the case for Sweden, though. The research that does exist on Swedish institutions, limited though it may be, shows they have a graduation rate of $77 \%(\mathrm{OECD}, 2018)$, an indication of effective student services.

While it is acknowledged that student services are important for college students, there is limited research on why they are important, particularly in Sweden. In fact, there is much less information on students in Sweden than on students in the United States. With the growing number of students choosing to study abroad, Aveni (2019) stressed the importance of having quality student services staff, and that begins by hiring individuals who have experience working with international students and who know how to help them be successful. In addition, Karmelita (2018) found that adult learners who study abroad will experience a variety of barriers, so it is also important to hire individuals capable of working with a wide variety of students and their varying needs.

This was the perspective from which the two overarching questions were addressed: "How does student success relate to study abroad advisement?" and "How can student services support international students studying in a new culture?"

\section{Purpose of the Study}

The purpose of this study was to gain a rich understanding of the student services offered at two direct exchange universities, one in Sweden and the other in the United States, and the impact those services have on students' collegiate success. The data collected provided information on the impact of student services on students who study abroad, particularly in Sweden and the United States, ultimately allowing for the creation of a student services program that provides an enriching international experience for exchange students.

The study was based on a qualitative research approach. Interviews were conducted with 10 students from Örebro University who had studied at UCM and 10 UCM students who had studied at Örebro University. In addition, student services personnel from both universities were interviewed. Observations were conducted by the 
researcher at an academic advising appointment as well as a student programming event. Students who are returnees of the direct exchange program completed the surveys.

\section{Design of Study}

To explore the perceptions of study abroad participants at UCM and at Örebro University, a qualitative study was utilized. A survey was sent, and interviews were conducted, and observations were made.

Setting

The setting of this study was two public universities of approximately the same size, University of Central Missouri (UCM) in Warrensburg, Missouri, and Örebro University in Örebro, Sweden. These two institutions have a direct exchange program.

UCM is a public, state-funded university located in Warrensburg, Missouri, United States. UCM was founded in 1871 and has total enrollment of 11,487 (University of Central Missouri [UCM], 2018). The number of international students is 799 undergraduate and graduate students from 55 different countries (UCM, 2018). UCM also has 25 international direct exchange agreements with universities worldwide (UCM, 2018).

Örebro University is a public state university located in Örebro, Sweden. The university was founded in 1977 as a college and became a university in 1999 (Facts, 2019). Örebro University offers various programs of study as well as professional schools of medicine and law. They have a total student enrollment of over 15,000, with 172 international students currently enrolled in both undergraduate and graduate programs (Facts, 2019).

\section{Conceptual Framework}

Theory is a way for student services staff to "describe, explain, predict, influence outcomes, assess practice, and generate new knowledge and research" (Jones \& Abes, 2013 , p. 151). Therefore, in this section, the two theoretical frameworks on which this study is based will be explored.

Schlossberg's Transition Theory (1984) of the 4 S's: Situation, Self, Support, and Strategies will be presented. Next, Astin's Theory of Student Involvement (1993), which focuses on how students change in relation to being involved, is presented. These theories are closely intertwined, often making it difficult to distinguish one from the other, but they both emphasize the significance of student services staff and their impact on study abroad students.

\section{Schlossberg's Transition Theory}

Schlossberg's Transition Theory (1984) is used by many student services staff to understand the transitions that college students experience. This theory is very relevant to international students, in particular, who must also assimilate into a new culture 
(Ehrenberg, 2012). The primary goal of student services staff is to assist students with their transition into college (Bista, 2015). In this study, specifically, the goal was to identify the elements that are most necessary to facilitate the transition into college as part of a study abroad experience.

\section{Astin's Theory of Student Involvement}

The second theory, Astin's Theory of Student Involvement, is relevant to the current study of international students because of its emphasis on the importance of student involvement, both academic and social, when studying abroad. Research documents the significant personal and professional benefits to students who are involved during their study abroad experiences (Astin, 1999; Elkins et al., 2011). Kjellberg and French (2011) also agreed with the importance of involvement during the study abroad experience and encouraged students to take part in social and cultural immersion activities on campus.

According to Astin (1999) and Elkins et al. (2011), the time students spend outside of the classroom is as important to their learning as the time they spend inside the classroom. As is commonly acknowledged, Astin's (1999) theory has been applied for many years and is especially noteworthy for his assertion that "students learn by being involved" (p. 133). Ultimately, the more students become involved in their collegiate experience, the more in-depth their learning and personal growth will be (Astin, 1999).

\section{Qualitative Data Analysis}

The first step was to organize the data so that it could be analyzed. To facilitate the organization required for this step, the researcher transcribed the interviews and prepared typed notes. Furthermore, writing notes following each interview in the course of this project meant reflecting on each interview, identifying emerging themes, and developing early ideas about where the research was heading (Merriam \& Tisdell, 2016; Seidman, 2013).

The second step was coding the data, which is defined as assigning a place that fits a variety of data so the data can be easily retrieved (Merriam \& Tisdell, 2016; Seidman, 2013). The coding was done by the researcher, who categorized the data into sections that had common themes as they corresponded to the research questions identified above (Creswell, 2014). Creswell suggested that a researcher should take notice of the different codes, especially those that may be surprising or unique to the study (Creswell, 2014).

This was conducted by "hand coding," as defined by Creswell. This hand coding allowed the researcher to work in-depth with the data. When the coding was completed, the researcher wrote an individual summary of reflection for each interview completed. The interview transcripts were then read again for accuracy as the researcher wanted to ensure that she was reflecting fairly on what the participants had stated. 
As recommended by professionals, the researcher started the data analysis very quickly after the data were collected in Örebro and UCM (Creswell, 2016; Merriam \& Tisdell, 2016; Seidman, 2013). Data analysis was ongoing throughout the entire study (Creswell, 2014).

\section{Research Questions}

The following research questions guided this study.

1. How would Swedish students define their study abroad experience regarding student services?

2. How would American students define their study abroad experience regarding student services?

3. How do exchange students perceive cultural learning?

4. What are the greatest challenges facing student affairs professionals regarding international education?

5. How do student affairs personnel prepare students for the psychosocial aspects of the study abroad experience?

\section{Significance of the Study}

This study provided an understanding, from the students' perspective, of the positive impacts a student services team can have on students when studying abroad, whether at UCM or at Örebro University. As the literature described, students who study abroad grow in ways they never could have imagined or anticipated (IES Abroad, 2019). Not only do they have the benefit of a broadened educational experience, but students who study abroad also report a changed worldview.

IES Abroad (2019) stated that many students continue their education after studying abroad and noted benefits of their study abroad experiences ranging from personal growth, professional growth, and an improved sense of self after returning to their home country, and elaborated on the personal growth of students who study abroad. For instance, living in a unfamiliar culture with people who are different pushes students out of their comfort zone, resulting in personal growth (IES Abroad, 2019)

This study makes a contribution to the literature on international education and study abroad involvement because it relies on the authentic experiences of students with study abroad experiences. When universities have relationships with other universities, known as "direct exchanges," a positive relationship develops over the years to help students be successful. Passionate student services teams in both the United States and Sweden will ensure a student knows they are valued, which will hopefully result in an overall positive experience.

\section{Findings}

The results of the qualitative findings include thoughts of current and former students who have studied abroad through the direct exchange between UCM and Örebro University, as well as student services staff from UCM and Örebro University. 
The findings of this research were compiled from 20 students' interviewers and surveys and from interviews of student services staff, and observations. For confidentiality purposes, pseudonyms are used for the entirety of this research study. Eight themes emerged from the data. Those eight themes were volunteer opportunities, comfort, relationships, multiple challenges, independence, personal and professional development, study differences (orientation, support, etc.), and reaching out. All of the themes were relevant to one another and all intertwined in the experiences that students had when studying abroad as well as the interactions student services staff had with the exchange students.

\section{Volunteer opportunities:}

Many students spoke about their desire to engage in volunteering, saying it was something they were involved with in their home country and wanted to continue in their host country. For example, Jessica said, "I am the president back home of a volunteer student organization, and I knew I wanted to do something similarly in Sweden; however, I was not sure how to seek that opportunities."

Sarah provided this reference to mentorship:

Volunteering makes me feel like I am making a difference when outside in the community. Yes, I am a student, but I want to help where the help is needed. Volunteering gives you that feeling that you are needed. It gave me the experience to meet other Swedish students as well as people in the community of Örebro. It is interesting how many of the needs in U.S., like people not having the access to food or warm clothes, are similar to the needs in Sweden. I was able to serve food at a soup kitchen in Sweden for people that did not have a warm meal. That made me feel so good as someone who isn't from Sweden, I was still helping their people.

\section{Comfort:}

The word "comfort" came up in each of the 24 interviews. When students spoke of their comfort levels, it was always linked to their experiences in the new school, country, and environment. "Comfort" is a powerful word in international education, and anyone who has studied abroad or worked with students studying in another culture knows that comfort, as a concept, means being pushed to a completely new level Jessica explained her feelings of stepping out of her comfort zone by studying abroad:

Before I left home, I had a routine and was so comfortable with my life. I would always go to the same coffee shop in the morning, then class, then to study in the library. I would then go work out and come home and cook dinner. Every day was the same for me. I loved the comfortable routine I had built. The thought of change terrified me. However, I knew for my future after college, I would experience many changes. I needed to understand that and how to cope with that, 
so I explored the opportunity of studying abroad. My life while studying abroad has been a series of taking chances. Whether it is asking someone in the grocery store what something is or exploring a new city by myself, those were leaps I had to take to help myself grow as a person.

\section{Relationships}

Relationships were mentioned in 19 of the interviews. When students study in a new culture, they build relationships with staff, professors, and other students. It was found that these relationships were strong, as those individuals became their new support system when they were in the new country.

Many students and student services staff spoke of the relationships they still have with those they met during their time abroad. They stated that they stay in contact with them through social media and commented that if they are ever in the area where they live they make arrangements to meet. David talked about the relationships he built while studying abroad.

The most important part was the friendships I made. I made a friend group with the international students and some Swedish students (approx. 80 people) that we now have annual reunions in different countries each year. 2020 will be our 13th annual reunion, and we will be meeting in Lisbon, Portugal. We had our 10-year reunion in Örebro and were featured by the local newspaper. Also, while I was there, I did lots of local Sweden travels around Sweden and around Europe. My second semester I became a part of the Fadderiet, which was a group of students that welcomed and helped the new incoming exchange students. Myself with 2 other Swedes were responsible for assisting a small groups of exchange students.

\section{Multiple Challenges}

During the interview, Jessica talked about the multiple challenges she experienced as a student in an unfamiliar country. She noted that even though there were challenges, they were positive aspects of her experience abroad. She said,

Every challenge I had was a positive outcome and a learning experience. For example, I got lost on the bus route back to my flat. I had groceries, but somehow I didn't get off at the right stop. It meant I had to be on the bus an hour longer, but it taught me the bus route, so at the time I was worried, but at the end of the experience I learned the bus system, which would help me the rest of time around using Örebro's public transportation.

Another student, Lacey, discussed the challenges she had with her living situation. She said,

I moved into a corridor in Studentgaten, this is the corridor name, much like a dorm. We had our own room and bathroom but all shared the same living room 
and kitchen. It took some time for me to build the confidence to go cook in the kitchen. There was always people in there and I did not want to get in anyone's way but I also knew I needed to overcome this challenge to cook which is something I love to do.

Lastly, Rebecca talked about her challenges with finding vegetarian food in Warrensburg. She said,

In Sweden, you can find vegetarian food anywhere, the supermarkets, convenient stores and there are always many options at restaurants. That is not the case in Warrensburg. There may be a few options at restaurants but you really have to go the store and make the food yourself.

\section{Independence}

The researcher discovered that when students study abroad, independence is an important issue to them. In fact, the word "independence" appeared in 21 of the 24 interviews. It was the perspective of both the students and the student services staff that independence is enhanced when studying abroad. Nick, a student services staff, talked about independence.

When students study abroad and then return home, there is so much growth that has occurred. Before they leave, they want me to hold their hand through each step, but then when they return, I see their growth of self-value, self-esteem, and being more secure in their own skin. They have this mindset that they can accomplish anything, and that is definitely a change from when I first met them in my office.

\section{Personal and Professional Development}

The main goal of every student who was interviewed about their study abroad experience was to grow personally and professionally, both of which have their own unique meanings. When one thinks of personal development, they think of inner growth, such as how to handle difficult situations when studying in a new culture, conflict management, and communication skills. Personal development can be contrasted with professional development, which involves developing yourself in your current environment, for example, school or workplace, and is the continuous enhancement of a skillset.

Many students, for example, talked about personal growth, specifically in their increased confidence. Blake stated, "It gave me the ability to see things from different perspectives and take on challenges outside my comfort zone, which helps not only in my everyday life but career."

\section{Study Differences}


There are noticeable differences in the higher education systems in Sweden and the United States. The students and student services staff spoke of these differences in their interviews. This theme of differences is important as students study in a new country because they must know and understand the differences of the institutions if they are going to be successful.

One difference found by many was the class load. Sarah, who studied at UCM, stated, "It was hard for me to get used to taking more than one class at a time. I was juggling five classes, reading for them all, completing assignments, and group projects." She said, "Back in Sweden, I always take a class for a month then exam, then onto the next class. That is very different than when I studied in the US."

\section{Reaching Out}

The topic of reaching out came up frequently in the interviews. Many students said they did not reach out to student services staff when they needed some direction. Likewise, student services staff said they could do better at reaching out to their students to see if they needed some direction. It appears, then, that reaching out is a two-way street and can be improved upon by both the students and the student services staff. Mallorie stated,

There were many times that I needed help, but I did not email my advisor. I just tried my best to figure it out; however, if I would have asked it probably would have been a lot less stressful for me.

Michelle, a student services staff member, said,

I am not very good at touching base with the students once orientation is over and I have got them settled. I don't want to bug them, so I just let them be, but reality is I should probably do a well-being check on them to ensure they don't need any help.

\section{Recommendations and Future Research}

It is the researcher's recommendation that University of Central Missouri (UCM) implement a mentorship program, called the International Student Mentoring Program, between current UCM students and the new exchange students. Leaving behind all you know to come to another country is a life-changing experience with many challenges, and the International Student Mentoring Program (ISMP) would assist students in overcoming these challenges. Areas of this organization would include socialization, mentorship, and acclimation to both UCM and Warrensburg, MO. The ISMP would provide support for the new students and reduce any feelings of isolation they may be experiencing. International students bring their home country and culture with them, so the ISMP is a perfect opportunity for local students to experience other cultures. 
Another recommendation is to create an inclusive learning and social environment. Mental health is a common issue on many college campuses, and it affects international students as well. When students study in a new country, they may bring with them completely different norms when it comes to mental health and how to understand those feelings. Many exchange students can struggle with how to understand their new health care system. It is important that student services staff bring this to students' attention so there is no stigma involved and they can ask for help when needed.

Furthermore, it is the researcher's recommendation that international student services staff at Örebro University reach out to their exchange students and hold monthly $\mathrm{Q}$ and A sessions for them. One idea could be to host a "Coffee and Conversation." Many of the exchange students felt that they could have received more direction and advice from their host university. They received information before they arrived; however, once they arrived, they often had questions and did not have anyone reaching out to them, nor would they reach out themselves to find the information they needed. Also suggested is students taking courses with predominately Swedish students or students from other countries than their own to fully immerse themselves in the Swedish culture.

Finally, research is needed to address the following questions that resulted from this study. How do universities guarantee that international students are being offered some sort of mentorship program when they arrive? How do the universities seek participation from current students? What are the best practices for ensuring students are receiving the necessary support to give them a meaningful experience at UCM or at Örebro University?

Studying abroad is a challenging experience that many students are willing to endure. The advantages out-weight the disadvantages, and students who are willing to open themselves to the opportunity come out better people at the end. All of the recommendations listed above are suggested to create a supportive and inclusive study abroad experience for all. 


\title{
Presentation for University Leadership
}

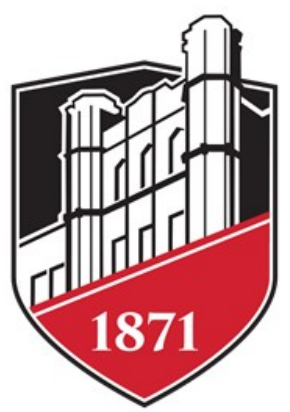

\author{
HIGHER EDUCATION STUDENT \\ SERVICES: A QUALITATIVE STUDY OF \\ TWO MID-SIZE UNIVERSITIES' DIRECT \\ EXCHANGE PROGRAMS \\ Presented By \\ Taylor N. Kinde
}

This dissertation is titled: Higher Education Student Services: A Qualitative Study of Two Mid-Size Universities’ Direct Exchange Programs.

Introduction to research: This study looked at two mid-size universities who have a direct exchange program with each other and the effect student services staff has on the students who participate in that exchange. 


\section{COMMITTEE}

* Dr. Hutchinson, UCM, Committee Chair, School of Professional Education and Leadership

* Dr. Martin, UCM, School of Professional Education and Leadership

* Dr. Hewitt, UCM, Director of Graduate School and International Student Services

* Dr. Thomas, UCM, School of Professional Education and Leadership

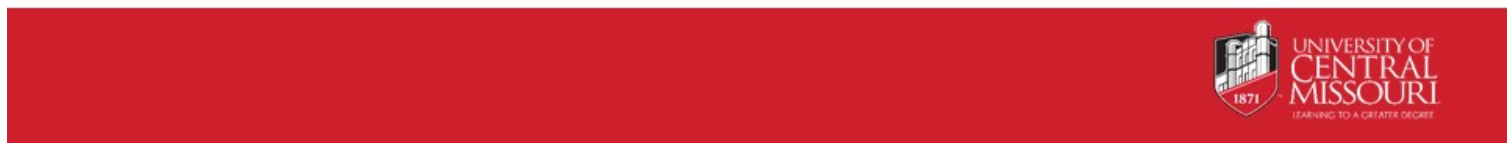

Acknowledgement to the committee members, Dr. Hutchinson, Dr. Martin, Dr. Hewitt, and Dr. Thomas. They were instrumental in this research. 


\section{INTRODUCTION}

* Student services are a key component of colleges and universities worldwide.

* Student services staff play an important role in the lives of students studying abroad.

* Students grow personally and professionally through studying abroad.

* Many students say they are different people because of their study abroad experience.

* Gaps have been identified where future research could be conducted.

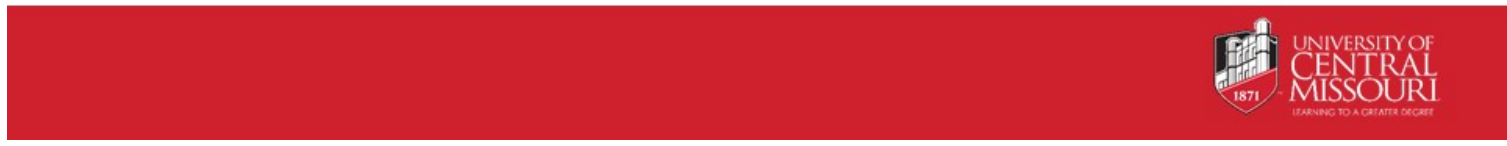

Student services staff are instrumental at every college and university, and that is no different at the two universities involved in this study. Student services staff are counselors and mentors for college students. The roles they play vary and can include academic advisors, international student advisors, counselors, and registrar staff.

Anyone who is helping students navigate the college experience is support to the students. In order for university leadership to successfully asisst students through college, they need the knowledge and theory of how to work with these students. 


\section{PURPOSE OF THE STUDY}

The purpose of this study was to gain a rich understanding of the student services offered at two direct exchange universities in Sweden and the United States and the impact those services have on students' collegiate experiences.

Investigation of the perceived experience of the direct exchange will provide the university leadership at both universities with the knowledge to increase the enrollment and strengthen the direct exchange.

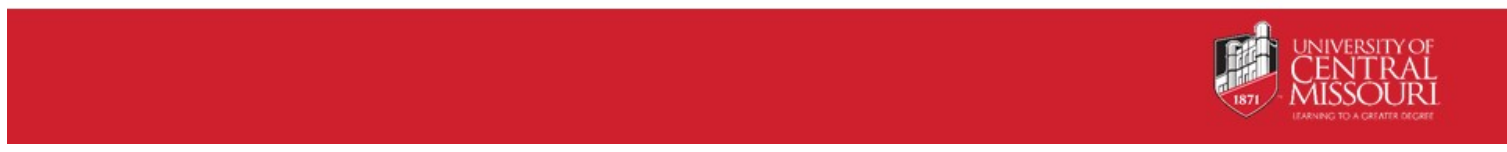

The purpose of this study was to gain a rich understanding of the direct exchange program between the two direct exchange universities in Sweden and the United States and the impact those services have on students' collegiate experiences.

Investigation of these experiences of students and student services staff will provide university leadership with the knowledge and tools to increase the enrollment and strengthen the direct exchange.

Involvement in study abroad should help students grow in their college experiences, both personally and professionally, to become well-rounded individuals.

An opportunity for a student to study abroad is a way of gaining cultural learning in a new country.

This particlar direct exchange program has a long history, and it is important to see the impact the student services staff members have on the the students' study abroad experiences. 


\section{DEFINITION OF KEY TERMS}

Direct exchange: A direct exchange is an agreement between two institutions that is, essentially, a "student swap" for either a semester or a year.

The direct exchange happens when UCM sends students to Örebro University and Örebro University sends students to UCM.

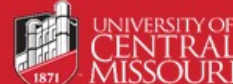

Key terms to help understand this qualitative study are as follows: direct exchange, cultural learning, and student services. It is important for readers to know these terms and understand the impact they have on the results of the study.These terms are mentioned many times in this dissertation.

Direct exchange is the agreement between these two particular institutions, essentially, a "student swap" where one US student goes to Sweden and one Sweden student comes to the US. 


\section{DEFINITION OF KEY TERMS, CONTINUED}

Cultural learning: When students study abroad, they need to understand their new culture. As such, they are constantly learning about the new culture in order to assimilate smoothly.

Student services: These are services provided to assist students with their growth and development and their ability to navigate the bureaucracy of higher education in a foreign country. This would include academic advising, counseling, student involvement, and more.

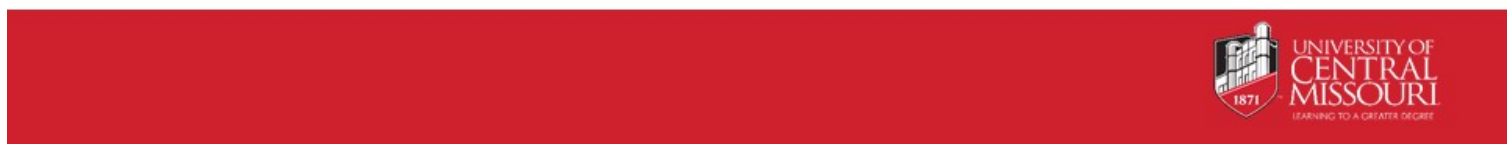

Cultural learning occurs when students study abroad. They are constantly learning about the new culture they are embracing.

Student services staff are individuals who are instrumental in helping college students navigate the system of higher education. 


\section{STATEMENT OF THE PROBLEM}

* The number of students studying abroad has more than doubled since 2000 (Institute for International Education, 2019).

* However, there are fewer students going to Sweden and fewer, in particular, in the direct exchange between UCM and Örebro University.

* More students are wanting to participate in the direct exchange program, but currently there is the $1: 1$ ratio. Also, there is the "exchange beyond match," which means students still come in as J1's but they are responsible for paying UCM for the tuition, housing, fees, meals, etc.

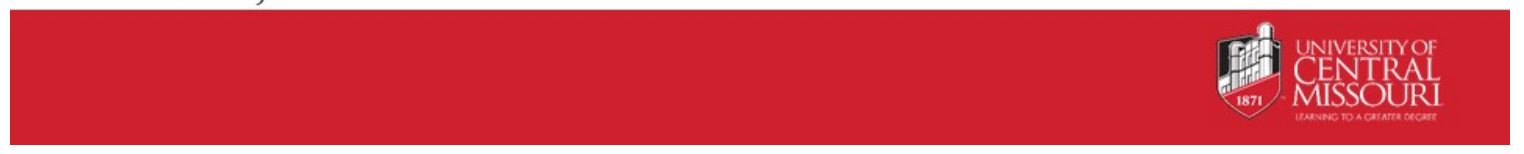

The number of students participating in this direct exchange has decreased significantly since 2016 . The number of students going abroad from UCM decreased from 379 in 2016-17 to 164 in 2017-18. The organizational changes within UCM's international student services occurred in 2018.

Currently, UCM has a 1:1 ratio, which means UCM sends one student and Örebro University sends one student. 


\section{RESEARCH QUESTIONS}

The following research questions guided this study:

1. How would Swedish students define their study abroad experience regarding student services?

2. How would American students define their study abroad experience regarding student services?

3. How do exchange students perceive cultural learning?

4. What are the greatest challenges facing student affairs professionals regarding international education?

5. How do student affairs personnel prepare students for the psychosocial aspects of the study abroad experience?

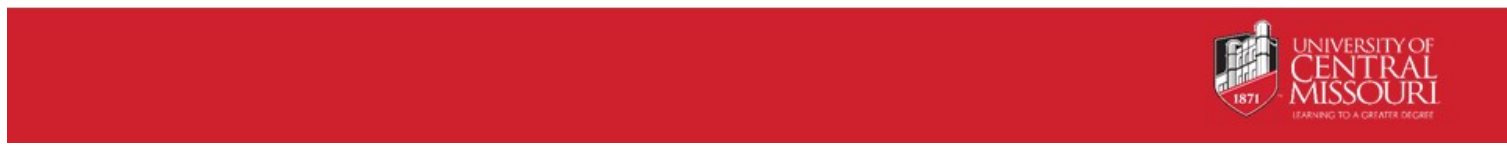

These are the research questions that helped guide this study.

Selecting a methodology for this study was based on how the researcher could best answer the planned research questions (Creswell, 2014). 


\section{CONCEPTUAL FRAMEWORK: SCHLOSSBERG'S TRANSITION THEORY}

* All students experience transitions in their collegiate experience, and this is especially true when studying abroad. Schlossberg et al. (1995) emphasizes two areas that affect students' transitions: a) demographic characteristics and b) psychological resources.

* Schlossberg's Transition Theory, known as the "4S model" (Situation, Self, Support, and Strategies), is a helpful framework for student services staff to use when working with students who are adjusting to a new culture.

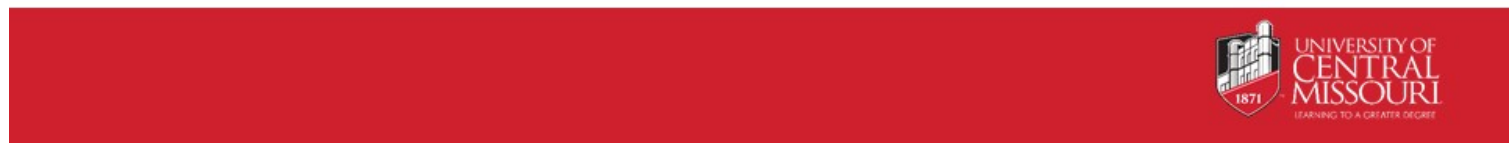

All students experience transition in college, especially when studying abroad. Schlossberg et. al (1995) identifies the effects that contribute to a student's transitions: a) demographic characteristics and b) psychological resources. Demographic characteristics refers to where they are living, and psychological resources means how to address or manage the new situation they are in. Given the scenario of learning and transitions that occur, one of the theoretical foundations for this study is Schlossberg's transition theory.

The 4S model (Situation, Self, Support, and Strategies) is used to understand these transitions that occur when studying abroad and provide insight into how to navigate them successfully (Schlossberg, 1995). 


\section{CONCEPTUAL FRAMEWORK: ASTIN'S THEORY OF STUDENT INVOLVEMENT}

It is vital that students who are studying abroad during their collegiate experience become involved socially as well as academically. The goal of student services teams and faculty is for their students to be equally successful both inside and outside of the classroom. According to Astin (1999), students who are most successful are involved within their academics as well as extracurricular activities.

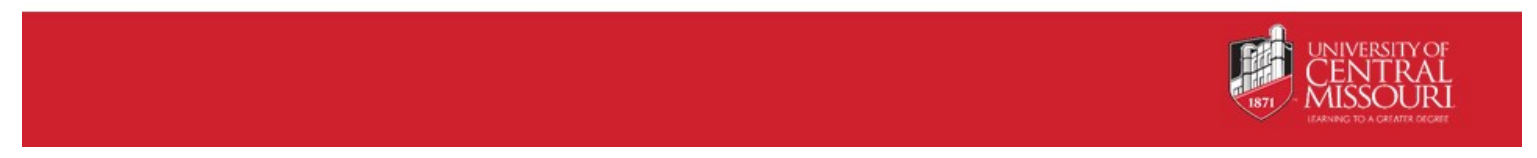

College students, especially those who study abroad, are encouraged to become involved both inside and outside of the classroom. This could occur by joining a study organization or volunteering with a local area in need. Astin (1999) encourages all students to be involved, both academically and socially. Astin's theory describes a learning process that occurs through the academic classroom as well as out of the classroom. This type of learning is a tool to evaluate the student's overall experience in college. 


\section{DESIGN OF THE STUDY}

Qualitative study allowed for individual experiences to be heard from students and student services staff.

Setting

* UCM

* Örebro University

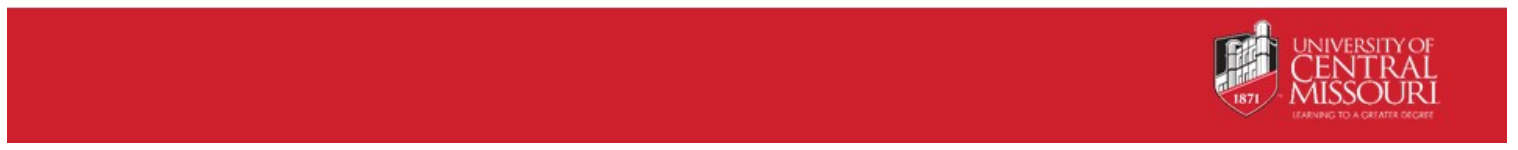

A qualitative case study allowed for individual experiences to be expressed by exploring the benefits gained through the direct exchange program.

This qualitative study was conducted at the two universities, UCM and Örebro University, who have the direct exchange program.

Areas of study abroad experience with regards to student experience and student services staff experiences were addressed through interviews, surveys, and observations. 


\section{SETTING-UCM}

The first university, UCM, is a public funded university located in Warrensburg, Missouri, United States. UCM, which was founded in 1871, has a total enrollment of 11,487 ( (University of Central Missouri [UCM], 2018). The number of international students is 799 undergraduate and graduate students from 55 different countries (UCM, 2018). UCM also has 25 international direct exchange agreements with universities worldwide (UCM, 2018).

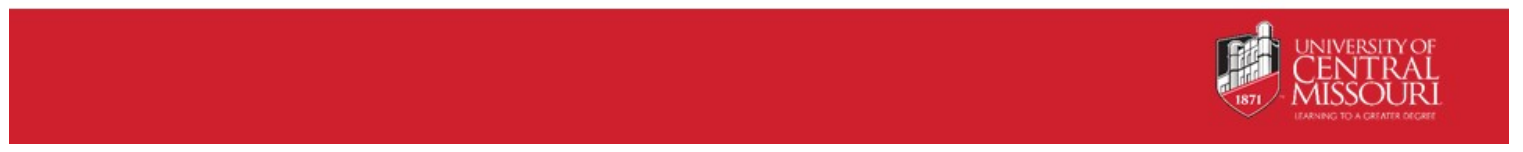

UCM, a public funded university located in Warrensburg, MO, was founded in 1871. UCM has a total of 25 international direct exchange agreements, Örebro University being one of them (UCM, 2018). 


\section{SETTING, CONTINUED- ÖREBRO UNIVERSITY}

The second university is Örebro University, a public state university located in Örebro, Sweden. The university was founded in 1977 as a college and became a university in 1999 (Facts, 2019). More than 15,000 students from around the world attend this university (Facts, 2019). Örebro University offers various programs of study as well as professional schools of medicine and law.

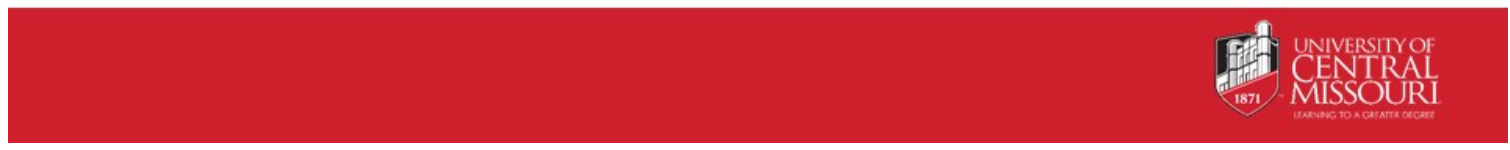

Örebro University is a public state university located in Örebro, Sweden. The university was founded in 1977 (Facts, 2019). 


\section{PARTICIPANTS}

* Twenty former exchange students were selected and interviewed.

* Ten were students from UCM who studied at Örebro, and ten were Örebro students who studied at UCM.

* The International Student Services Coordinator from Örebro University and the Study Abroad Coordinator from UCM were interviewed.

* The study advisor from Örebro and Coordinator of Exchange and Sponsored Programs from $\mathrm{UCM}$ were also interviewed.

* All of these individuals provided insight on their experiences within the direct exchange program.

* Purposeful sampling (Creswell, 2014) was utilized to choose participants as they needed to have participated as students or have worked very closely with the students as student services staff.

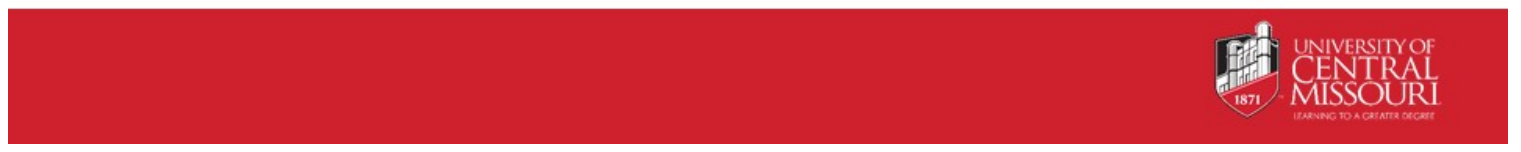

Twenty former exchange students, all of whom participated in the direct exchange, were interviewed for this qualitative study.

Four student services staff, all of whom work closely with students who study abroad, were interviewed for this qualitative study. These individuals were the International Student Services Coordinator, Study Advisor, Coordinator of Exchange and Sponsored Programs, and Study Abroad Coordinator.

Purposeful sampling (Creswell, 2014) was utilized to choose participants as they needed to have participated as students in the direct exchange or have worked very closely with the students as student services staff. 


\section{DATA COLLECTION: INDIVIDUAL INTERVIEWS}

* 20 total interviews were conducted with students.

* 4 total interviews were conducted with student services staff

$>$ Study Abroad Advisor (UCM)

$>$ International Student Services Coordinator (Örebro University)

$>$ Coordinator of Exchange and Sponsored Programs (UCM)

> Study Advisor (Örebro University)

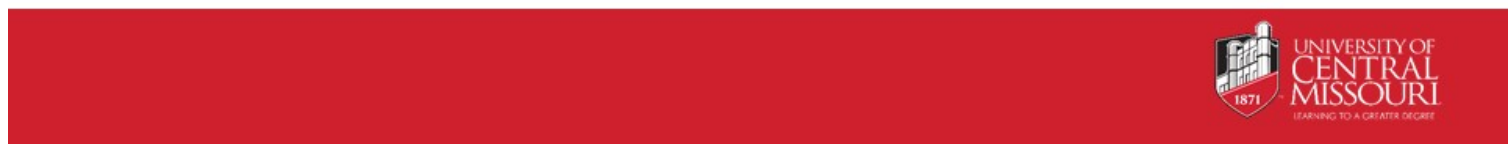

20 total interviews were conducted with students at both universities. All of these interviews were held on campus in the US and Sweden. The target population of students was students who have themselves participated in the direct exchange program. Also, 4 total interviews were conducted with student services staff who work very closely with the students participating in the direct exchange at both universities. Prior to beginning the interview, each participant was asked to complete a consent form.

All interviews were recorded and transcribed. 


\section{DATA COLLECTION: OBSERVATIONS}

- One advantage is that unusual aspects were perceived when these observations occurred (Creswell, 2014).

* For the qualitative observations that took place in this study, the researcher took field notes on the activities occurring at the research sites, which included UCM and Örebro University (Creswell, 2014).

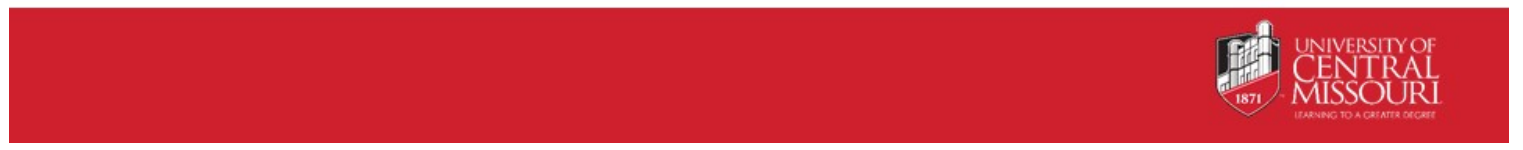

Observations took place at both universities as part of the data collection process.

The researcher took field notes on activities and conversations that occurred at the research sites (Creswell, 2014). 


\section{DATA COLLECTION: SURVEYS}

Data were collected by the International Student Services Coordinator at Örebro University from UCM students who studied at Örebro University. Data were also collected by the Study Abroad Coordinator at UCM from Örebro University students who studied at UCM. The data collected came from surveys that were distributed to the former exchange students, who were also interviewed.

\section{Set

Surveys were sent out to the students who participated in the direct exchange. Of the 20 surveys sent out, 19 were returned. The surveys were sent to the same direct exchange participants who were interviewed.

The survey was disseminated via UCM and Örebro University student email accounts using each university's directory.

Prior to completing the survey, participants were asked to complete an online consent form.

The survey consisted of 14 questions. 


\section{QUALITATIVE DATA ANALYSIS}

* Hand coding, meaning reviewing the transcriptions line by line, allowed the researcher to find the themes that were consistent through each interview and assign codes to those themes (Creswell, 2014).

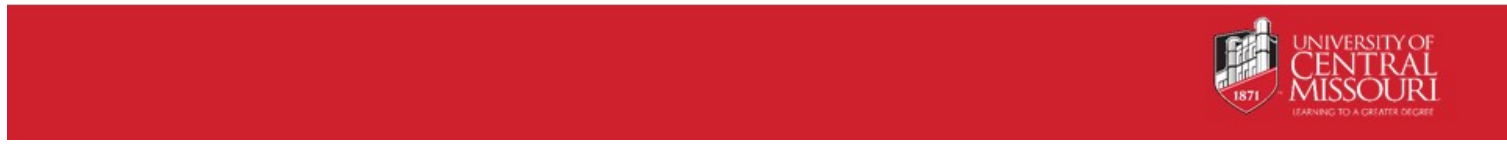

Hand coding was utilized for this study, which means the researcher read the transcriptions line by line to identify themes. Codes were assigned to the themes found. 
* Areas of Focus

\section{QUALITATIVE FINDINGS}

- Eight themes were found through interviews, surveys, and observations.

Volunteer opportunities

> Comfort

$>$ Relationships

- Multiple challenges

Independence

> Personal and professional development

> Study differences

$>$ Reaching out

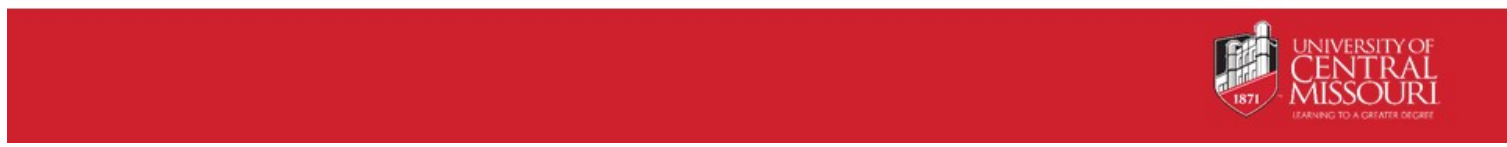

Eight themes were identified through the interviews, surveys, and observations. These eight themes were volunteer opportunities, comfort, relationships, multiple challenges, independence, personal and professional development, study differences, and reaching out. All of these themes were mentioned in interviews, observations, and the surveys. The students and student services staff provided valuable meaning behind these themes. 


\section{ANSWERING THE RESEARCH QUESTIONS}

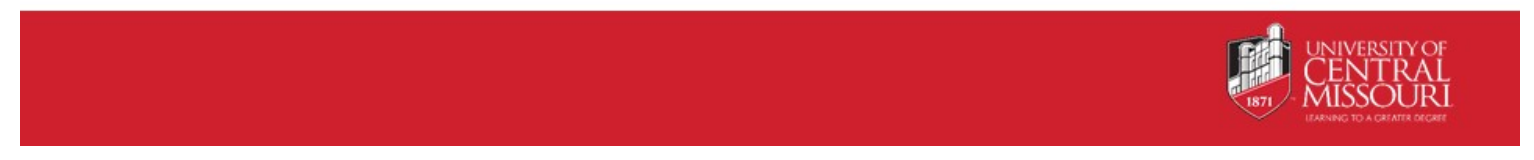

The researcher's goal was to answer the research questions. 


\section{RESEARCH QUESTION \# 1}

\section{Student perception:}

The experience of Swedish students at UCM was great at the beginning of their time there, but they felt that support was lacking throughout the entire semester, citing a lack of programming or things to do regarding programming.

Sarah stated, "It would have been thoughtful to just receive a simple email stating, "How is your stay going? Anything I can help you with while you are here? Anything you need or have questions about?"”

Another student, Jessica, stated, "A quick one sentence email asking how I am doing and there anything I need direction with would have helped."

John added, "I am not the type to email or stop by someone's office when I am struggling or have a question, so if they would have had some sort of communication that goes out to students with the subject, any questions, that would have helped me."

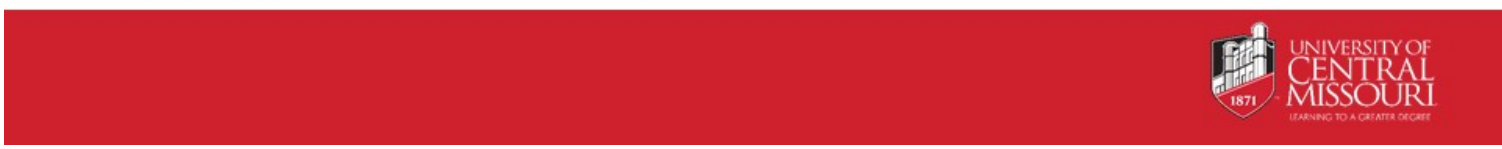

Research Question \#1: How would Swedish students define their study abroad experience regarding student services?

All of the research questions were answered by combining the analyzed data that was collected through interviews, observations, and survey results. The student perceptions are mentioned first. 


\section{RESEARCH QUESTION \#1}

\section{Student services staff perception:}

Student services staff felt they gave the students the necessary support when they arrived.

The student services staff in Sweden felt they were always available to the students.

Becky from Örebro University stated, "When students have questions, I hope they know they can email me and ask for help. I am always here to help and give direction."

Andrea from Örebro University stated, "I often think that students are not comfortable with reaching out when they need help. They may be embarrassed or feel they can just ask a friend."

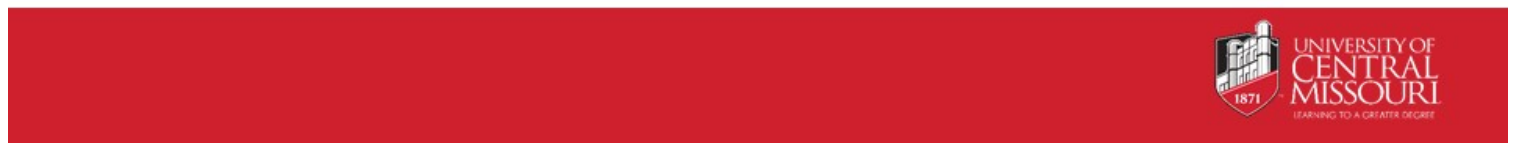

The student services staff also provided their perceptions of research question one. 


\section{RESEARCH QUESTION \#2}

\section{Student perception:}

American students at Örebro University felt they had support throughout their entire stay because of the relationships that were built.

David talked about the relationships he built while studying abroad and how that helped him feel supported.

"The most important part was the friendships I made. I made a friend group with the international students and some Swedish students (approx. 80 people) that we now have annual reunions in different countries each year. 2020 will be our 13th annual reunion, and we will be meeting in Lisbon, Portugal. We had our 10 year reunion in Örebro and were featured by the local newspaper. Also, while I was there, I did lots of local Sweden travels around Sweden and around Europe. My second semester I became a part of the Fadderiet, which was a group of students that welcomed and helped the new incoming exchange students. Myself with 2 other Swedes were responsible for assisting a small group of exchange students."

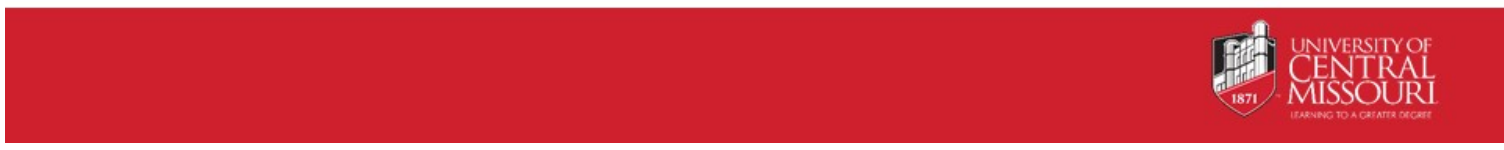

Research Question \#2: How would American students define their study abroad experience regarding student services?

The student perceptions are mentioned first. 


\section{RESEARCH QUESTION \#2}

Student services staff perception:

Student services staff in Sweden felt they were supportive before the students arrived and remained supportive throughout their study. It was found through analyses of the clata that student services staff can help provide goal setting, interventions, and relationship building, all to help guide students through the 4 S's.

Andrea shared her thoughts:

"Many students, before they study abroad, express their concerns to me about being out of their comfort zone by being in a country, school, and simply a whole new way of life. I have to explain to them being concerned of their level is normal. It will be pushed, and that will help them grow, whether they believe it or not."

Becky also stated about comfort:

"My goal as an advisor is to ensure they do step out of their comfort zone. Many students come to me and want to study the same subjects they would in their home country, and I challenge them to explore some law courses, even if they are music majors."

She went on to add, "I tell them to step out of their comfort zone and what they know."

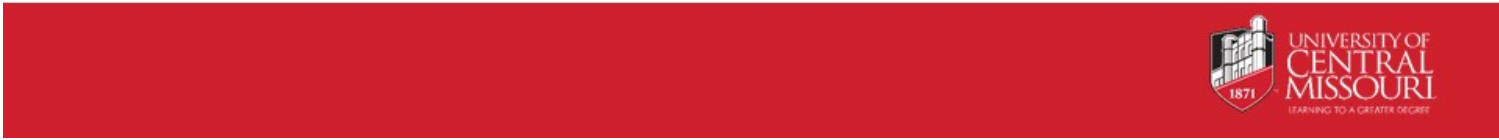

Student services staff perceptions are mentioned now. 


\section{RESEARCH QUESTION \#3}

\section{Student perception:}

Cultural learning is the constant state of learning that occurs globally as well as in the classroom and occurs when an individual is studying in a new country.

It includes being exposed to a new language and a new atmosphere, which results in cultural learning.

David identified many instances where he was completely stepping out of his comfort zone.

"In the US, I have my car and I usually always know where I am going. If I do not, I have my phone GPS, but in Sweden you rely on the bus or train system or by feet to get you anywhere. I did get lost a couple times. I got off at the wrong stop. When you are dealing with a new language and new cities, you aren't always sure what is going on. However, even though I got off the wrong spot, I knew it wasn't the end of the world and I just waited to get back on the train and head back to the direction I knew. I think of it as, I saw a new area I wouldn't have seen if I didn't get off at that spot. I saw new faces, new buildings, new everything, so for me it was worth being out of my comfort zone."

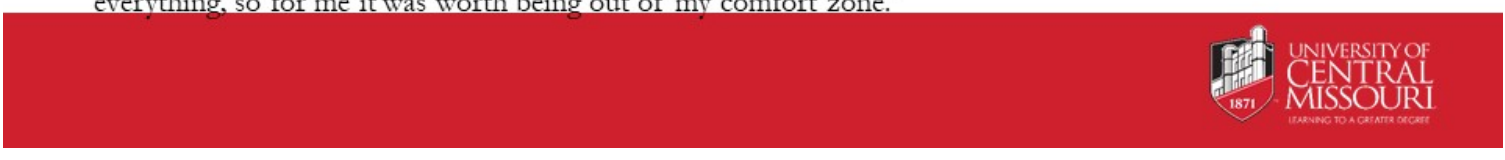

Research Question \#3: How do exchange students perceive cultural learning?

Student perceptions are noted first. 


\section{RESEARCH QUESTION \#3}

\section{Student services staff perception:}

Cultural learning occurs when new students interact and gain new information and then share that information with their peers.

Andrea, a student services staff member, added to this notion by saying,

"Cultural learning is happening constantly for students from being in the Swedish classroom, to grocery store, to riding the local bus. You are always interacting when you are in a new culture and that is when the learning is occurring, sometimes even when you do not realize it."

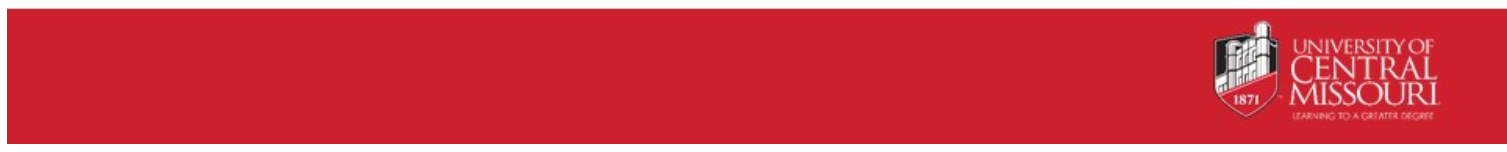

Student services staff perceptions are mentioned now. 


\section{RESEARCH QUESTION \#4}

Student perception:

The main challenge perceived by students was the support they received from the advisors. Students often felt they needed help, but that help was not always provided to them. The students did not know how to ask for support when they needed it, and they often felt they were being an inconvenience to the advisors when they did ask for assistance.

Mallorie stated,

"There were many times that I needed help, but I did not email my advisor. I just tried my best to figure it out; however, if I would have asked it probably would have been a lot less stressful for me."

Ashley shared her comments on the matter by saying,

"There were moments when I needed to ask someone for guidance, but I just made mvself figure it out. I could have asked someone, but I was shy and didn't want to bother anyone. However, after struggling a couple times with the bus system in Sweden, I finally asked the international office how to use it effectively and had them explain the routes to me. It was a much smoother stay after that. I learned that is okay to ask for help and to understand that staff or people are there to help you."

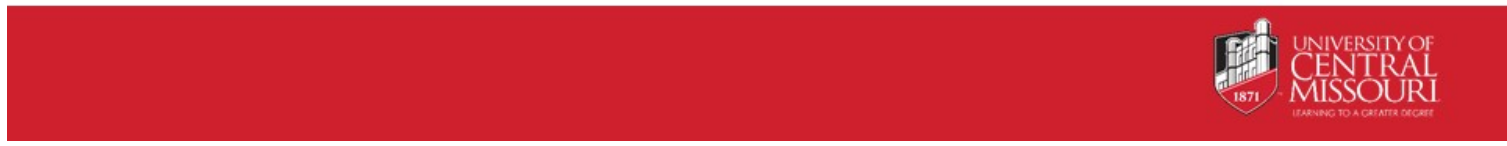

Research Question \#4: What are the greatest challenges facing student affairs professionals regarding international education?

\section{Student perceptions are mentioned first.}




\section{RESEARCH QUESTION \#4}

\section{Student services staff perception:}

Student services staff felt that the main challenge facing international education right now is the constant state of change regarding immigration rules and regulations.

The type of student they are helping is changing, including the overall demographic of the type of student who studies abroad but specifically the needs, wants, and desires of those students.

Another challenge for student services staff is the ability to stay up-to-date with changes in the types of students who study abroad and the needs of students currently participating in the direct exchange.

Michelle, a student services staff member, said,

"I am not very good at touching base with the students once orientation is over and I have got them settled. I don't want to bug them, so I just let them be, but reality is I should probably do a well-being check on them to ensure they don't need any help."

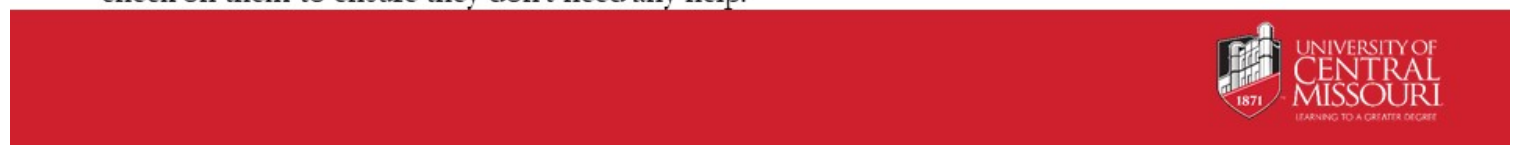

Student service staff perceptions are mentioned now. 


\section{RESEARCH QUESTION \#5}

\section{Student perception:}

It was found that all students who study abroad experience a sense of homesickness and isolation. For some, they worked through it with support from friends and families. Many students like Rebecca said,

"When you study abroad, you are most likely doing it alone. You leave your home country and go experience a new one." She went on to say, "I know it is so exciting to do something new, but I also experienced that feeling of culture shock and I needed the support of student services staff to support me through."

Similarly, Hannah stated, "I think that when you study abroad you experience so many emotions. Thankfully, the orientation before I left informed me of this and how to seek the support when I needed it."

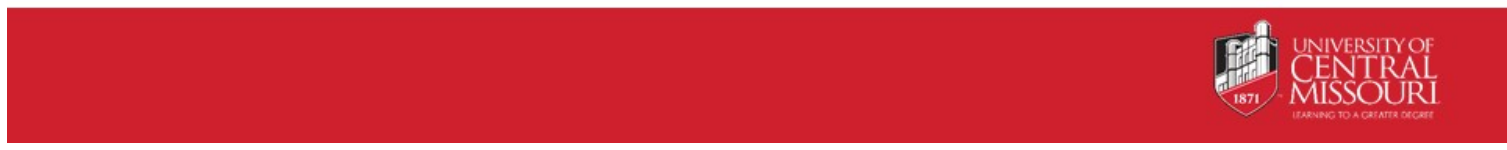

Research Question \#5: How do student affairs personnel prepare students for the psychosocial aspects of the study abroad experience?

Student perceptions are mentioned first. 


\section{RESEARCH QUESTION \#5}

\section{Student services staff perception:}

It is evident that when students study abroad, they will experience loneliness and stress. These emotions arise at different times during their study abroad experience. It is important that student services staff are aware of these feelings and experiences so they can prepare students ahead of time for whatever culture shock they might experience during their time abroad.

Andrea, a student services staff, stated, "All students are excited when they come to orientation and cannot wait for their experience in another country. However, I know the importance of speaking honestly to them, taking care to point out the different types of emotions they might experience and ways to understand those emotions. I want students to be successful during their time abroad, so I work very diligently to bring attention to the psychosocial aspects that affect students.

In addition, Michelle, another student services staff, stressed the importance of preparing students for the psychosocial aspects of studying abroad.

Michelle stated, "The emotions I see most frequently in students are stress, loneliness, and social integration.

Through orientation, I address the importance of being aware of the different emotions that can occur during the study abroad experience."

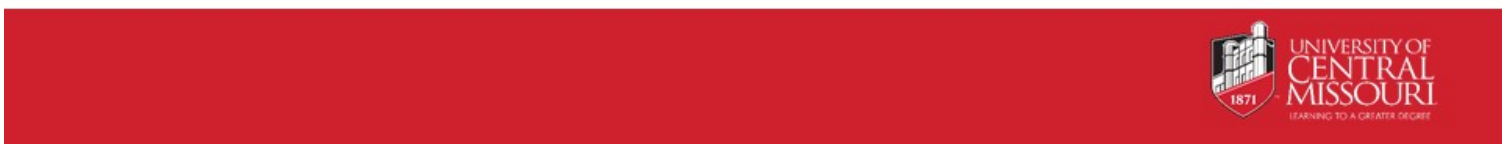

Student services staff perceptions are mentioned now. 


\section{RECOMMENDATIONS FOR UCM}

It is the researcher's recommendations that UCM implement a mentorship program, called the International Student Mentoring Program, between current UCM students and the new exchange students.

This program would assist with

- Socialization

- Mentorship

- Acclimation to both UCM and Warrensburg

- Creating inclusive learning and social environments

- Managing mental health issues

Lastly, despite time and budget constraints, it is important for international educators to attend conferences as that is an excellent way to stay current on the best way to provide services to students.

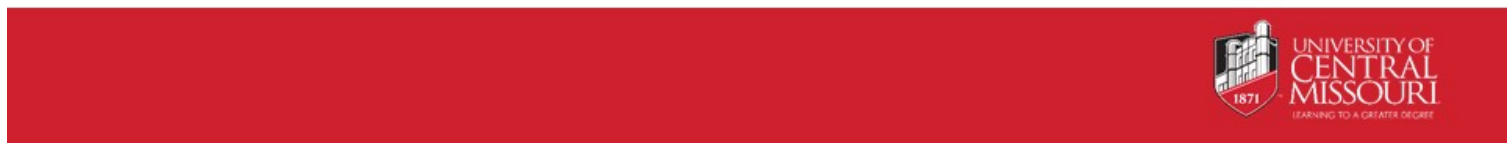

The researcher recommends that UCM implement a mentorship program, called the International Student Mentoring Program, between UCM students and the new exchange students. This program would help with socialization, mentorship, acclimation to both UCM and Warrensburg, creating inclusive learning and social environments, and managing mental health issues. 


\section{RECOMMENDATIONS FOR ÖREBRO UNIVERSITY}

It is the researcher's recommendations that Örebro University reach out to their exchange students and hold monthly $\mathrm{Q}$ and $\mathrm{A}$ sessions for them.

- Coffee and conversation

- Cultural Adjustment to the Swedish Classroom Workshop

- Students taking courses with predominately Swedish students or students from other countries than their own.

- Lastly, despite time and budget constraints, it is important for international educators to attend conferences as that is an excellent way to stay current on the best way to provide services to students.

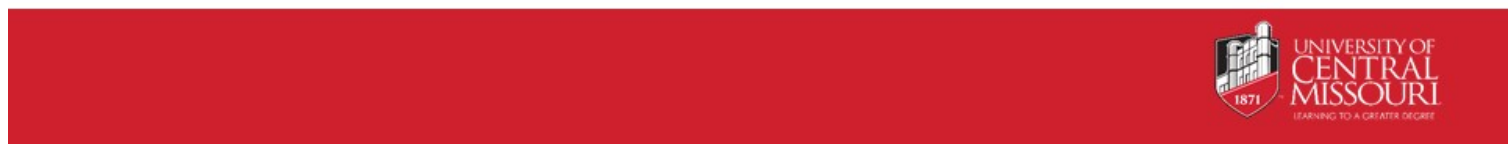

The researcher recommends that Örebro University reach out to their students and hold monthly Q and A sessions to help them with any questions or concerns they may have during their stay. This could be done through coffee and conversation, a cultural adjustment to the Swedish Classrom Workship, as well as students being ensured they take classes with Swedish students or students from countries other than their own to increase the cultural learning. 


\section{RECOMMENDATIONS FOR FUTURE RESEARCH}

Additional research is needed to answer the following questions that resulted from this study.

- How do universities guarantee that internationals students are being offered some sort of mentorship program when they arrive?

- How do universities seek participation from current students?

- What are the best practices for ensuring students are receiving the necessary support to give them a meaningful experience at UCM or at Örebro University?

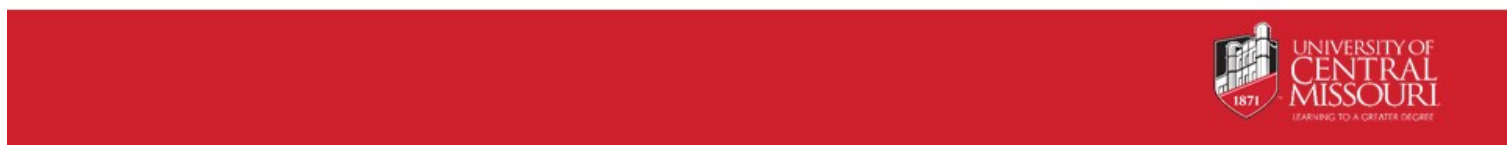

It is suggested that additional research be done to answer the following questions that resulted from this study. 


\section{REFERENCES}

Astin, A. W. (1999). Student involvement: A developmental theory for higher education. Journal of College Student Development, 40(5), 518-29.

Creswell, J. W. (2014). Research design: qualitative, quantitative, and mixed methods approaches (4th ed.). Thousand Oaks, CA: Sage Publications.

Merriam, S. B., \& Tisdell, E.J (2016). Qualitative researcb: A guide to design and implementation. San Francisco, CA: JoseyBass.

University of Central Missouri (2018). Fact Book. https://wwwucmo.edu/offices/university-analytics-andinstitutional-research/factbook.pdf

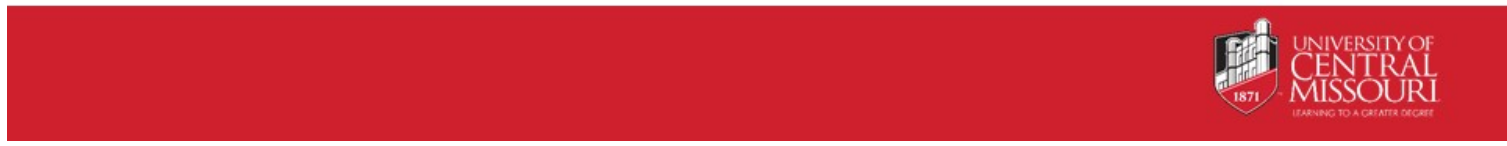

References are above. Thank you all for listening. I look forward to answering any questions you have about my study. 
SECTION FIVE:

CONTRIBUTION TO SCHOLARSHIP 


\section{Target Journals}

The following article will be submitted to NAFSA (National Association of Foreign Student Advisors), which began in 1948, is the leading international organization that serves international educators around the world by promoting the belief that international education improves through scholarship and creating understanding and respect for all people. NAFSA believes that "international education lies at the core of an interconnected world characterized by peace, security, and well-being for all. NAFSA believes that diversity in our classrooms, our communities, and our workplaces is our strength" (NAFSA, 2019). 


\section{Journal Article}

Higher Education Student Services: A Qualitative Study of Two Mid-size Universities'

Direct Exchange Programs

Taylor N. Kinde

University of Missouri 


\begin{abstract}
This qualitative study was designed to explore the experiences of students and student services staff involved in the direct exchange program between University of Central Missouri (UCM) and Örebro University. The researcher explored the impact of student services staff assistance on students participating in this direct exchange.

The conceptual framework of this research study included Schlossberg's Transition Theory (1984), which was selected as it explains what happens for students who are experiencing a significant transition. It directs them to the help they need when studying abroad in a new culture. Another theory that was utilized was Astin's Theory of Student Involvement (1985), which reveals how students who get involved in their study abroad experience through co-curricular activities have a better overall experience.

Participants of this study included students who participated in this direct exchange as well as student services staff who work very closely with the exchange students. Data collection for this qualitative study included individual interviews, observations, and an online survey.

Overall analysis of the data disclosed eight themes, such as volunteer opportunities, comfort, relationships, multiple challenges, independence, personal and professional development, study differences (orientation, support, etc.), and reaching out. All of the findings provide real information describing the richness of the direct exchange established between UCM and Örebro University.
\end{abstract}


Higher Education Student Services: A Qualitative Study of Two-Mid Size Universities' Direct Exchange Programs

Zhou and Cole (2017) indicated that in 2012 approximately 4.5 million students pursued higher education outside of their home country. This is double the number of students who took advantage of the same kind of higher education opportunity in 2000 (Zhuo \& Cole, 2017), with the United States responsible for the vast majority of those international student enrollments. The researcher investigated student services in a higher educational setting for two direct exchange universities, University of Central Missouri (UCM) in Warrensburg, Missouri, and Örebro University in Örebro, Sweden. The researcher examined the importance of student services staff and how they impact the experiences of international students at both UCM and Örebro University.

Whether in the United States or Sweden, student services are important to both the academic and personal success of students. Jones and Abes (2013) provided direction to student services professionals as they connected the work of higher education to the development of all students. This handbook serves as a tool as they assist students in having successful study abroad experiences. Agosti, Andersson, Bringsén, and Janlöv (2019) also want students to be successful, and that can occur through the work-life balance they recommend for all students.

One question asked by many is why students choose to study abroad. Lesjak et al. (2015) identified the main reasons as personal and professional growth. According to Van Hoof and Verbeetem (2005), the number one reason North American students choose to study abroad is for personal development. In addition, Zhelanov (2019) stated that students choose to study in Sweden more for personal growth than academic growth. 
Presumably, this is because of the independent approach to instruction and the freedom to study whatever they wish, which is unique and remarkable to Sweden. Finally, McMilan and Opem (2019) and Terzuolo (2018) noted that intercultural competence, the ability to communicate effectively with members of another culture, is an expected outcome and another important reason students choose to study abroad.

\section{Research Questions}

The following research questions guided this study.

1. How would Swedish students define their study abroad experience regarding student services?

2. How would American students define their study abroad experience regarding student services?

3. How do exchange students perceive cultural learning?

4. What are the greatest challenges facing student affairs professionals regarding international education?

5. How do student affairs personnel prepare students for the psychosocial aspects of the study abroad experience?

\section{Conceptual/Theoretical Framework}

The number of international students studying in the United States, according to 2018 Open Doors Report on International Educational Exchange, is 1,094,792, representing approximately $5.5 \%$ of all U.S universities' students (2019, May 1). There are also many international students at Swedish institutions. Enrollment of international students at Swedish institutions has increased because of the many Asian students who are choosing to study there (Viggo, 2018). According to the Pie News, News and 
Business Analysis for Professionals in International Education, the number of international students in Sweden during the 2016-17 academic term was 35,900 (Viggo, 2018).

The increase in international student enrollment at Swedish institutions has had student services teams, administrators, and faculty thinking of the best way to serve these students. International students, regardless of their background, experience different barriers from what non-international students experience. Barriers can include, but are not limited to, language, smooth assimilation into a new culture, lack of involvement on campus, and lack of social and academic support from the institution they are attending (Braskamp, Braskmap, Merill \& Engberg, 2013).

Gill (2018) identified the different barriers that international students may encounter. Identifying these barriers allowed interested parties at universities to assist those students in overcoming them (Brock, 2010). For that to happen, it is essential that students are provided with the necessary direction (Gill, 2018).

For this study, Schlossberg's Transition Theory (1984) was utilized. Schlossberg developed this theory as a way to explain and understand adult development. The 4 S's, Situation, Self, Support, and Strategies, outline the challenges these international students face when studying abroad. Schlossberg's Transition Theory helps one understand the 4 S's that influence a student's transition into a new culture. Student developmental theories as such are helpful to guide student affairs practitioners. A main goal of Schlossberg's Transition Theory (1984) was to facilitate an understanding of adults in transition and to assist them in connecting to individuals who can help them adjust to their situation. 
Astin's Theory of Student Involvement (1993) was also explored as a way to understand the importance of student involvement, both academic and social, when studying abroad. Astin's Theory of Student Involvement is a simple approach to the learning that occurs and, in this study in particular, to learning that occurred while studying abroad. This learning happened through social, academic, and cultural lessons.

\section{Methodology}

A qualitative case study was utilized in this study to explore the experiences of students and student services staff of whom were involved in the direct exchange program. Selecting a methodology for this study was based on how the researcher could best answer the planned research questions (Creswell, 2014).

\section{Participants}

Twenty former exchange students were selected and interviewed. Ten were students from UCM who studied at Örebro, while 10 were Örebro students who studied at UCM. In addition, the International Student Services Coordinator from Örebro and the Study Abroad Coordinator from UCM were interviewed. Finally, the Study Advisor from Örebro and the Coordinator of Exchange and Sponsored Programs from UCM were interviewed.

\section{Data Collection}

\section{Surveys}

The International Student Services coordinator at Örebro University collected descriptive data from UCM students who studied at Örebro University. The Study Abroad Coordinator at UCM also collected data from Örebro University students who studied at UCM. The data collected came from Google Surveys that were distributed to 
the 20 former exchange students who participated in the direct exchange by the International Student Services staff.

\section{Observations}

The researcher also conducted two types of observations. The first observations occurred at student advising appointments at both UCM and Örebro University. A student advising appointment is when an academic advisor meets with a student to help guide them through the enrollment process and determine the courses they need to enroll in to complete their studies. The advising observations lasted one hour.

The second set of observations occurred at student programming events at both UCM and Örebro University. A student programming event is a social event for students to help with their assimilation into a new culture. The student programming observations lasted two hours.

\section{Individual Interviews}

A total of 24 interviews were conducted. The individual student interviews included 10 Örebro University students who have studied at UCM and 10 UCM students who have studied at Örebro University. The four student services staff interviews included two from UCM and two from Örebro University, all of whom played a vital role in the success of students who studied abroad through the direct exchange.

\section{Qualitative Data Analysis}

The first step was to organize the data so that it could be analyzed. To facilitate the organization required for this step, the researcher transcribed the interviews and prepared typed notes. Furthermore, writing notes following each interview in the course of this project meant reflecting on each interview, identifying emerging themes, and 
developing early ideas about where the research was heading (Merriam \& Tisdell, 2016; Seidman, 2013).

The second step was coding the data, which is clearly defined as assigning a place that fits a variety of data so the data can be easily retrieved (Merriam \& Tisdell, 2016; Seidman, 2013). The coding was conducted by the researcher, who categorized the data into sections that had common themes as they corresponded to the research questions identified above (Creswell, 2014). Creswell suggested that a researcher should take notice of the different codes, especially those that may be surprising or unique to the study (Creswell, 2014).

To complete the coding, the researcher reviewed the transcriptions line by line, found the themes that were consistent through the interviews, and assigned codes (Creswell, 2014). This was done by "hand coding," as defined by Creswell. This allowed the researcher to work in-depth with the data. When the coding was completed, the researcher wrote an individual summary of reflection for each interview completed.

As recommended by professionals, the researcher started the data analysis very quickly after the data were collected in Örebro and UCM (Creswell, 2014; Merriam \& Tisdell, 2016; Seidman, 2013). Data analysis was ongoing throughout the entire study (Creswell, 2014).

\section{Qualitative Findings}

The findings include thoughts of current and former students who have studied abroad through the direct exchange between UCM and Örebro University, as well as student services staff from UCM and Örebro University. For confidentiality purposes, pseudonyms are used for the entirety of this research study. Through analysis of all the 
data collected from the interviews, surveys, and observations, from both the students and the student services staff, eight themes emerged. Those eight themes were volunteer opportunities, comfort, relationships, multiple challenges, independence, personal and professional development, study differences (orientation, support, etc.), and reaching out. All of the themes were relevant to one another and all intertwined in the experiences that students had when studying abroad, as well as the interactions student services staff had with the exchange students.

\section{Volunteer opportunities}

First, volunteer opportunities was a recurring theme. Many students spoke about their desire to engage in volunteering, saying it was something they were involved with in their home country and wanted to continue in their host country. For example, Jessica said, "I am the president back home of a volunteer student organization, and I knew I wanted to do something similarly in Sweden; however, I was not sure how to seek those opportunities."

Sarah provided this reference to mentorship:

Volunteering makes me feel like I am making a difference when outside in the community. Yes, I am a student, but I want to help where the help is needed. Volunteering gives you that feeling that you are needed. It gave me the experience to meet other Swedish students as well as people in the community of Örebro. It is interesting how many of the needs in US, like people not having the access to food or warm clothes, are similar to the needs in Sweden. I was able to serve food at a soup kitchen in Sweden for people that did not have a warm meal. That made 
me feel so good as someone who isn't from Sweden, I was still helping their people.

\section{Comfort}

The word "comfort" came up in each of the 24 interviews. When students spoke of their comfort levels, it was always linked to their experiences in the new school, country, and environment. "Comfort" is a powerful word in international education, and anyone who has studied abroad or worked with students studying in another culture knows that comfort, as a concept, means being pushed to a completely new level.

Jessica explained her feelings of stepping out of her comfort zone by studying abroad:

Before I left home, I had a routine and was so comfortable with my life. I would always go to the same coffee shop in the morning, then class, then to study in the library. I would then go work out and come home and cook dinner. Every day was the same for me. I loved the comfortable routine I had built. The thought of change terrified me. However, I knew for my future after college, I would experience many changes. I needed to understand that and how to cope with that, so I explored the opportunity of studying abroad. My life while studying abroad has been a series of taking chances. Whether it is asking someone in the grocery store what something is or exploring a new city by myself, those were leaps I had to take to help myself grow as a person.

Hannah talked about her experiences living in a smaller city in Sweden, which were very different from her experiences at home. 
In the US, I am from a very large city, so in Sweden I was not used to all the nature that was around me. Often my friends and I would have barbeques around the lake and always have a bonfire. It was so neat because the wood was always provided too. I loved the comfort of the fresh air and cool water.

\section{Relationships}

Relationships were mentioned in 19 of the interviews. When students study in a new culture, they build relationships with staff, professors, and other students. It was found that these relationships were strong, as those individuals became their new support system when they were in the new country.

Many students and student services staff spoke of the relationships they still have with those they met during their time abroad. They stated that they stay in contact with them through social media and commented that if they are ever in the area where they live they make arrangements to meet. David talked about the relationships he built while studying abroad.

The most important part was the friendships I made. I made a friend group with the international students and some Swedish students (approx. 80 people) that we now have annual reunions in different countries each year. 2020 will be our 13 th annual reunion, and we will be meeting in Lisbon, Portugal. We had our 10-year reunion in Örebro and were featured by the local newspaper. Also, while I was there, I did lots of local Sweden travels around Sweden and around Europe. My second semester I became a part of the Fadderiet, which was a group of students that welcomed and helped the new incoming exchange students. Myself with two other Swedes were responsible for assisting a small groups of exchange students. 
Veronica opened up about the relationships she built when in Sweden. When talking about those relationships, she said,

In the US, all my friends are from Missouri basically, but in Sweden I had friends from all over the world. I had friends from Sweden, Austria, Germany, Spain, Italy, Australia, and Canada. Every relationship is unique in its own way. I had friends that I did homework with, and others that I went on excursions with. I am thankful that I keep in touch with many of these friends still to this day. I know that if I get the opportunity to travel to Italy or Spain, I would have a place to stay.

\section{Multiple Challenges}

During the interview, Jessica talked about the multiple challenges she experienced as a student in an unfamiliar country. She noted that even though there were challenges, they were positive aspects of her experience abroad. She said,

Every challenge I had was a positive outcome and a learning experience. For example, I got lost on the bus route back to my flat. I had groceries, but somehow I didn't get off at the right stop. It meant I had to be on the bus an hour longer, but it taught me the bus route, so at the time I was worried, but at the end of the experience I learned the bus system, which would help me the rest of time around using Örebro's public transportation.

Another student, Lacey, discussed the challenges she had with her living situation. She said,

I moved into a corridor in Studentgaten. This is the corridor name, much like a dorm. We had our own room and bathroom but all shared the same living room and kitchen. It took some time for me to build the confidence to go cook in the 
kitchen. There were always people in there and I did not want to get in anyone's way, but I also knew I needed to overcome this challenge to cook, which is something I love to do.

Lastly, Rebecca talked about her challenges with finding vegetarian food in Warrensburg. She said,

In Sweden, you can find vegetarian food anywhere, the supermarkets and convenience stores, and there are always many options at restaurants. That is not the case in Warrensburg. There may be a few options at restaurants, but you really have to go the store and make the food yourself.

\section{Independence}

The researcher discovered that when students study abroad, independence is an important issue to them. In fact, the word "independence" appeared in 21 of the 24 interviews. It was the perspective of both the students and the student services staff that independence is enhanced when studying abroad.

Nick, a student services staff, stated about independence, When students study abroad and then return home, there is so much growth that has occurred. Before they leave, they want me to hold their hand through each step, but then when they return I see their growth of self-value, self-esteem, and being more secure in their own skin. They have this mindset that they can accomplish anything, and that is definitely a change from when I first met them in my office.

Jade, a student from UCM, talked about how she grew to be much more independent when she was in Sweden. 
In the US I did everything with my friends and my parents did a lot for me. I then came to Sweden and had to do everything myself. At first, it was a bit of an adjustment, but I really enjoyed the opportunity to be brave and take care of myself. I enjoyed riding the bus alone and exploring everything that was so unfamiliar. I had that feeling of accomplishment when I found a new hidden gem or conquered the bus system without getting lost. I had created that feeling of relying on myself and doing everything by myself and that was so refreshing to me.

Brittney, another student from UCM, explained how her independence grew when in Sweden.

There is something about successfully navigating your way through a new city and school. I loved going into the grocery store alone and figuring out the Swedish labels. I enjoyed that feeling of freedom. I very much miss my life in Sweden. I went to class every day, and then I would go explore the nature, cook dinner, homework, and on the weekends explore new cities and countries. I had never felt so free and independent in my life. Thankfully, even though I miss Sweden greatly, the independence I created over there transferred back to the US where I am now successful in my job. When I am given a new task at work, I have that confidence to know I can do it by myself.

Dana, another student from UCM, cannot believe it was so long ago that she studied abroad. She said,

It seems just like yesterday I was attending exchange student orientation. Studying abroad made me more open to new experiences. Back home, I only 
lived an hour away from the university, so I would go home on the weekends and be with my family. Well, I didn't have that option when I was in Sweden, so I explored and created new memories. The whole studying abroad experience forced me to be alone and to be okay with that.

\section{Personal and Professional Development}

The main goal of every student who was interviewed about their study abroad experience was to grow personally and professionally, both of which have their own unique meanings. When one thinks of personal development, they think of inner growth, such as how to handle difficult situations when studying in a new culture, conflict management, and communication skills. Personal development can be contrasted with professional development, which involves developing yourself in your current environment, for example, school or workplace, and is the continuous enhancement of a skillset.

Many students, for example, talked about personal growth, specifically in their increased confidence. Blake stated, "It gave me the ability to see things from different perspectives and take on challenges outside my comfort zone, which helps not only in my everyday life but career."

\section{Study Differences}

There are noticeable differences in the higher education systems in Sweden and the United States. The students and student services staff spoke of these differences in their interviews. This theme of differences is important as students study in a new country because they must know and understand the differences of the institutions if they are going to be successful. 
One difference found by many was the class load. Sarah, who studied at UCM, stated, "It was hard for me to get used to taking more than one class at a time. I was juggling five classes, reading for them all, completing assignments, and group projects." She said, "Back in Sweden, I always take a class for a month then exam, then onto the next class. That is very different than when I studied in the US."

\section{Reaching Out}

The topic of reaching out came up frequently in the interviews. Many students said they did not reach out to student services staff when they needed some direction. Likewise, student services staff said they could do better at reaching out to their students to see if they needed some direction. It appears, then, that reaching out is a two-way street and can be improved upon by both the students and the student services staff. Mallorie stated,

There were many times that I needed help, but I did not email my advisor. I just tried my best to figure it out; however, if I would have asked it probably would have been a lot less stressful for me.

Michelle, a student services staff member, said, I am not very good at touching base with the students once orientation is over and I have got them settled. I don't want to bug them, so I just let them be, but reality is I should probably do a well-being check on them to ensure they don't need any help.

\section{Recommendations and Future Research}

It is the researcher's recommendation that University of Central Missouri (UCM) implement a mentorship program, called the International Student Mentoring Program, between current UCM students and the new exchange students. Leaving behind all you 
know to come to another country is a life-changing experience with many challenges, and the International Student Mentoring Program (ISMP) would assist students in overcoming these challenges. Areas of this organization would include socialization, mentorship, and acclimation to both UCM and Warrensburg, MO. The ISMP would provide support for the new students and reduce any feelings of isolation they may be experiencing. International students bring their home country and culture with them, so the ISMP is a perfect opportunity for local students to experience other cultures. Another recommendation is to create an inclusive learning and social environment.

Lastly, it became apparent to the researcher that mental health is a common concern for college students and especially those who study abroad. When students study in a new country, they may be bringing completely different norms when it comes to mental health and how to understand those feelings. Many exchange students can struggle with how to understand their new health care system. Therefore, it is recommended that student services staff and faculty bring this to students' attention so there is no stigma involved and they can ask for help when needed.

Furthermore, it is the researcher's recommendation that international student services staff at Örebro University reach out to their exchange students and hold monthly Q and A sessions for them. One idea could be to host a "Coffee and Conversation." Many of the exchange students believe that they could have received more direction and advice from their host university. They received information before they arrived; however, once they arrived, they often had questions and did not have anyone reaching out to them, nor would they reach out themselves to find the information they needed. It is also 
recommended that students take courses with predominantly Swedish students or students from countries other than their own.

Finally, research is needed to address the following questions that resulted from this study. How do universities guarantee that international students are being offered some sort of mentorship program when they arrive? How do the universities seek participation from current students? What are the best practices for ensuring students are receiving the necessary support to give them a meaningful experience at UCM or at Örebro University?

Lastly, despite time and budget constraints, it is important for international educators to attend conferences, as that is an excellent way to stay current on the best way to provide services to students.

\section{Summary}

Studying abroad is a challenging experience that many students are willing to endure. The advantages out-weight the disadvantages, and students who are willing to open themselves to the opportunity come out better people at the end. 


\section{References}

Agosti, M.T., Andersson, I., Bringsén, Å., \& Janlöv, A. (2019). The importance of awareness, support and inner strength to balance everyday life - A qualitative study about women's experiences of a workplace health promotion program in human service organizations in Sweden. BMC women's health.

Astin, A. W. (1999). Student involvement: A developmental theory for higher education. Journal of College Student Development, 40(5), 518-29.

Braskamp, L.A., Braskamp, D. C. \& Engberg, M.E. (2013). Global Perspective Inventory: Its purpose, construction, potential uses, and psychometric characteristics. Retrieved from http://citeseerx.ist.psu.edu/viewdoc/download?doi=10.1.1.584.9216\&rep=rep1\&typ $\mathrm{e}=\mathrm{pdf}$

Brock, T. (2010). Young adults and higher education. Barriers and breakthroughs to success. The Future of Children, 20(1), 109-132. doi:10.1353/foc.0.0040

Creswell, J. W. (2014). Research design: Quantitative, qualitative, and mixed methods approaches (4th ed.). Thousand Oaks, CA: Sage

Gill, S. (2010). Developing a learning culture in nonprofit organizations. Los Angeles: Sage.

Jones, S. R. \& Abes, E. S. (2013). In J. H. Schuh, S.R. Jones, \& S. R. Harper (Eds.) Student Services: A handbook for the profession (5th ed., pp.149-167). San Francisco,: CA Jossey-Bass.

Juvan, E., Yap, M. H., Ineson, E. M., Lesjak, M., \& Podovšovnik, E. (2015). Erasmus student motivation: Why and where to go?. Higher Education, 70(5), 845-865

Merriam, S. B., \& Tisdell, E.J. (2016). Qualitative research: A guide to design and implementation. San Francisco, CA: Jossey-Bass. 
McMilan, A., \& Opem, G. (2019). Study abroad: A lifetime of benefits. Abroad View Magazine, 6(2), 58-60. Retrieved from https://www.iesabroad.org/system/files/abroadview\%20\%28McMillan\%2C\%20Opem\%2 9.pdf

Schlossberg, N. K. (1984). Counseling adults in transition. New York, NY: Springer Publishing Company.

Seidman, I. (2013). Interviewing as qualitative research: A guide for researchers in education and the social sciences (4th ed.). New York, NY: Teachers College Press

Terzuolo, E. R. (2018). Intercultural development in study abroad: Influence of student and program characteristics. International Journal of Intercultural Relations, 65, 86-95. https://doi.org/10.1016/j.ijintrel.2018.05.001

The Power of International Education. (2020) Open doors. Retrieved from https://www.iie.org/Research-and-Insights/OpenDoors?fbclid=IwAR1cUy29CJQAO32cDr45XdXHRsfleAwRTLpucLDb-FWuETjq0BzrvgXo38

Viggo, Stacey (2018, January 15) Sweden sees growth in Asian students. Retrieved from https://thepienews.com/news/sweden-experiences-growth-in-asian-students/

Zhou, J., \& Cole, D. (2017). Comparing international and American students: Involvement in college life and overall satisfaction. Higher Education (00181560), 73(5), 655-672. https://doi.org/10.1007/s10734-016-9982-2 


\section{SECTION SIX:}

SCHOLARLY PRACTITIONER REFLECTION 


\section{Introduction}

Reflection is an essential part of the growth process and takes time, structure, and intent to produce a transformation of learning (Merriam \& Bierema, 2014: Mezirow, 1991; Taylor, 2009). As I reflect on the three years since I began the University of Missouri Statewide EdD Cooperative Doctorate Program, I recognize the remarkable growth, both personal and professional, that I have experienced. According to Datnow and Park (2014), “information is data with meaning" (p. 12).

Throughout this reflection, you will see my understanding of this whole process as a doctoral student then candidate and recognize how that has prepared me to be a leader in higher education, particularly in International Student Services. I have always been a leader, but this program has helped shape me into the best possible leader. One question I continuously ask myself is, "What kind of leader do I aspire to be?" I would always say servant leader, and that remains true today. I want to serve and be an empathetic leader, and I feel that I am. I am aware of the feelings of others, and I make sure to listen to their situations so I know best how to support them.

\section{Dissertation contributions to personal growth and excellence in education leadership}

The entire doctoral program, from the coursework and comprehensive exams to the proposal and the dissertation, has helped refine my leadership skills. This program has given me the necessary tools to be an effective leader within international education. I remember my advisor, Dr. Hutchinson, telling our group, "Choose a topic you are passionate about." I did exactly that. From a very young age, the culture of Sweden has been important to me. Through this dissertation process, I have had the opportunity to 
read the literature surrounding my topic and give back to the area of international education.

I also had the opportunity to return to Örebro, Sweden, where I had been an exchange student in 2011, to collect my data. This return brought me full circle and was a truly humbling experience. So much time has passed and my life has changed in so many ways since I studied there my junior year in college. I graduated with my bachelor's degree, completed my master's degree, got married, started a doctorate degree, and welcomed a baby girl into this world.

When I was in Örebro in 2011, I was a young, free-spirited, and driven college student, but this trip was an opportunity for me to serve the students who participate in this direct exchange. I felt a great many responsibilities on this return visit. How could I ensure that when students study abroad in this direct exchange they feel supported? How could I guarantee they have a meaningful and memorable experience? How could I ensure that when they experience those psychosocial struggles they know how to get past them?

Through the data collection, interpretation, and presentation of my findings, I hope to have touched the life of at least one student who has studied abroad or who hopes to. When a student mentions they want to study abroad, I get excited and immediately want to share with them the results of my research. However, my hope is that these findings and recommendations will strengthen the direct exchange between UCM and Örebro University. I know it is something special because of the people, the universities, and the communities, and I hope others can see that, too. 
One way I have been touched by this experience is through understanding how important student services staff can be in contributing to a student's study abroad experience. Student services staff counsel, advise, and mentor students and help them as they work to integrate into a new culture. The impact these personnel have on students during these exhilarating yet difficult times can make all the difference in the life of a student. Knowing they can go to their student services staff when they need direction is a critical part of a positive study abroad experience. Without student services, students do not have the cultural, emotional, or academic support that allows them to connect to the host university.

\section{The dissertation experience and its effect on personal scholarly advancement}

This dissertation process has helped me research and interpret data. There are numerous databases available, and I now have the confidence to navigate them to find the necessary information. I have also become familiar with individuals at the MU library who are there to help ELPA students. Their knowledge, kindness, and guidance were greatly appreciated throughout this doctorate process. As I now consider myself a scholar, I will continue my research journey after I have completed this degree. Understanding how to interpret data and read statistics has made me more confident in my abilities as a researcher.

Through my personal research growth, I have become a better scholar overall. For many assignments, papers, group work, and beyond, we were required to complete research, and every part of this experience contributed to my becoming a better scholar. In addition, the numerous readings made me more competent in the area of Educational Leadership. People have often asked me, "Why did you decide to earn your doctorate?" I 
would say the answer to that question is so I can be the absolute best version of myself. Whether it is leading my students, being a role model for my daughter, or supporting my family, I want to be competent in my field so I can be helpful to the learners of tomorrow.

I hope to stay involved within international education and always find the most relevant information to share with my students. I feel this program shaped me personally and professionally within my role in higher education, but it will be the continuous research I do as a scholar that will ensure I remain current on the ever-changing world of international education and the needs of its students. I am sure I will continue to grow in the application of everything I have learned as I take on future leadership opportunities. However, I am truly thankful to have been given the tools and foundations to be a leader within education.

\section{Summary}

Altogether, I am a better leader because of the opportunity I had to be a part of this program. My professors, peers, and the individuals I have met while completing my projects each semester have taught me a great deal about myself, both personally and professionally. I am grateful every day to be a part of Cohort 11 MU ELPA Cooperative Doctoral program. The faculty has taught me about leadership, administration, and the importance of always doing what is right for students.

The entire experience has been truly remarkable. I am honored to have spent this much time with individuals from across the state who are all leaders in their own right but, like me, were working to be the best version of leader that they could be. I am thankful for what I have learned from both the faculty and my peers because what each of them brought to the experience was unique and touched me and taught me in some way. 
I have come a long way since starting this program, but I know my journey is not over. Quite honestly, I do not think it ever will be. The professors and friends I have met have made me a better person and a better leader. I have learned from their strengths and their skills, and I feel enriched by our shared experiences. I knew when I applied to this program that it would take dedication, flexibility, and passion, and this reflection has shown me how important all three have been to my success.

My advisor, Dr. Hutchinson, always told us to "remember where you started and came from." When we began the program, she gave us a picture of a pair of shoes. Often, we get to a place in our professional lives and forget that we were once in the same position as those we lead. While it is important we never forget the effort it took to get where we are, it is equally important that we value the efforts of those with whom we work, regardless of their status. Therefore, I will always treat others the way I want to be treated, never be afraid of change, and always remember to be ethical in my actions.

What has become especially clear to me, however, is the belief that international understanding and intercultural competence are becoming increasingly more significant, in both a person's education and their personal life. Taking part in international opportunities like the direct exchange between UCM and Örebro University will lead to that international understanding and intercultural competence. 
APPENDIX 


\section{Appendix A}

Interview questions for students

1. Tell me about yourself.

2. Why did you want to study abroad? Talk about your experience. Application process, visa, orientation, arrival, things you did while studying abroad

3. What prepared most for your time abroad?

4. What were the most important parts of your time abroad? Student involvement? Travel? Did you make friends? What did you do outside of your classroom time?

5. Talk about your transitional time. What did you find most difficult? What was the easiest? What services and support were provided to you that helped with the transition? What do you wish you had had? Give me some details of what would have been helpful?

6. What did you find most helpful in your experiences abroad?

7. Who were the key people in helping you be successful?

8. What are you glad others did for you? What do you wish others had done for you?

9. What have you gained personally and professionally through your study abroad experience? How will it help you in your future?

10. What did you find most rewarding about your study abroad experience?

11. Have you ever had any regrets about your decision to study abroad? (being away from friends and family?)

12. Who did you find to be the most supportive during your time abroad? Was it a professor, family, friends, support services, or nobody?

13. How did you get involved at your host university, both socially and academically? 


\section{Appendix B}

Interview questions for student services staff

1. Tell me about yourself and your education. How did you end up in this position and what drew you to serve international students?

2. Could you please describe your job?

3. What do you believe to be the most important parts of your job?

4. What do you hope for your international students? How do you ensure they receive that?

5. What support do you provide students when they arrive in the US?

6. How do students enroll in their classes and what direction do you give them?

7. What are the housing options for students and how do you assist them?

8. What do you feel are the biggest struggles our international students face?

9. What guidance do you believe international students need when it comes to their academics?

10. How do you integrate and engage the international students into the campus culture?

11. What ongoing support do you provide throughout their time here?

12. Do students approach you for support or do you find yourself reaching out to them? Could you please go into detail?

13. What do you enjoy most about working with international students? Do you experience frustrations? What are those? 
Appendix C

Survey Questions for Students

\section{Direct exchange survey UCM and Örebro} University

Form description

What do you like about your academic advisor?

Short answer text

What do you like about your international student advisor?

Short answer text

Do you attend student programming events?

Short answer text

Where did you grow up?

City in the United States

City in Sweden

Elsewhere 
What do you enjoy about studying at your university?

Long answer text

How do you feel supported at the university you are studying at?

Long answer text

How do you utilize the counseling center, career services, and academic services provided to your university?

Long answer text

Gender

Male

Female

Other 
How often do you meet with your study abroad coordinator/ international coordinator?

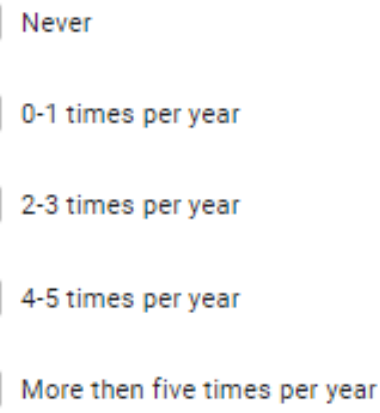


How many emails do you send to your academic or international student advsior per year?

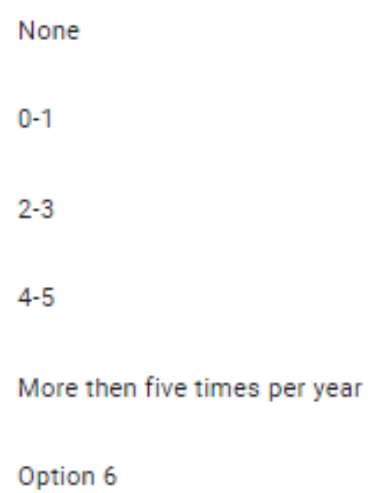

What are the comparisons and differences of student services in your home country and your host country?

Long answer text

What is your favorite part about studying in Sweden?

Long answer text

What is your favorite part about studying in the United States?

Long answer text 
Appendix D

Individual Interview Consent Form

\section{可 \\ University of Missouri}

Individual Interview Consent Form

CONSENT FORM TO PARTICIPATE IN A RESEARCH STUDY

Researcher's Name: Taylor Nicole Kinde

Project Number: 2016584

Project Title: Higher Education Student Services: A Qualitative Study of Two Mid-size Universities' Direct Exchange Programs

\section{STUDY SUMMARY:}

You are being asked to participate in a research study. This research is being conducted to investigate the experiences of study abroad students who participated in the direct exchange through University of Central Missouri and Örebro University. You have the right to know what you will be asked to do so that you can decide whether or not you would like to participate. Your participation is voluntary. You may refuse to be in the study and nothing will happen.

If you do not want to continue to be in the study, you may stop at any time without penalty or loss of benefits. You may skip any question you do not feel comfortable answering.

\section{PURPOSE OF THE STUDY:}

The purpose of this study is to gain a rich understanding of the student services offered at two direct exchange universities in Sweden and the United States and the impact those services have on students' collegiate experiences,

\section{REQUEST FOR PARTICIPATION:}

I am inviting you to participate in a study on the research involving the direct exchange program between UCM and Örebro University. You are being asked to complete an interview. 


\section{QUESTIONS, CONCERNS, OR COMPLAINTS:}

Please contact Sandy Hutchinson, Dissertation Chair, hutchinson@ucmo.edu, if you have questions about the research. Additionally, you may ask questions, voice concerns, or register complaints to the researcher, Taylor Nicole Kinde, kinde@ucmo.edu. There is also IRB, which is a group of people who review research studies to make sure the rights of participants are protected. Their phone number is 573-882-3181 or email irb@missouri.edu. 


\section{Appendix E}

Email to Study Abroad Participants at the University of Central Missouri and Örebro University

\section{Greetings,}

I am a doctoral candidate under the supervision of Dr. Sandy Hutchinson at the University of Missouri Columbia and I am looking for participants for my study titled: Higher Education Student Services: A Qualitative Study of Two Mid-size Universities' Direct Exchange Programs. Through this qualitative study, I hope to increase awareness of the value and benefit of student services on those who participated in the direct exchange of UCM and Örebro University. I studied through this direct exchange program so hearing about your experience will be meaningful to me.

Participants are being asked to contribute by completing 30-60 minute individual interviews. Also, you will be asked to complete a survey that will be sent out through Google Forms. Confidentiality will be maintained through the whole process. There are no anticipated risks in participating in this study. The benefit of participating in this study is the opportunity to discuss your student abroad experience.

If you are interested in providing insight into your study abroad experience, I would be so grateful. Please contact me, Taylor N. Kinde, via email at kinde@,ucmo.edu to participate. Thank you for your time during this process of growing international student experiences.

Sincerely,

Taylor Nicole Kinde 


\section{Appendix F}

\section{Exchange Students Electronic Google Survey Consent Form}

CONSENT FORM TO PARTICIPATE IN A RESEARCH STUDY

\section{INTERNET-BASED SURVEY CONSENT FORM}

Identification of Researchers: This research is being done by Taylor Kinde a doctoral student at the University of Missouri, Columbia.

Purpose of the study: The purpose of this study is to gain a rich understanding of the student services offered at two direct exchange universities in Sweden and the United States and the impact those services have on students' collegiate experiences

Request for participation: I am inviting you to participate in a study on the research involving the direct exchange program between UCM and Örebro University. It is your decision if you wish to participate. If you choose not to, you will not be penalized in any way. If there are certain questions you do not want to answer or are unsure of, you may skip them.

Exclusions: You must be a participant of a study abroad experience.

Description of Research Method: This study involves completing a survey about your study abroad experience. The survey will ask about your study abroad experience. The survey will take about 20 minutes to complete.

Privacy: The researcher will always make confidentiality a priority. No names will be recorded. All of the information will be anonymous. Your confidentiality will be maintained always through technology.

Explanation of Risks: The risks associated with participating in this study will be similar to the risks of everyday life.

Questions, Concerns, or Complaints: Please contact Sandy Hutchinson, Dissertation Chair, hutchinson@ucmo.edu, if you have questions about the research. Additionally, you may ask questions, voice concerns, or register complaints to the researcher, Taylor Nicole Kinde, kinde@ucmo.edu. There is also IRB which is a group of people who review research studies to make sure the rights of participants are protected. Their phone number is $573-882-3181$.

Please click the following indicating your choice to be in the study.

*Required

Survey Consent:

I have read this statement above and to complete this survey regarding my study abroad experience. 


\section{Appendix G}

Themes and Implications

Through analysis of all the data collected from the interviews, surveys, and observations, from both the students and the student services staff, eight themes emerged. Those eight themes were volunteer opportunities, comfort, relationships, multiple challenges, independence, personal and professional development, study differences (orientation, support, etc.), and reaching out. All of the themes were relevant to one another and all intertwined in the experiences that students had when studying abroad as well as the interactions student services staff had with the exchange students.

Every individual involved in this study, both the students who had studied abroad in the direct exchange and the student services staff, contributed to each area within the research. All of the individuals were chosen because of their in-depth involvement with the direct exchange program between University of Central Missouri and Örebro University.

\section{Volunteer Opportunities}

First, volunteer opportunities was a recurring theme within the data analysis. Many students spoke about their desire to engage in volunteering, saying it was something they were involved with in their home country and wanted to continue in their host country. For example, Jessica said, "I am the president back home of a volunteer student organization, and I knew I wanted to do something similar in Sweden; however, I was not sure how to seek that opportunity."

Sarah provided this reference to mentorship: 
Volunteering makes me feel like I am making a difference when outside in the community. Yes, I am a student, but I want to help where the help is needed. Volunteering gives you that feeling that you are needed. It gave me the experience to meet other Swedish students as well as people in the community of Örebro. It is interesting how many of the needs in US, like people not having the access to food or warm clothes, are similar to the needs in Sweden. I was able to serve food at a soup kitchen in Sweden for people that did not have a warm meal. That made me feel so good as someone who isn't from Sweden, I was still helping their people.

Another student, Lacey, talked about the happiness that mentorship brought to her during her time abroad.

When I volunteer, I feel like I am helping where help is needed. When abroad, I had a lot of free time because I wasn't working like I always do in my home country. My goal was to use my time effectively, so volunteering was a way of being productive. I was unsure of how to go about volunteering in Sweden, but after I spoke to my advisor and other Swedish students, they were able to connect me to some different options. I then tried them out and found the one I felt was the best fit. My goal when I get home back to the US is to keep volunteering too. I work so much when home along with being a student that I wasn't able to manage volunteering too, but I think it's time management and I could do better at it. Even if it is like five hours a week, I am still making a difference. Lastly, Jessica spoke about her volunteering experiences when she was a student in the US. 
I had not ever volunteered in Sweden, but when I came to the US I was asked by classmates if I was interested in helping them pick up trash for their sorority. At first, I was a little hesitant because we don't have much trash in Sweden. There is strict sustainability, and throwing trash on the ground is not acceptable. At first, I was unsure what I was doing as people were putting gloves on and picking up the trash, but I did what they were all doing and we picked up so much trash. I couldn't believe the amounts that were on the ground. It was kind of sad, to be honest. In my culture, this would not be allowed at all. However, even though it was an interesting experience I felt good about my contributions to UCM and their Greek life who needed volunteers. The area we cleaned up looked so much better and fresh.

\section{Comfort}

The word "comfort" came up in every one of the 24 interviews conducted. When students spoke of their comfort levels, it was always linked to their experiences in the new school, country, and environment. "Comfort" is a powerful word in international education, and anyone who has studied abroad or worked with students studying in another culture knows that comfort, as a concept, means being pushed to a completely new level.

Jessica explained her feelings of stepping out of her comfort zone by studying abroad:

Before I left home, I had a routine and was so comfortable with my life. I would always go to the same coffee shop in the morning, then class, then to study in the library. I would then go work out and come home and cook dinner. Every day was 
the same for me. I loved the comfortable routine I had built. The thought of change terrified me. However, I knew for my future after college, I would experience many changes. I needed to understand that and how to cope with that, so I explored the opportunity of studying abroad. My life while studying abroad has been a series of taking chances. Whether it is asking someone in the grocery store what something is or exploring a new city by myself, those were leaps I had to take to help myself grow as a person.

Another student, David, said, "Life should always be about stepping out of your comfort zone and going on that journey. Otherwise, you end up being the same person. You don't become the best version of yourself; just imagine how you could be." He went on to say, "I am not going to sit here and say stepping out of your comfort zone is easy, but there are ways to build up that courage."

In addition, student services personnel addressed the theme of comfort. Andrea shared her thoughts:

Many students, before they study abroad, express their concerns to me about being out of their comfort zone by being in a country, school, and simply a whole new way of life. I have to explain to them being concerned of their level is normal. It will be pushed, and that will help them grow, whether they believe it or not.

Becky also stated about comfort:

My goal as an advisor is to ensure they do step out of their comfort zone. Many students come to me and want to study the same subjects they would in their 
home country, and I challenge them to explore some law courses, even if they are music majors.

She went on to add, "I tell them to step out of their comfort zone and what they know."

Every student also spoke about how nervous they were when they first arrived in the new country. Sarah explained, "I thought I had prepped myself so well. I had read about my host country, read about their food, schools, people, norms, but somehow I was still pushed to a whole new level of comfort."

Brittney said,

I felt that when I arrived to my new country, it was every second that I was out of my comfort zone. I would interact with someone on the street, at the store, in class, and it always did not feel natural. However, after time I became more comfortable with my surroundings. But if you ask me about my limits of my comfort, they were definitely pushed.

Another student, Shannon, talked about her feelings concerning stepping out of her comfort zone.

When I arrived to Sweden, I had a new city, culture, school, everything was different in front of my eyes and I could either embrace it or be scared, so I embraced it. I had a new way of never feeling comfortable, but over time that changed. My new life over here has been a series of taking risks, whether it is small, like ordering something on the menu that I wasn't sure what I was getting, or booking a train ticket when I wasn't sure what I was booking because it was all in Swedish. I knew, at this point in my life, it was a time to laugh, smile, and 
enjoy the journey. Yes, I may be uncomfortable at times, or I may be scared I am going to get lost, but every experience I had, whether good or bad, I learned so much. I learned so much about myself and the country. For the reason that I stepped out my comfort zone, I feel I can now go back to my home country and accomplish all I need to after graduation, like a new job, possible new city. I have no fears thanks to studying abroad and stepping out of my comfort zone.

Blake also commented on stepping out of his comfort zone. He said, Life should always be about taking risks and going on new adventures. Otherwise, you live a boring life and have pretty boring stories to tell. Of course, it is not always easy. At times, it takes strength but if I can do it, anyone can. Another student, Erin, talked about her feelings concerning stepping out of her comfort zone.

When I came to the US, I had no idea what to expect. I knew I was going to live in the middle of the United States and that I would experience all seasons of weather. However, I am used to having a lot of planning in my life. I always know what is coming and what will likely happen in situations. This was my feeling of comfort, always planning and organizing. Although I knew I needed to overcome the fear of not always knowing what is ahead of me. To participate in the direct exchange program meant I was going to have to accept not always knowing what was next. I decided to let my excitement for the unknown conquer my fears. I told myself this is a once in lifetime opportunity; for that, I am grateful and will always make the most of every experience, even it means stepping out of my comfort zone. 
Finally, David identified many instances where he was completely stepping out of his comfort zone.

In the US, I have my car and I usually always know where I am going. If I do not, I have my phone GPS, but in Sweden you rely on the bus or train system or by feet to get you anywhere. I did get lost a couple times. I got off at the wrong stop. When you are dealing with a new language and new cities, you aren't always sure what is going on. However, even though I got off the wrong spot, I knew it wasn't the end of the world and I just waited to get back on the train and head back to the direction I knew. I think of it as, I saw a new area I wouldn't have seen if I didn't get off at that spot. I saw new faces, new buildings, new everything, so for me it was worth being out of my comfort zone.

\section{Relationships}

Relationships were mentioned in 19 of the interviews. When students study in a new culture, they build relationships with staff, professors, and other students. It was found that these relationships were strong, as those individuals became their new support system when they were in the new country.

Many students and student services staff spoke of the relationships they still have with those they met during their time abroad. They stated that they stay in contact with them through social media and commented that if they are ever in the area where they live they make arrangements to meet. David talked about the relationships he built while studying abroad. 
The most important part was the friendships I made. I made a friend group with the international students and some Swedish students (approx. 80 people) that we now have annual reunions in different countries each year. 2020 will be our 13th annual reunion, and we will be meeting in Lisbon, Portugal. We had our 10-year reunion in Örebro and were featured by the local newspaper. Also, while I was there, I did lots of local Sweden travels around Sweden and around Europe. My second semester I became a part of the Fadderiet, which was a group of students that welcomed and helped the new incoming exchange students. Myself with 2 other Swedes were responsible for assisting a small groups of exchange students. Becky, a student services staff member, said,

In the beginning when I first meet a new exchange student is when our relationship begins. There are some students that I have become closer to. There are some that really seek that mentorship, which builds a strong relationship between the student and me.

Andrea, another student services staff member, added to this notion by saying, You spend a lot a time with the student going abroad. You meet when they express their interest in going abroad, then orientation, then when they return from their time abroad. Some of them reach out to you when they are abroad because they have questions or simply want to say thank you for believing in them as someone who could experience this journey and be successful. Andrea also stated, "The relationships I build are relationships that sometimes last forever. I have students from 10 years ago that I am still in contact with. It is neat to see 
where they end up after going abroad." In addition, Dana spoke about the relationships she built.

I still keep in contact with my friends from abroad. Meeting friends from around the world helped me understand their cultures and value everyone's differences. All of my friends I met are very special to me, and they are all unique in their own ways. I literally have friends all around the world, which is pretty neat to be able to say.

Shannon voiced her feelings on relationships.

My main goal when I left the US was to build relationships with friends who had the same interests and joys that I do. Such as someone who enjoys soccer like I do or thrift shopping. Someone that I could spend time with and build that comfort with. I was thankful enough to have built so many relationships. I was always with a group of friends. I was rarely alone, which helped me when I felt homesick. I was around laughter, positivity, and a whole lot of culture.

Finally, Caleb spoke about the relationships he created when studying at UCM.

When I lived in the United States, I had another Swedish student that I lived with but what I really was grateful for was the other exchange students from other countries that were also studying at UCM. We created our own little family away from home. The relationships I built in the US are special to me, and when I hopefully visit again someday, I would like to have a reunion in Warrensburg. 


\section{Multiple Challenges}

During the interview, Jessica talked about the multiple challenges she experienced as a student in an unfamiliar country. She noted that even though there were challenges, they were positive aspects of her experience abroad. She said, Every challenge I had was a positive outcome and a learning experience. For example, I got lost on the bus route back to my flat. I had groceries, but somehow I didn't get off at the right stop. It meant I had to be on the bus an hour longer, but it taught me the bus route, so at the time I was worried, but at the end of the experience I learned the bus system, which would help me the rest of time around using Örebro’s public transportation.

Another student, Blake, said,

One of the most challenging things for me was shopping for food. It seemed like the small basic things that were norms in our everyday life became the biggest struggles. Things like shopping, knowing where to go to get the basic necessities, using public transport, etc. What helped me the most was the Fadderiet group that assisted us new exchange students with things like this throughout the time there, especially the initial arrival and transitional period. This group made it much easier.

Ashley spoke about the challenges she faced when studying in Sweden.

The challenges I had were through the transition time. From the time I arrived in Sweden, to settling into my flat, attending class for the first time, the grocery store for the first time, there were many firsts and it took some transition time to 
overcome that challenge of feeling quite uncertain about my surroundings and new way of life.

John spoke about his multiple challenges in his time abroad.

There were so many challenges I experienced when coming to study in the US. One in particular was not having a reliable bus system or family member to get a ride with. I had to build the confidence up to ask people to give me a ride to the store, which for me, who is more reserved, was a challenge. In Sweden, we can jump on the bus just about anywhere to get from place to place. For US, in Central Missouri, that is, it takes much more planning. I know there are wonderful transportations in the US. However, Warrensburg is smaller and doesn't have that.

Beth opened up about one challenge in particular that she found to be hard when away from home.

In Sweden, I was always with someone. I would always be with a friend to go shopping, running, and to class. I was never alone. When I arrived to the US, I did not know anyone. I was forced to be alone, and that was very difficult for me. I knew it was temporary and I would eventually meet friends to fill that void. Thankfully, after not much time I met many wonderful friends to do all the normal things I did in Sweden. Studying abroad has so many joys, so many highs, but it also has lows, just like anything in life, but it is temporary, you just have to push through it and see the light again.

\section{Independence}

The researcher discovered that when students study abroad, independence is an important issue to them. In fact, the word "independence" appeared in 21 of the 24 
interviews. It was the perspective of both the students and the student services staff that independence is enhanced when studying abroad. Nick, a student services staff, stated about independence,

When students study abroad and then return home, there is so much growth that has occurred. Before they leave, they want me to hold their hand through each step, but then when they return I see their growth of self-value, self-esteem, and being more secure in their own skin. They have this mindset that they can accomplish anything, and that is definitely a change from when I first met them in my office.

One question that was asked during the student interviews was why the student wanted to study abroad. One student mentioned becoming independent as the top priority. Blake said,

I don't really remember much of the initial steps or why I wanted to study abroad, other than to become independent. ... I think it was just my desire to explore. I didn't really plan on studying abroad. It randomly came up, so I looked into it and next thing I know I was studying in Sweden. The arrival and orientation was very welcoming by the University and the Fadderiet group. I was welcomed at the train station and given a ride to the university and shown where I would be staying. The orientation was held away from the University at a place called Fiskeboda and lasted a few days. We stayed in cabins near a lake and played games and other things to help us get to know the other new exchange students.

Veronica shared her thoughts on independence. 
Before I went abroad, I thought I was pretty independent by working 20 hours a week and going to college full time. However, when I studied abroad, I learned what being independent really meant. I went to a completely new country to live and study, and I only had myself to rely on. Of course, I had friends and family back home and new friends in Sweden and support from the university, but it was solely me that I could rely on. I became a whole different person because of my study abroad experience. I normally would call my dad if I needed something, and he would be there in a second. However, that wasn't really an option when I was so far from home. I had to be independent and figure it out for myself. Since returning back to the US, I feel I could accomplish anything and alone. I don't need friends, my parents, my boyfriend. I just need me. I can do it. Jade opened up about her desire to find herself. I have always felt like I have been comfortable in my own skin, but I never have felt fully content with who I am. There was still a lot of soul searching to be done in my life. I had wonderful guidance from my parents growing up, but when I moved onto college, I was still trying to figure so much out. I relied on my parents a lot. I needed to learn how to take care of me by myself. I needed to figure out how to manage my money, shop for my own groceries, and learn about the area I was surrounded in. I decided to study abroad to Sweden to try to help myself become independent. I thought if I lived in another country, I would be forced to rely only on myself. Living in Sweden helped me grow so much. It helped me feel confident in my own skin. It gave me the feeling that I could conquer and do anything alone, and that is what my goal of studying abroad was. 
Lastly, Amanda shared how she learned to be more independent when abroad.

The experience as a whole makes individuals be independent. I always thought I was pretty independent, but it was definitely not until I studied abroad that I became fully able to care for myself alone. When you find yourself in a place that is unfamiliar, you are forced to navigate your way through. You will learn that you only have yourself to rely on during difficult times. Each time you are thinking you are struggling, just remember how much you are gaining through the process. You will become more resilient as a person after studying abroad in a new culture.

\section{Personal and Professional Development}

The main goal of every student who was interviewed about their study abroad experience was to grow personally and professionally, both of which have their own unique meanings. When people think of personal development, they think of inner growth, such as how to handle difficult situations when studying in a new culture, conflict management, and communication skills. Personal development can be contrasted with professional development, which involves developing yourself in your current environment, for example, school or workplace, and is the continuous enhancement of a skillset.

Many students, for example, talked about personal growth, specifically in their increased confidence. Blake stated, "It gave me the ability to see things from different perspectives and take on challenges outside my comfort zone, which helps not only in my everyday life but career.” Another student, Veronica, said,

I wanted to prepare myself for after college, when I begin looking for jobs. I wanted to make sure I had the necessary skillset that employers were looking for 
and because of my study abroad, I feel prepared, professionally especially. I am not afraid anymore to speak in front of large groups, to work with a stranger on a group project, or to turn in assignments in another country. I feel so much more mature after this experience, and that has contributed to the personal growth that occurred when I was abroad.

Hannah spoke about the benefits to her career when she participated in the direct exchange program.

Before going to Sweden, I only spoke English, but now I can say I understand a lot of Swedish. I speak some of it but understand enough to be able to communicate effectively. I developed cross-cultural communication skills that have helped me. I feel confident to visit with people who English is not their native language. Another benefit to my professional growth was the ability to juggle many things at once. I was juggling my friendships and family back home with my new friends in Sweden. I was working on team projects for classes, attending lectures, etc. Now, in my professional career after graduation, I know how to handle my professional life and personal life.

Andrea, a student services staff member, explained her feelings about her students growing personally and professionally.

Me as a person, I have always loved to travel, to experience new cultures and to learn different languages. Since I got such a great opportunity to do so during my studies, I really wanted to be part of the team at the University that gave our students this opportunity. To see students grow, especially as people, as I did as an exchange student, it is so rewarding. I hope an exchange will give students, 
both incoming and outgoing, tools they can use in life, both private and professional. I will give a few examples. To stay a longer time in a county, so you get your everyday life in another cultural environment gives you a preparedness to face new and different situations and also a bigger understanding for your own and others' cultures. You also learn that despite the differences between countries, there are also big similarities between us. A great experience and knowledge to have both in your private and professional life.

\section{Study Differences}

There are noticeable differences in the higher education systems in Sweden and the United States. The students and student services staff spoke of these differences in their interviews. This theme of differences is important as students study in a new country because they have to know and understand the differences of the institutions if they are going to be successful.

One difference found by many was the class load. Sarah, who studied at UCM, stated, "It was hard for me to get used to taking more than one class at a time. I was juggling five classes, reading for them all, completing assignments, and group projects." She said, "Back in Sweden, I always take a class for a month then exam, then onto the next class. That is very different than when I studied in the US.” An American student, Dana, stated,

I thought it was different to only take one class at a time, but it was a good different... I felt I could focus on that one individual class, wrap it up, and then move onto the next. It's a neat way of education, different than the US, but I don't think one way is better than the other, just a different way of learning. 
When speaking about her classes, Dana also said, "When I studied at Örebro University, I was surprised to find out that my professors were not Swedish. Instead, they were all visiting professors from other countries around the world." She said, "I found this really neat as I was in a new culture but didn't expect to learn about so many other cultures as well."

Another difference between Örebro University and UCM is the way they conduct orientation for their new students. Örebro University has a three-week orientation, organized by the international center student assistant, for all new exchange students, starting with a welcome reception. At this reception, students are given the names of all the people who will provide services to them during their stay (advisors, housing, health, etc.) as well as information on the bus system, housing, insurance, bank accounts, and postal services. Andrea, a student services staff member, stated that, "Academic systems differ in many ways; still they will still both give you tools to find knowledge."

In addition, there is a presentation on "Understanding Sweden" and ways to cope with cultural adjustment and culture shock. Finally, the orientation includes programming events for the new students. These events give students an opportunity to meet their "fadders" (Swedish mentors), attend sporting events, cultural events, and movies, and go on tours around the city. There is even a Swedish crash course in helping students learn the basics of the Swedish language, such as how to say hi, thank you, and goodbye.

When asked about the key people who helped him be successful, Blake stated it had been Örebro University's Fadderiet group. Another student, Dana, stated, When I first arrived to Sweden I was so nervous, but that changed very quickly when I met my fadder and the other exchange students in my group. The 
programming they created and offered us was so nice. We had excursions in Sweden as well to other countries nearby.

She then said, "I felt like they really knew the importance of programming and making exchange students feel comfortable and a part of their country. This made all the difference for my stay in Sweden.”

At UCM, orientation for new students officially begins on a Tuesday and ends the following Saturday and includes picking up the exchange students from the airport in Kansas City, MO. The first day of orientation includes an introduction by staff and volunteers covering all the logistics. Next, there are a variety of speakers that come to speak about technology support and Friendship Families, a student support group that matches international students with local families. In the afternoon, students listen to immigration presentations so they understand their student visas, lastly, the students have dinner at a local church and then go shopping at the supermarket for necessities.

The second day includes more meetings with academic departments, a welcome from the president of UCM, Dr. Roger Best, a health center screening, and dinner at a local church. On the third day, students have an open session when they can ask questions about insurance and US health care as well as sessions over the American culture, classroom expectations, financial services of UCM and Central cash, public safety, and a tour of campus. That day concludes with another dinner at a local church. Friday is when students complete the enrollment process. Finally, students spent the last day of orientation with social activities such as seeing a movie at the movie theater and shopping. 
Brittney explained the differences she felt in her home university compared to her host university.

In the US when I was a student, I always juggled multiple courses at once, which I thought was the norm. However, in Sweden you take one class at a time for about a month, take an exam, and then move onto the next. I can see the pros to the Swedish educational system for higher education. Even though at first it took some time to get used to, it was really a neat concept and something that I enjoyed. I felt I was able to really dig deep into that one subject and work diligently on just that one, compared to reading and doing homework for multiple classes.

\section{Reaching Out}

The topic of reaching out came up frequently in the interviews. Many students said they did not reach out to student services staff when they needed some direction. Likewise, student services staff said they could do better at reaching out to their students to see if they needed some direction. It appears, then, that reaching out is a two-way street and can be improved upon by both the students and the student services staff. Mallorie stated,

There were many times that I needed help, but I did not email my advisor. I just tried my best to figure it out; however, if I would have asked it probably would have been a lot less stressful for me.

Michelle, a student services staff member, said, I am not very good at touching base with the students once orientation is over and I have got them settled. I don't want to bug them, so I just let them be, but reality 
is I should probably do a well-being check on them to ensure they don't need any help.

The question this raises is who bears the ultimate responsibility for reaching out. Ashley shared her comments on the matter by saying,

There were moments when I needed to ask someone for guidance, but I just made myself figure it out. I could have asked someone, but I was shy and didn't want to bother anyone. However, after struggling a couple times with the bus system in Sweden, I finally asked the international office how to use it effectively and had them explain the routes to me. It was a much smoother stay after that. I learned that is okay to ask for help and to understand that staff or people are there to help you.

\section{Summary of Themes}

These eight themes show a true qualitative reflection of the feelings of both the students and the student services staff. The eight themes that emerged from these reflections included volunteer opportunities, comfort, relationships, multiple challenges, independence, personal and professional development, study differences, and reaching out. These themes were identified because of the consistent information shared with the researcher. 


\section{Appendix $\mathrm{H}$}

Implications

It is the researcher's recommendation that University of Central Missouri (UCM) implement a mentorship program, called the International Student Mentoring Program, between current UCM students and the new exchange students. Leaving behind all you know to come to another country is a life-changing experience with many challenges, and the International Student Mentoring Program (ISMP) would assist students in overcoming these challenges. Areas of this organization would include socialization, mentorship, and acclimation to both UCM and Warrensburg, MO. The ISMP would provide support for the new students and reduce any feelings of isolation they may be experiencing. International students bring their home country and culture with them, so the ISMP is a perfect opportunity for local students to experience other cultures. Another recommendation is to create an inclusive learning and social environment.

Lastly, it became apparent to the researcher that mental health is a common concern for college students and especially those who study abroad. When students study in a new country, they may be bringing completely different norms when it comes to mental health and how to understand those feelings. Many exchange students can struggle with how to understand their new health care system. Therefore, it is recommended that student services staff and faculty bring this to students' attention so there is no stigma involved and they can ask for help when needed.

Furthermore, it is the researcher's recommendation that international student services staff at Örebro University reach out to their exchange students and hold monthly Q and A sessions for them. One idea could be to host a "Coffee and Conversation." Many of the exchange students felt that they could have received more direction and advice 
from their host university. They received information before they arrived; however, once they arrived, they often had questions and did not have anyone reaching out to them, nor would they reach out themselves to find the information they needed. It is also recommended that students take courses with predominantly Swedish students or students from other countries other than their own.

Finally, research is needed to address the following questions that resulted from this study. How do universities guarantee that international students are being offered some sort of mentorship program when they arrive? How do the universities seek participation from current students? What are the best practices for ensuring students are receiving the necessary support to give them a meaningful experience at UCM or at Örebro University? 


\section{References}

Adewale, T., D’Amico, M. M., \& Salas, S. (2018). “It's kinda weird”: Hybrid identities in the international undergraduate community. Journal of International Students, 8(2), 861. Retrieved from http://proxy.mul.missouri.edu/login?url=http://search.ebscohost.com/login.aspx?direct=tr ue $\& \mathrm{db}=$ eric $\& \mathrm{AN}=\mathrm{EJ} 1180892 \&$ site $=$ eds-live $\&$ scope $=$ site

Agosti, M.T., Andersson, I., Bringsén, Å., \& Janlöv, A. (2019). The importance of awareness, support and inner strength to balance everyday life - A qualitative study about women's experiences of a workplace health promotion program in human service organizations in Sweden. BMC Women's Health.

Altbach, P. G., \& Knight, J. (2007). The internationalization of higher education: Motivations and realities. Journal of Studies in International Education, 11(3-4), 290-305.

Altschwager, T., Dolan, R., \& Conduit, J. (2018). Social brand engagement: How orientation events engage students with the university. Australasian Marketing Journal (AMJ), 26(2), 83-91. https://doi.org/10.1016/j.ausmj.2018.04.004

American Educational Research Association (AERA) (2011). Code of ethics. Educational Researcher, 40(3), 145-156. doi: 10.3102/0013189X11410403

Andersson, C., Antelius, J., Månsson, J., \& Sund, K. (2017). Technical efficiency and productivity for higher education institutions in Sweden. Scandinavian Journal of Educational Research, 61(2), 205-223.

Anderson, P. H., \& Lawton, L. (2015). Student motivation to study abroad and their intercultural development. Frontiers: The Interdisciplinary Journal of Study Abroad.

Andrade, M. S. (2006). International students in English-speaking universities. Journal of Research in International Education, 5(2), 131-154. 
Arthur, N. (2003). Counseling international students: Clients from around the world. New York, NY: Springer Science \& Business Media.

Astin, A. W. (1999). Student involvement: A developmental theory for higher education. Journal of College Student Development, 40(5), 518-29.

Aveni, M. (2019). Tips for success on the institutional services side of a higher education environment: A manager's point of view. College and University, 94(1), 31-32. Retrieved from http://search.ebscohost.com/login.aspx?direct=true\&db=eric\&AN=EJ1206228\&site=edslive $\&$ scope $=$ site

Bista, K. (2015). Roles of international student advisors: Literature and practice in American higher education. International Education, 44(2), 87.

Bolman, L. G., \& Deal, T. E. (2013). Reframing organizations: Artistry, choice, and leadership (5th ed.). San Francisco, CA: Jossey-Bass.

Bracht, O., Engel, C., Janson, K., Over, A., Schomburg, H., \& Teichler, U. (2006). The professional value of ERASMUS mobility, final report. International Centre for Higher Education Research (INCHERKassel), University of Kassel, Kassel.

Braskamp, L.A., Braskamp, D. C. \& Engberg, M.E. (2013). Global Perspective Inventory: Its purpose, construction, potential uses, and psychometric characteristics. Retrieved from http://citeseerx.ist.psu.edu/viewdoc/download?doi=10.1.1.584.9216\&rep=rep1\&typ $\mathrm{e}=\mathrm{pdf}$

Braskamp, L.A., Braskamp, D. C. Merrill, K. C. \& M. Engberg (2010). Global perspective inventory (gpi): Its purpose, construction, potential uses, and psychometric characteristics [PDF]. Retrieved 
from http://citeseerx.ist.psu.edu/viewdoc/download?doi=10.1.1.584.9216\&rep=rep1\&typ $\mathrm{e}=\mathrm{pdf}$

Brock, T. (2010). Young adults and higher education. Barriers and breakthroughs to success. The Future of Children, 20(1), 109-132. doi:10.1353/foc.0.0040

Carr, J. L., Koyama, M., \& Thiagarajan, M. (2003). A women's support group for Asian international students. Journal of American College Health, 52, 131-134.

Chen, G. M. (2012). The impact of new media on intercultural communication in global context. Chickering, A. W., \& Reisser, L. (1993). Education and identity (2nd ed.). San Francisco, CA: Jossey-Bass.

Civinini C. (2019, June 11). Career is key motivator for study abroad. Retrieved June 13, 2019 from https://thepienews.com/news/career-idp-survey-2019/.

Coertjens, L., Brahm, T., Trautwein, C., \& Lindblom-Ylänne, S. (2017). Students' transition into higher education from an international perspective. Higher Education (00181560), 73(3), 357-369. https://doi.org/10.1007/s10734-016-0092-y

Cohn, E. R., \& Mullennix, J. W. (2007). Diversity as an integral component of college curricula. In J. Branch, E. R. Cohn, \& J. W. Mullennix (Eds.), Diversity across the curriculum: A guide for faculty in higher education (pp.11-17) San Francisco, CA: Jossey-Bass.

Creswell, J. W. (2014). Research design: Quantitative, qualitative, and mixed methods approaches (4th ed.). Thousand Oaks, CA: Sage

Datnow, A., \& Park, V. (2014). Data-driven leadership. San Francisco: Jossey-Bass.

Deardorff, D. K. (2008). Intercultural competence: A definition, model, and implications for education abroad. In V. Savicki (Ed.), Developing intercultural competence and transformation (pp. 32-52). Sterling: Stylus Publishing. 
Deen, J. (2007). Higher education in Sweden: IHEM country report. Retrieved from https://www.wissenschaftsmanagement-online.de/sites/www.wissenschaftsmanagementonline.de/files/migrated_wimoarticle/2007countryreportsweden.pdf

Dmytro Zhelanov. (2019). Higher education of Sweden: European standards and Scandinavian style. Journal of Vasyl Stefanyk Precarpathian National University, 6(1), 126-132. https://doi-org.proxy.mul.missouri.edu/10.15330/jpnu.6.1.126-132

Dwyer, M. M. (2004). More is better: The impact of study abroad program duration. Frontiers: The Interdisciplinary Journal of Study Abroad, 10, 13.

Ehrenberg, R. G. (2012). American higher education in transition. The Journal of Economic Perspectives, 26 (1), 216:193-216. doi:10.1257/jep.26.1.193

Elkins, D.J., Forester, S. A., \& Noel-Elkins, A. V. (2011). Students' perceived sense of campus community: The influence of out-of-class experiences. College Student Journal, 45(1), 105-121. Retrieved from http://search.ebscohost.com/login.aspx?direct=true \&db=s3h\&AN=59618811\&site=edslive\&scope=site

Ekström, A., Liu, S., \& Beljulji, D. (2011). Educational service quality in Sweden : A perspective of students from the BRIC countries. Retrieved from http://proxy.mul.missouri.edu/login?url=http://search.ebscohost.com/login.aspx?direct=tr ue \&db=edsndl\&AN=edsndl.oai.union.ndltd.org.UPSALLA1.oai.DiVA.org.hj15524\&site $=$ eds-live \&scope $=$ site

Evans, N. J., Forney, D.S., Guido, F., Patton, L., \& Renn, K. (2010). Student development in college: Theory, research, and practice (2nd ed.). San Francisco, CA: Jossey-Bass. 
Fass-Holems, B., \&amp; Vaughn, A.A. (2014). Are international undergraduates struggling academically? Journal of International Students, 4 (1), 60-73.

Fink, A. (2017). How to conduct surveys: A step-by-step guide. Thousand Oaks CA: Sage Publications.

Gill, S. (2010). Developing a learning culture in nonprofit organizations. Los Angeles: Sage.

Gillie, B., \& Guo-Ming Chen. (2019). The impact of social network sites on international student adjustment on a US college campus. China Media Research, 15(1), 41-51.

Golden, K. A. (2010). The development of cultural adaptability including relevant experiences and perceptions of traditional college students: A perspective from a small, private liberal arts university Available from ERIC. (864942091; ED517234). Retrieved from http://proxy.mul.missouri.edu/login?url=https://search.proquest.com/docview/864942091 ?accountid $=14576$

Head, B. W., \& Alford, J. (2013). Wicked problems: Implications for public policy and management. Administration \& Society, 47(6), 711-739. doi:10.1177/0095399713481601 (Sage).

Heifetz, R., \& Laurie, D. (2011). The work of leadership. In HBR's 10 must reads on leadership (pp.57-78). Boston, MA: Harvard Business Review Press. (Reprinted from January 1997) Institute of International Education. (2019). International students: Enrollment trends. Retrieved from http://www.iie.org/Research-and-Publi-cations/Open-Doors/Data/InternationalStudents/Enrollment-Trends/1948-2011.

Jones, S. R. \& Abes, E. S. (2013). The nature and use of theory. A handbook for the profession (5 $5^{\text {th }}$ ed., pp.149-167). San Francisco,: CA Jossey-Bass. 
Junco, R (2014). Engaging students through social media: Evidence-based practices for use in student affairs. San Francisco, CA, US: Jossey-Bass.

Juvan, E., Yap, M. H., Ineson, E. M., Lesjak, M., \& Podovšovnik, E. (2015). Erasmus student motivation: Why and where to go?. Higher Education, 70(5), 845-865

Kalpazidou Schmidt, E. (2017). Quality assurance policies and practices in Scandinavian higher education systems: Convergence or different paths? Journal of Higher Education Policy \& Management, 39(3), 247-265. https://doi.org/10.1080/1360080X.2017.1298194

Karmelita, C. E. (2018). Exploring the experiences of adult learners in a transition program. Journal of Adult and Continuing Education, 24(2), 141-164. Retrieved from http://search.ebscohost.com/login.aspx?direct=true\&db=eric\&AN=EJ1201133\&site=edslive \&scope $=$ site

KIM, E. (2012). An alternative theoretical model: Examining psychosocial identity development of international students in the United States. College Student Journal, 46(1), 99. Retrieved from http://proxy.mul.missouri.edu/login?url=http://search.ebscohost.com/login.aspx?direct=tr $\mathrm{ue} \& \mathrm{db}=\mathrm{f5h} \& \mathrm{AN}=73951022 \&$ site $=$ eds-live $\&$ scope $=$ site

Kotter, J. P. (2011). What leaders really do. In HBR's 10 must reads: On leadership (p. 37-55). Boston, MA: Harvard Business Review Press. (Reprinted from May 1990)

Kronholz, J. F., Pawley, E. K. \& Hou, P. C. (June, 2015). Celebrating success through creative career counseling. Roundtable presentation at the National Career Development Association (NCDA) Global Conference, Denver, CO. Retrieved from http://www.career.fsu.edu/Tech-CenterNew/Resources/Presentations/NCDAPresentations 
Levi, D.J. (2017). Group dynamics for teams (5th ed.). Los Angeles, CA: Sage

Manning, K. (2013). Organizational theory in higher education. New York, NY: Routledge

Merriam, S. B., \& Bierema, L. L. (2014). Adult learning: Linking theory and practice. San Francisco, CA: Jossey-Bass.

Merriam, S. B., \& Tisdell, E.J. (2016). Qualitative research: A guide to design and implementation. San Francisco, CA: Jossey-Bass.

McMilan, A., \& Opem, G. (2019). Study abroad: A lifetime of benefits. Abroad View Magazine, 6(2), 58-60. Retrieved from https://www.iesabroad.org/system/files/abroadview\%20\%28McMillan\%2C\%20Opem\%2 9.pdf

Milinchuk, O. (2017). Tourism studies in the higher education in Sweden: Focusing on sustainability. Baltic Journal of Economic Studies, 3(2).

Murray, M. (2011, November). Constraining divergent voice: Western media coverage of protests during the 2008 Beijing Olympic Games. Paper presented at the annual conference of National Communication. New Orleans, Louisiana

NAFSA: Association of International Educators. (2003). Securing America's future: Global education for a Global Age. Report of the Strategic Task Force on Education Abroad. Retrieved from https://www.nafsa.org/sites/default/files/ektron/uploadedFiles/NAFSA_Home/Resource_ Library_Assets/Public_Policy/securing_america_s_future.pdf

NAFSA: Association of International Educators. (2019, August 7) Mission, vision, alues Retrieved from https://www.nafsa.org/about/about-nafsa/mission-vision-vbaralues 
Nilsson, P. A. (2015). Expectations and experiences of inbound students: Perspectives from Sweden. Journal of International Students, 5(2), 161-174. Retrieved from http://search.ebscohost.com/login.aspx?direct=true \&db=eric\&AN=EJ1060053\&site=edslive $\&$ scope $=$ site

Nilsson, P. A. (2015). Life satisfaction among outbound students in northern Sweden. World Journal of Education, 5(4), 87-92. Retrieved from http://search.ebscohost.com/login.aspx?direct=true \&db=eric\&AN=EJ1158602\&site=edslive \&scope $=$ site

Northouse, P. G. (2016). Leadership: Theory and practice (7th ed.). Thousand Oaks, CA: Sage.

Olivas, M., \& Li, C. (2006). Understanding stressors of international students in higher education: What college counselors and personnel need to know. Journal of Instructional Psychology, 33(3), 217-222.

Örebro University. (2019) Facts about Örebro University. Retrieved from https://www.oru.se/english/about-us/facts-about-orebro-university/

Paige, R. M., Harvey, T. A., \& McCleary, K. S. (2012). The maximizing study abroad project: Toward a pedagogy for culture and language learning. Student learning abroad: What our students are learning, what they're not, and what we can do about it, 308-334.

Redding, E. (2019, April 23). International student numbers in U.S. decline. Retrieved from https:/www.insidehighered.com/quicktakes/2019/04/23/international-student-numbers-usdecline?fbclid=IwAR1qPSWOOoSRJgWjLLuRFbob8SRxfvEn3nOvk5sqyryqIgLxYWE_ Xs1Ja84

Rosvall, P.-Å., \& Nilsson, S. (2016). Challenges of engagement with health services in Sweden's schools: Listening to the Views of school nurses and students with recurrent pain. 
Pastoral Care in Education, 34(1), 3-12. Retrieved from

http://proxy.mul.missouri.edu/login?url=http://search.ebscohost.com/login.aspx?direct=tr ue $\& \mathrm{db}=$ eric $\& A N=E J 1089528 \&$ site $=$ eds-live $\&$ scope $=$ site

Royal, G., Noto, R., High McCord, K., \&amp; Pitcher, E. (2015). NSSC student success model. Retrieved from https://nssc.msu.edu/about/studentsuccessmodel.html

Schlossberg, N. K. (1984). Counseling adults in transition. New York, NY: Springer Publishing Company.

Seidman, I. (2013). Interviewing as qualitative research: A guide for researchers in education and the social sciences (4th ed.). New York, NY: Teachers College Press

Sidelinger, R. J., Frisby, B. N., \& Heisler, J. (2016). Students' out of the classroom communication with instructors and campus services: Exploring social integration and academic involvement. Learning and Individual Differences, 47, 167-171. https://doi.org/10.1016/j.lindif.2016.02.011

Smith, R. A., \& Khawaja, N. G. (2011). A review of the acculturation experience of international students. International Journal of Intercultural Relations, 35(6), 699-713.

Souto-Otero, M., Husiman, J., Beerkens, M. De, Wit, H., \& Vujjic, S. (2013). Barriers to international student mobility: Evidence from the ERASMUS program. Educational Researcher, 42(2), 70-77.

State University (2017). University of Central Missouri. http://centralmissouri.stateuniversity.com

Stribling, R. (2018). Create a home for international student-athletes. Student Affairs Today, 21 (2), 6. Retrieved from 
http://search.ebscohost.com.proxy.mul.missouri.edu/login.aspx?direct=true\&db=edb\&A $\mathrm{N}=129157642 \&$ site $=$ eds-live \&scope $=$ site

Svensson, L., Wihlborg, M. (2010), Internationalizing the content of higher education: The need for a curriculum perspective. Higher Education, 60(6). 595-613.

Sweden-An Overview. (2018, December 6). Retrieved from https://sweden.se/society/sweden-an-overview/

Terzuolo, E. R. (2018). Intercultural development in study abroad: Influence of student and program characteristics. International Journal of Intercultural Relations, 65, 86-95. https://doi.org/10.1016/j.ijintrel.2018.05.001

The Power of International Education. (2020) Open doors. Retrieved from https://www.iie.org/Research-and-Insights/OpenDoors?fbclid=IwAR1cUy29CJQAO32cDr45XdXHRsfleAwRTLpucLDb-FWuETjq0BzrvgXo38

Thunborg, C., \& Bron, A. (2019). Being in constant transition or recurrent formation: Nontraditional graduates' life transitions before, during and after higher education in Sweden. Studies in the Education of Adults, 51(1), 36-54.

Thunborg, C., Bron, A., \& Edström, E. (2013). Motives, commitment and student identity in higher education-Experiences of non-traditional students in Sweden. Studies in the Education of Adults, 45(2), 177-193.

Torres, V., Jones, S. R., \& Schuh, J. H. (2017). Student services: A handbook for the profession. San Francisco, CA: Jossey-Bass, A Wiley imprint, [2017]. Retrieved from http://search.ebscohost.com/login.aspx?direct=true $\& d b=$ cat04885a\&AN=merlin.b124105 $84 \&$ site $=$ eds-live $\&$ scope $=$ site 
University of Central Missouri (2018). Fact Book. https://www.ucmo.edu/offices/universityanalytics-and-institutional-research/factbook.pdf

University of Central Missouri (2019). Name change guidelines. https://www.ucmo.edu/about/fast-facts/ucm-history/index.php

University of Central Missouri (2019). University Leadership. https://www.ucmo.edu/about/university-leadership/index.php_

U.S. News \& World Report. (2019). Sweden. Retrieved from https://www.iesabroad.org/news/study-abroad-lifetimebenfits?fbclid=IwAR1VaJ_wWI_awc-am5OzjvGvcJoC4OCpB5BBTZ9LdhpeNIYz36y9Lqnjc\#sthash.Zv3vg5Gq.DIOansLg.dpbs

Van Hoof, H.B., \& Verbeeten, M. J. (2005). Wine is for drinking, water is for washing: Students opinions about international exchange programs. Journal of Studies in International Education, 9(1), 42-61.

Viggo, Stacey (2018, January 15) Sweden sees growth in Asian Students. Retrieved from https://thepienews.com/news/sweden-experiences-growth-in-asian-students/

Zhelanov, D. (2019). Higher education of Sweden: European standards and Scandinavian style. Journal of Vasyl Stefanyk Precarpathian National University, 6(1), 126-132.

Zhou, J., \& Cole, D. (2017). Comparing international and American students: involvement in college life and overall satisfaction. Higher Education (00181560), 73(5), 655-672. https://doi.org/10.1007/s10734-016-9982-2 


\section{VITA}

Taylor Nicole Kinde was born in Hamburg, Iowa, in 1990. She grew up in Shenandoah, Iowa, and graduated from Shenandoah High School, home of the Mustangs and Fillies. Taylor graduated from the University of Central Missouri with a Bachelor's of Science in Social Work and a Bachelor of Arts in International Studies. After her undergraduate work, she worked for a year in foster care and adoption and then went on to the University of Nebraska Lincoln to earn her Master of Arts in Educational Administration, Student Affairs.

After graduating from UNL, she moved to Warrensburg, Missouri, to begin work in her current position as Director of International Student Coordination at the University of Central Missouri. While in this position, she began working toward her Doctorate of Education in Educational Leadership and Policy Analysis from the University of Missouri Columbia.

She is very involved within NAFSA and has served that organization in a variety of capacities. Currently, she serves on the Leadership Development Committee and is the International Education Leadership Representative of Region IV.

Taylor has had an interest in international education for many years. She lived in Italy during her high school years and studied abroad numerous times after that. Those experiences led her to work in international education, where she can share with others her passion for international students and their experiences in new cultures. Taylor hopes to pursue future leadership roles so she can continue touching students' lives by helping them through the process of assimilating into a new culture. 